\title{
Вестник научных
} конференций

$2015 \cdot N$ 1-7(1)

\author{
Bulletin of \\ Scientific Conferences
}

\author{
Труды \\ Естественнонаучного и \\ гуманитарного факультета \\ Тамбовского государственного \\ технического университета
}


Вестник научных конференций. 2015. № 1-7(1). Труды Естественнонаучного и гуманитарного факультета Тамбовского государственного технического университета. $130 \mathrm{c.}$

\section{ISSN 2412-8988}

\section{DOI: $10.17117 / \mathrm{cn} .2015 .01 .07$ https://ukonf.com/doc/cn.2015.01.07.pdf}

Издание предназначено для научных и педагогических работников, преподавателей, аспирантов, магистрантов и студентов с целью использования в научной работе и учебной деятельности. Содержит труды сотрудников Естественнонаучного и гуманитарного факультета ФГБОУ ВПО «Тамбовский государственный технический университет».

Информация об опубликованных статьях предоставляется в систему Российского индекса научного цитирования - РИНЦ (договор № 255-04/2015).

Редакиионная коллегия: д.м.н., проф. Аксенова С.В.; д.п.н., проф. Ахметов М.А.; д.с.-Х.н., проф. Баширов В.Д.; д.фил.н., проф. Гасанова У.У.; д.э.н., проф. Гнездова Ю.В.; д.х.н. Гоциридзе Р.С.; д.соц.н., проф. Доника А.Д.; д.п.н., проф. Дыбина О.В.; д.п.н., проф. Егорова Г.И.; д.э.н., проф. Жуков Б.М.; д.фил.н., проф. Зайнуллина Л.М.; д.п.н., проф. Залозная Г.М.; д.б.н., проф. Калинина И.Н.; д.соц.н., проф. Кесаева Р.Э.; д.ф.н., проф. Кильберг-Шахзадова Н.В.; д.фарм.н., проф. Кобелева Т.А.; д.э.н., проф. Кожин В.А.; д.т.н., проф. Коротков В.Г.; д.псх.н., проф. Лобанов А.П.; д.п.н., проф. Марченко М.Н.; д.м.н. Матиевская Н.В.; д.т.н., проф. Мегрелишвили З.Н.; д.э.н., проф. Мейманов Б.К.; д.э.н. Ниценко В.С.; д.м.н., проф. Новиков Ю.О.; д.т.н., проф. Оболенский Н.В.; д.куль., проф. Пирожков Г.П.; д.х.н. Попова А.А.; д.т.н., проф. Прохоров В.Т.; д.и.н. Рябцев А.Л.; д.пол.н., проф. Рябцева Е.Е.; д.в.н., проф. Сазонова В.В.; д.куль., проф. Скрипачева И.А.; д.и.н., проф. Сопов А.В.; д.б.н., проф. Тамбовцева Р.В.; д.э.н., проф. Теренина И.В.; д.э.н., проф. Ферару Г.С.; д.т.н., проф. Хажметов Л.М.; д.т.н., проф. Халиков А.А.; д.фил.н. Храмченко Д.С.; д.п.н. Черкашина Т.Т.; д.т.н., проф. Шекихачев Ю.А.; д.п.н., проф. Шефер О.Р.; д.м.н., проф. Шулаев А.В.

Статьи, поступающие в редакцию, рецензируются. Материалы публикуются в авторской редакции. За содержание и достоверность статей ответственность несут авторы. Мнение редакции может не совпадать с мнением авторов статей. При использовании и заимствовании материалов ссылка на издание обязательна. Выходит 12 раз в год. Свидетельство о регистрации средства массовой информации ЭЛ № ФС 77-62122 от 19.06.2015 г. выдано Федеральной службой по надзору в сфере связи, информационных технологий и массовых коммуникаций (Роскомнадзор). Учредитель и издатель: ООО «Консалтинговая компания Юком». Адрес редакции: Россия, 392000, г. Тамбов, а/я 44. Издание основано в 2015 году. Усл. печ. л. 8,13. URL: https://ukonf.com/cn E-mail: conf@ukonf.com 


\section{СОДЕРЖАНИЕ}

РаЗДеЛ І. ЕСТЕСТВЕННЫЕ И МАТЕМАТИЧЕСКИЕ НАУКИ........................5

Дмитриев О.С., Живенкова А.А. Метод и алгоритм определения теплофизических характеристик на основе цифрового

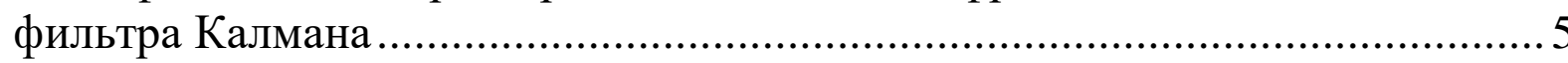

Дутов С.Ю., Шамшина Н.В. Тамбовский опыт возрождения ГТО: успехи и трудности 14

Жуковская Т.В. О нахождении множества достижимости линейной управляемой функционально-дифференциальной системы. 18

Кондракова Е.Ю., Харченко В.Ю. Экспресс-методика определения константы активности фталоцианинового катализатора

Протасов Д.Н. Построение модели кредитно-инвестиционных ресурсов малого предприятия

Пучков Н.П. Формирование компетенции на основе использования математического стиля мышления при решении контекстных задач. 36

Толстых С.С., Подольский В.Е., Бабичев А.М., Толстых С.Г. Вычислительная сложность решения систем линейных алгебраических уравнений: этап эксперимента 42

Толстых С.С., Подольский В.Е., Бабичев А.М., Толстых С.Г. Структурно-параметрическая минимизация орграфа облачной вычислительной системы

Харченко В.Ю. Выбор метода решения задачи энергосберегающего управления при производстве строительных материалов

Шибкова В.П., Комендантов Г.А. Влияние атлетической гимнастики на формирование тела.

Шпагин С.В. Комплексно-комбинированные занятия оздоровительной физической культурой для женщин различного возраста 
Атаев Э.Б., Толстяков Р.Р. Специфика маркетинговой среды на рынке строительных услуг

Бородулина Н.Ю., Гуляева Е.А., Макеева Д.Д.

Лингвокогнитивные характеристики профессионального языка

архитекторов: переводческий аспект.

Гливенкова О.А., Евенко Е.В., Лябина О.Г.

Репрезентация фоносемантического аспекта смысла-тональности

в интерпретации художественного текста. 85

Горбунов И.Н., Толстяков Р.Р. Информационные системы геомаркетинга 89

Григорьева В.С. К вопросу о «многомерности» концептуальной структуры дискурса

Ильина И.Е., Морозова О.Н., Шмаков С.И.

Социокультурный аспект в обучении иностранному языку

Исаева О.В. Организация учебной работы в Политехническом лицее-интернате ФГБОУ ВПО «Тамбовский государственный технический университет» 107

Мамонтова Д.А., Толстяков Р.Р. Некоммерческие организации в пространстве российской действительности: сущность и характеристика

Нгуен Тхи Ча Ми, Толстяков Р.Р. Фандрайзинг в благотворительных организациях

Толстяков Р.Р., Гавриков В.А., Анохин С.А.

Качество пасажирских перевозок как основной показатель деятельности ПАТП в сфере БДД 


\title{
Раздел I. \\ ЕСТЕСТВЕННЫЕ И \\ МАТЕМАТИЧЕСКИЕ НАУКИ
}

\section{Дмитриев О.С., Живенкова А.А. Метод и алгоритм определения теплофизических характеристик на основе цифрового фильтра Калмана}

\author{
Dmitriev O.S., Zhyvenkova A.A. \\ The method and algorithm for determining \\ of the thermophysical characteristics based on digital Kalman filter
}

Тамбовский государственный технический университет Tambov State Technical University

Предложен метод и алгоритм экспериментального определения теплофизических характеристик, созданных с использованием иифррового фильтра Калмана. Разработанный алгоритм положен в основу прикладного программного обеспечения информационно-измерительной системы исследования теплофизических характеристик полимерных композиционных материалов.

The methods and algorithms for the experimental determination of the thermophysical characteristics are offered in this study. They are created by using a digital Kalman filter. The developed algorithm is the basis for the application software of computer-measuring system for studies the thermophysical characteristics of polymer composite materials.

Ключевые слова: обратная задача теплопроводности; полимерные композиционные материаль; теплофизические характеристики; фильтр Калмана; экспериментальные данные.

Keywords: inverse problem of heat conduction; polymer composite materials; thermophysical characteristics; Kalman filter; experimental data.

Определение теплофизических характеристик (ТФХ) материалов является важной научной и технической задачей, поскольку они характеризуют интенсивность теплообменных процессов и являются значимыми параметрами математических моделей. К основным теплофизическим характеристикам относятся теплоемкость С и теплопроводность $\lambda[1 ; 12]$.

Методы определения теплофизических характеристик материалов относятся к косвенным методам измерений. В процессе эксперимента непосред- 
ственно измеряется не сама интересующая нас величина, а другие величины, подвергаемые прямым измерениям, к которым относятся температура Т, толщина образца L, плотность теплового потока q и т. д. Особенно процесс измерения осложняется для химически реагирующих сред, к которым относятся полимерные композиционные материалы (ПКМ) в процессе отверждения. Причем для расчета оптимального режима отверждения необходимы теплофизические характеристики ПКМ как в отвержденном состоянии, так и при отверждении. В связи с этим возникает потребность в разработке средств исследования теплофизических характеристик ПКМ [1;9].

Большинство современных методов определения теплофизических характеристик материалов основаны на решении задачи теплопроводности, которая отражает связь между пространственными и временными изменениями температуры исследуемого объекта под действием источника тепла [1; 10]. Поскольку ТФХ материала определяют распределение тепла в нем, а, следовательно, и его температурное поле, то по известному изменению температуры тела можно рассчитать его теплоемкость и теплопроводность. Однако решение задачи теплопроводности с нелинейными ТФХ является трудной проблемой. В связи с этим в теплофизическом эксперименте стремятся реализовать такие начальные и граничные условия, которые позволили бы упростить метод и расчетные уравнения $[1 ; 10]$.

Для получения результатов требуемой точности и обеспечения возможности использования упрощенных алгоритмов обработки экспериментально полученных данных исследование ТФХ целесообразно проводить, используя специальные образцы и экспериментальные установки, а также обеспечивать создание и поддержание специальных граничных условий. Учитывая тот факт, что теплоперенос в материалах является в высокой степени информационно-емким процессом, то для решения проблемы определения теплофизических характеристик необходимо привлечение средств автоматизации и компьютерной техники, т. е. создание автоматизированного устройства. Для этой цели была разработана информационно-измерительная система (ИИС) определения ТФХ полимерных композитов $[3 ; 4 ; 7 ; 14]$.

Для проведения исследований ТФХ удобно работать с температурным распределением, близким к температурному полю неограниченной пластины. Поэтому в ИИС создается такое температурное распределение путем одностороннего нагрева образца плоской формы, обеспечивая тепловую изоляцию противоположной нагревателю стороны образца. Такой нагрев позволяет вдвое сократить расход исследуемых материалов.

При решении задачи теплопроводности удобно в качестве входных данных для расчета использовать значения тепловых потоков q на поверхностях исследуемого образца. В связи с этим при построении математической модели нагрева будут заданы граничные условия второго рода [8; 10$]$.

Таким образом, обобщая приведенные выше рекомендации, построим математическую модель, описывающую процесс нагрева образца в ИИС, аналогичную модели неограниченной пластины, в виде системы дифференциальных уравнений теплопроводности с граничными условиями второго рода для случая зависимости теплофизических свойств от температуры образца при отсутствии 
тепловыделений и пренебрежительно малом температурном расширении образца и химической усадке:

$$
\begin{gathered}
C(T) \frac{\partial T}{\partial t}=\frac{\partial}{\partial x}\left(\lambda(T) \frac{\partial T}{\partial x}\right), \\
T \equiv T(x, t), \quad 0<x<L, \quad 0<t \leq t_{m}, \\
T(x, 0)=f_{0}(x), \quad 0 \leq x \leq L, \\
-\left.\lambda(T) \frac{\partial T}{\partial x}\right|_{x=0}=q_{0}(t), \quad 0<t \leq t_{m}, \\
-\left.\lambda(T) \frac{\partial T}{\partial x}\right|_{x=L}=q_{L}(t), \quad 0<t \leq t_{m} .
\end{gathered}
$$

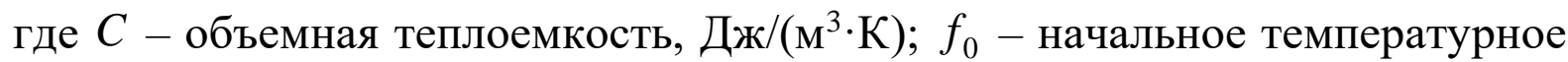
распределение, $\mathrm{K} ; q_{0}, q_{L}$ - плотность тепловых потоков на поверхностях образца, Вт/м² $L$ - толщина образца, м; $T$ - температура, K; $t$ - время, с; $t_{m}-$ продолжительность эксперимента, c; $x$ - пространственная координата, м; $\lambda$ - теплопроводность, Вт/(м·К).

Кроме приведенной нелинейной модели возможен также случай, когда ТФХ являются константами $C, \lambda$ или функциями времени $C(t), \lambda(t)$. При этом имеет место линейная математическая модель теплопроводности.

На практике частым является случай слабой температурной зависимости теплоемкости $C(T)$ такой, что ей можно пренебречь, либо теплоемкость из-за протекания химической реакции изменяется только во времени. Возможно также особое построение эксперимента, при котором температурное поле $T(x, t)$ слабо изменяется по координате $x$, то есть перепад температуры по толщине $T_{L}(t)-T_{0}(t) \approx 3 \div 5^{\circ} \mathrm{K}$. При этом преобладает временная зависимость теплоемкости, и решение поставленной задачи может быть получено относительно временных характеристик.

При температурно-временном характере процесса нагрева возможно соотнесение времени $t$ к температуре $T(t)$, т. е. получение зависимостей $C(T(t))$, $\lambda(T(t))$. При таком подходе ТФХ принимают смысл среднеинтегральных характеристик по толщине образца $L$, относящихся к среднеинтегральной температуре

$$
T_{c p}(t)=\frac{1}{L} \int_{0}^{L} T(x, t) d x .
$$

Задача определения ТФХ по температурному распределению внутри образца относится к классу обратных задач теплопроводности (ОЗТ). Большинство О3Т являются некорректно поставленными, поскольку малым возмущениям исходных данных могут соответствовать сколь угодно большие возмущения решения, т. е. ошибки при решении обратных задач существенно зависят от погрешности входных данных [10].

Экспериментально измеренные данные в зависимости от характера проявления погрешностей, а также причин их появления могут содержать систематические, случайные и грубые погрешности. Исходя из этого, экспериментальные данные можно представить как сумму двух составляющих - истинного значения 
измеряемой величины и случайной погрешности измерения с нулевым математическим ожиданием.

В нашем случае, в разработанной ИИС, экспериментально измеренные данные - это дискретные величины $T_{i, j}=T\left(x_{i}, t_{j}\right), q_{j}=q\left(t_{j}\right)$, измерение которых производится в отдельные моменты времени $t_{j}$ и в некоторых точках пространства $x_{i}$. Количество точек $j$ по времени ограничено только объемом полученной информации. В то время как количество точек $i$ по пространственной координате ограничено возможностью и количеством установления термопар внутри образца. Поэтому математический аппарат обработки экспериментальных данных должен позволять не только уменьшать случайную погрешность экспериментальных данных, но и производить над ними операции устойчивого численного дифференцирования и интегрирования.

В качестве метода математической обработки экспериментальных данных, направленных на сглаживание случайных помех и не затрагивающих исследуемую зависимость измеряемой величины, а также решения обратной задачи теплопроводности предлагается использовать цифровой фильтр Калмана [11; 13; 15], который является математическим средством построения оптимальных оценок системных переменных на основе выполненных измерений и построенной математической модели объекта или процесса.

Задача фильтрации в общем случае может быть представлена следующим образом: для наблюдения доступны реализации случайного процесса $\xi(t)$, который является детерминированной функцией полезного сигнала $s(t, \eta(t))$, а также помехи $n p(t): \xi(t)=\Phi(s(t, \eta(t)), n p(t))$. Полезный сигнал $s(t, \eta(t))$ в свою очередь является функцией сообщения $\eta(t)$ и времени $t$. Имеется текущее наблюдение случайного процесса в интервале от 0 до $t$. Известны некоторые априорные сведения о наблюдаемом процессе. Имея априорные сведения и доступную непосредственному наблюдению реализацию процесса $\xi(t)$, нужно получить оценку сообщения $\eta(t)$ для каждого $t$ [13]. Исходя из выше сказанного, получаем уравнение наблюдения:

$$
\xi(t)=s(t, \eta(t))+n_{0}(t),
$$

где $n_{0}(t)$ - белый гауссовский шум, имеющий нулевое математическое ожидание и одностороннюю спектральную плотность $N_{0}$.

При такой общей постановке задача фильтрации не находит приемлемого решения. Необходимы дополнительные данные о характере случайного сообщения. Случайное сообщение $\eta(t)$ предполагается заданным стохастическим дифференциальным уравнением вида:

$$
\frac{d \eta}{d t}=g(t, \eta)+n_{\eta}(t), \eta(0)=\eta_{0},
$$

где $n_{\eta}(t)$ - формирующий белый гауссовский шум, имеющий нулевое математическое ожидание и одностороннюю спектральную плотность $N_{\eta} ; \eta_{0}-$ начальное значение. Причем шумы $n_{0}(t)$ и $n_{\eta}(t)-$ независимы [13].

В дискретном времени уравнения наблюдения (3) и сообщения (4) будут иметь вид: 


$$
\begin{aligned}
& \xi_{j}=s\left(t_{j}, \eta_{j}\right)+n_{0 j}, \\
& \eta_{i}=g\left(t_{j}, \eta_{j-1}\right)+n_{\eta j}, j=1, \ldots, m .
\end{aligned}
$$

Задачи фильтрации делятся на два класса:

- линейная фильтрация - уравнения наблюдения и сообщения линейны относительно сообщения $\eta$ и его начальное значение $\eta_{0}$ имеет нормальное распределение;

- нелинейная фильтрация - уравнения наблюдения или сообщения нелинейны относительно сообщения $\eta$, или начальное значение сообщения $\eta_{0}$ не является гауссовской случайной величиной.

Рассмотрим методику определения ТФХ ПКМ с применением цифрового фильтра Калмана. Запишем частный случай задачи фильтрации - линейную фильтрацию в дискретном времени:

$$
\begin{aligned}
& \xi_{j}=H_{j} \eta_{j}+n_{0 j}, \\
& \eta_{j}=\omega_{j-1} \cdot \eta_{j-1}+n_{\eta j}, \\
& \eta(0)=\eta_{0}, \quad j=1, . ., m .
\end{aligned}
$$

где $H_{j}=H\left(t_{j}\right)$ и $\omega_{j}=\omega\left(t_{j}\right)$ - заданные функции от времени; $n_{0 j}$ и $n_{\eta j}-$ дискретные белые гауссовские шумы с нулевым математическим ожиданием и дисперсиями $D_{0 j}$ и $D_{\eta j}$ соответственно; $\eta_{0}-$ начальное значение, является нормально распределенной случайной величиной; $j$ - номер итерации.

Для данной задачи уравнения фильтра Калмана имеют вид [13]:

$$
\begin{aligned}
& \hat{\eta}_{j}=\beta_{j-1} \hat{\eta}_{j-1}+\kappa_{j}\left(\xi_{j}-H_{j} \omega_{j-1} \hat{\eta}_{j-1}\right), \\
& \frac{1}{\vartheta_{j}}=\frac{1}{\omega_{j-1}^{2} \vartheta_{j-1}+D_{\eta j}}+\frac{H_{j}^{2}}{D_{0 j}}, \\
& \kappa_{j}=\frac{H_{j} \vartheta_{j}}{D_{0 j}},
\end{aligned}
$$

где $\hat{\eta}_{j}$ - условное математическое ожидание, являющееся оптимальной оценкой $\eta_{j} ; \vartheta_{j-1}-$ апостериорная дисперсия.

Перейдем к построению фильтра Калмана для задачи определения ТФХ по температурному полю согласно математической модели (1) для дискретного времени $t_{j}$.

Аналитическое решение уравнения теплопроводности с граничными условиями второго рода для задачи нагрева пластины толщиной $L$ с одной стороны согласно [10] имеет вид:

$$
\begin{aligned}
& T(x, t)=T_{0}(x)+\frac{q_{L}(x, t)}{\lambda(x, t)} \times \\
& \times\left\{\frac{\lambda(x, t) t}{C(x, t) L}-\frac{L^{2}-3 x^{2}}{6 L}+L \sum_{k=1}^{\infty}(-1)^{k+1} \frac{2}{k^{2} \pi^{2}} \cos \left(\frac{k \pi x}{L}\right) \exp \left(-\frac{\pi^{2} k^{2} \lambda(x, t) t}{C(x, t) L^{2}}\right)\right\} .
\end{aligned}
$$

В квазистационарном режиме математическое ожидание последнего слагаемого равно нулю, поэтому оценку температурного поля в дискретном времени можно записать в следующем виде: 


$$
\hat{T}_{j}=T_{0}(x)+\frac{q_{L} t_{j}}{C_{j} L}-\frac{q_{L}\left(L^{2}-3 x^{2}\right)}{6 \lambda_{j} L} .
$$

Получаем, что оценка температурного поля зависит от двух неизвестных независимых случайных величин $\lambda_{j}$ и $C_{j}$.

Разобьем поставленную задачу на две подзадачи. Пусть в первой задаче $\lambda_{j}=$ const является постоянной известной величиной, тогда с помощью фильтра Калмана найдем $C_{j}$. Во второй задаче примем $C_{j}=$ const, взяв полученные в первой задаче значения $C_{j}$, рассчитаем с помощью фильтра Калмана значения $\lambda_{j}$

Рассмотрим первую подзадачу. Пусть $\lambda_{j}=$ const , обозначим

$$
\begin{gathered}
\tilde{T}_{j}=T_{0}(x)-\frac{q_{L j}\left(L^{2}-3 x^{2}\right)}{6 \lambda_{j} L}=\text { const }, \\
\bar{T}_{j}=T_{j}-\tilde{T}_{j}=\frac{q_{L j} t_{j}}{C_{j} L},
\end{gathered}
$$

где $T_{j}$ - экспериментально измеренные значения температуры по времени на поверхности пластины толщиной $L$.

Преобразуем уравнение (11) так, чтобы оно было линейным относительно $C_{j}$. Обозначив $C_{j}^{\prime}=\frac{1}{C_{j}}$, получим уравнение наблюдения:

$$
\bar{T}_{j}=\frac{q_{L j} t_{j} C_{j}^{\prime}}{L} .
$$

В качестве априорных сведений о наблюдаемом процессе возьмем

$$
C_{j}^{\prime}=C_{j-1}^{\prime} \text {. }
$$

Сравнивая уравнения наблюдения (12), сообщения (13) и систему (6) получаем при $\omega=1, H_{j}=\frac{q_{L j} t_{j}}{L}$. Используя фильтр Калмана (7), получаем итерационную процедуру определения оценки теплоемкости $C$ :

$$
\begin{aligned}
C_{j}^{\prime} & =C_{j-1}^{\prime}+\frac{q_{L j} t_{j} \vartheta_{j}}{L D_{j}}\left(\bar{T}_{j}-\frac{q_{L j} t_{j}}{L} C_{j-1}^{\prime}\right), \\
\frac{1}{\vartheta_{j}} & =\frac{1}{\vartheta_{j-1}}+\frac{q_{L j}^{2} t_{j}^{2}}{L^{2} D_{j}}, \\
\bar{T}_{j} & =T_{j}-T_{0}(x)+\frac{q_{L j}\left(L^{2}-3 x^{2}\right)}{6 \lambda_{j} L}, \\
C_{j}^{\prime} & =\frac{1}{C_{j}} .
\end{aligned}
$$

где $D_{0}$ - определяется погрешностью измерения температуры.

Для расчета по формулам (14) не хватает значений теплопроводности $\lambda_{j}$. Для расчета начального приближения значений теплопроводности можно ис- 
пользовать любой метод решения обратной задачи теплопроводности, дающий приближенные результаты.

Рассмотрим вторую подзадачу. Пусть $C_{j}=$ const, тогда обозначим

$$
\begin{array}{r}
\tilde{T}_{j}=T_{0}(x)+\frac{q_{L j} t_{j}}{C_{j} L}=\text { const }, \\
\bar{T}_{j}=T_{j}-\tilde{T}_{j}=-\frac{q_{L j}\left(L^{2}-3 x^{2}\right)}{6 L \lambda_{j}},
\end{array}
$$

где $T_{j}$ - экспериментально измеренные значения температуры.

Преобразуем уравнение (16) таким образом, чтобы оно было линейным относительно $\lambda_{j}$. Обозначив $\lambda_{j}^{\prime}=\frac{1}{\lambda_{j}}$, получим уравнение наблюдения

$$
\bar{T}_{j}=-\frac{q_{L j}\left(L^{2}-3 x^{2}\right) \lambda_{j}^{\prime}}{6 L} .
$$

В качестве априорных сведений о наблюдаемом процессе возьмем

$$
\lambda_{j}^{\prime}=\lambda_{j-1}^{\prime} \text {. }
$$

Сравнивая уравнения наблюдения (17), сообщения (18) и систему (6), получаем при

$$
\omega=1, H_{j}=-\frac{q_{L j}\left(L^{2}-3 x^{2}\right)}{6 L} .
$$

Используя уравнения фильтра Калмана (7), получаем итерационную процедуру для нахождения оценки коэффициента теплопроводности $\lambda$ :

$$
\begin{aligned}
& \lambda_{j}^{\prime}=\lambda_{j-1}^{\prime}-\frac{q_{L j}\left(L^{2}-3 x^{2}\right) \vartheta_{j}}{6 L D_{j}}\left(\bar{T}_{j}+\frac{q_{L j}\left(L^{2}-3 x^{2}\right)}{6 L} \lambda_{j-1}^{\prime}\right), \\
& \frac{1}{\vartheta_{j}}=\frac{1}{\vartheta_{j-1}}+\frac{q_{L j}^{2}\left(L^{2}-3 x^{2}\right)^{2}}{36 L^{2} D_{j}}, \\
& \bar{T}_{j}=T_{j}-T_{0}(x)-\frac{q_{L j} t_{j}}{C_{j} L}, \\
& \lambda_{j}^{\prime}=\frac{1}{\lambda_{j}} .
\end{aligned}
$$

Таким образом, получен рекурсивный фильтр, позволяющий оценить ТФХ образца по серии неточных зашумленных измерений температурного распределения в нем. Алгоритм численной реализации метода обработки экспериментальных данных и расчета теплофизических характеристик с помощью цифрового фильтра Калмана представлен на рис. 1.

Алгоритм позволяет определять ТФХ по значительно возмущенным экспериментальным данным и является устойчивым при обработке любых экспериментов, проведенных с помощью ИИС. Это является несомненным достоинством разработанного алгоритма. Возможности алгоритма, его устойчивость при обработке сильно возмущенных данных и погрешность была исследована с помощью имитационного моделирования экспериментов по нагреву и отвержде- 
нию ПКМ с последовательным плавным поочередным изменением входных условий, что позволило установить зависимости между входными данными эксперимента и погрешностью работы алгоритма. В результате были получены оптимальные условия использования алгоритма и область наименьшей погрешности расчета ТФХ.

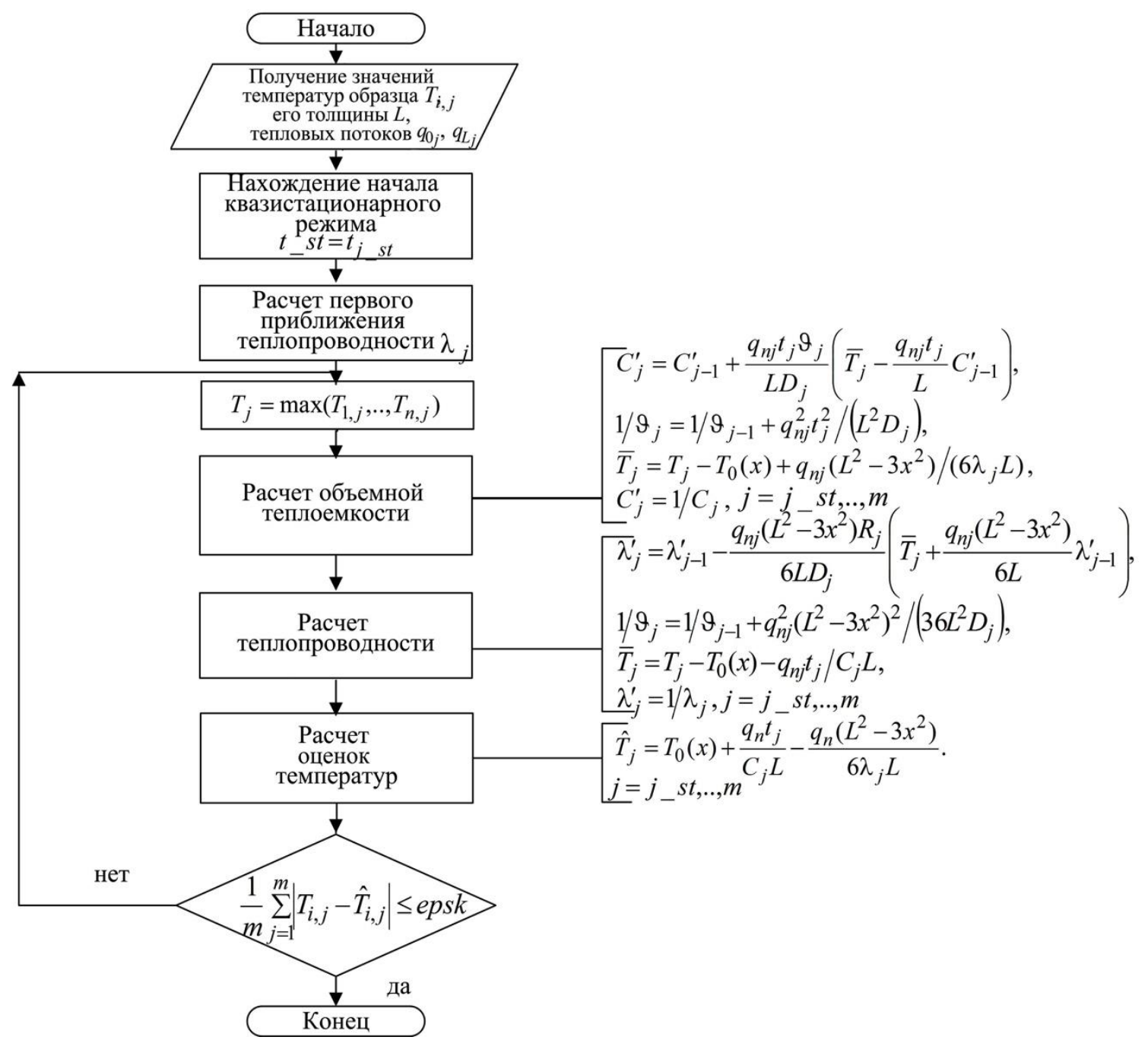

Рис. 1. Блок-схема алгоритма расчета ТФХ на основе фильтра Калмана

Разработанный алгоритм положен в основу прикладного программного обеспечения ИИС исследования ТФХ ПКМ, работающей в составе интегрированной ИИС исследования свойств и расчета оптимальных температурновременных режимов отверждения изделий из полимерных композиционных материалов $[2 ; 5 ; 6]$.

1. Годовский Ю.К. Теплофизические методы исследования полимеров. М.: Химия, 1976. 216 с.

2. Дмитриев О.С., Дмитриев А.О., Живенкова А.А. Исследование характеристик полимерных композитов в процессе отверждения для анализа и выбора оптимальных режимов производства толстостенных изделий из них // Труды Естественнонаучного и гуманитарного факультета Тамбовского государственно- 
го технического университета: сборник научных и научно-методических статей. Тамбов, 2014. С. 52-64.

3. Дмитриев О. С., Живенкова А. А., Дмитриев А. О. Интеллектуальная информационно-измерительная система для определения теплофизических характеристик полимерных композитов // Вестник Тамбовского государственного технического университета. 2013. Т. 19. №1. С. 73-83.

4. Дмитриев О. С., Кириллов В. Н., Мищенко С. В., Дмитриев А. О. Измерительно-вычислительная система для исследования свойств клеевых препрегов и расчета режимов отверждения ПКМ на их основе // Клеи. Герметики. Технологии. 2009. №6. С. 22-28.

5. Дмитриев О. С., Кириллов В. Н., Мищенко С. В., Дмитриев С. О. Оптимизация режима отверждения изделий из полимерных композитов на основе клеевых препрегов // Клеи. Герметики. Технологии. 2009. №5. С. 17-24.

6. Дмитриев О. С., Кириллов В. Н., Зуев А. В., Черепахина А. А. Влияние типа наполнителя на оптимальные режимы отверждения толстостенных ПКМ // Клеи. Герметики. Технологии. 2011. №11. С. 27-36.

7. Дмитриев О.С., Мищенко С.В., Дмитриев А.О. Касатонов И.С., Дмитриев С. О. Интегрированная информационно-измерительная система исследования свойств и расчета режимов отверждения полимерных композитов // Вестник Тамбовского государственного технического университета. 2008. Т. 14. №2. С. 230-240.

8. Дмитриев О. С., Мищенко С. В., Пономарев С. В. Математическое моделирование процесса отверждения изделия из полимерных композиционных материалов методом горячего прессования // Вестник Тамбовского государственного технического университета. 1998. Т. 4. №4. С. 390-399.

9. Кербер М. Л., Виноградова В. М., Головкин Г. С. и др. Полимерные композиционные материалы: структура, свойства, технология / под ред. А.А. Берлина. СПб.: Профессия, 2008. 560 с.

10. Коздоба Л. А., Круковский П. Г. Методы решения обратных задач теплопереноса. Киев: Наук. думка, 1982. 360 с.

11. Мацевитый Ю. М., Мултановский А. В. Идентификация в задачах теплопроводности. Киев: Наук. думка, 1982. 240 с.

12. Новиченок Л. Н., Шульман 3. П. Теплофизические свойства полимеров / под ред. А.Г. Шашкова. Минск: Наука и техника, 1971. 120 с.

13. Тихонов В. И., Харисов В. Н. Статистический анализ и синтез радиотехнических устройств и систем: Учебное пособие для вузов. М: Радио и связь, 1991. $608 \mathrm{c}$.

14. Dmitriev O. S., Kirillov V. N., Mischenko S. V., Dmitriev A. O. ComputerMeasuring System for Research into Properties of Glutinous Prepregs and Calculation of Curing Cycles of the Polymer Composite Materials on Their Base // Polymer Science. Series D. 2010. Vol. 3. No. 1. P. 20-25.

15. Kalman Filter [Электронный pecypc] / Edited by Vedran Kordic. InTech, 2010. 400 p. 


\title{
Дутов С.Ю., Шамшина Н.В. \\ Тамбовский опыт возрождения ГТО: \\ успехи и трудности
}

\author{
Dutov S.Yu., Shamshina N.V. \\ Tambov experience revival GTO: successes and challenges
}

Тамбовский государственньй технический университет Tambov State Technical University

Тамбовская область не вошла в число экспериментальных регионов, где с 2014 2. был введен комплекс ГТО, однако подготовка к реализации проекта началась здесь еще с 2012 г. Повсеместно тамбовчанами успешно сдаются установленные нормативы, когда силу и выносливость пока демонстрируют исключительно физически подготовленные люди, а их в регионе - около $30 \%$. В данной статье исследуются современные реалии по возрождению норм ГТО, приводятся доводы и стимуль для воспитания поколения в стиле ЗОЖ.

Tambov region was not included in the pilot regions where the routine of GTO have introduced since 2014, but preparations for the project implementation started in 2012 here. Throughout Tambov people are passed established standards successful, where strength and endurance are shown only by physically trained people, and they are about $30 \%$ in the region. This article examines the current realities on the revival of the norms GTO, the arguments and incentives for generation are given in the style of healthy lifestyle.

Ключевые слова: Тамбовская область; возрождение норм ГТО; физическая подготовленность; физическая культура; здоровый образ жизни, здоровое поколение.

Keywords: Tambov Region; revival of GTO norms; physical fitness; physical culture; healthy lifestyle; healthy generation.

В марте 2014 г. президентом Российской Федерации Владимиром Путиным был подписан указ о возрождении норм ГТО. Официальные заявки на тестирование нового комплекса под некогда популярным советским названием «Готов к труду и обороне» раньше других подали двенадцать российских регионов: Карелия, Марий Эл, Мордовия, Татарстан, Удмуртия, Красноярский край, а также Белгородская, Владимирская, Московская, Свердловская, Смоленская и Ярославская области.

Тамбовская область в число первооткрывателей, увы, не вошла. Несмотря на это, уже не первый год местные приверженцы здорового образа жизни периодически испытывают свои силы и активно готовятся к сдаче норм ГТО. По собственному желанию нормативы сдают рабочие трудовых коллективов и госслужащие, тамбовские студенты и школьники. 
Одной из последних ярких побед стало участие команды школьников на I Всероссийском фестивале ГТО, который прошел в конце августа в Белгороде. Более 140 соперников из 75 субъектов РФ сумела обойти юная тамбовчанка Ксения Авдеева. По сумме баллов во всех видах спорта среди участников 11-13 лет она заняла первое место и привезла домой золотой значок Всероссийского физкультурно-спортивного комплекса «Готов к труду и обороне».

Между тем, впервые после долгого незаслуженного забвения аббревиатуру в регионе вспомнили еще в мае 2012 г., когда на стадионе «Спартак» состоялся областной смотр физической подготовки обучающихся в учреждениях начального и среднего профессионального образования. Тогда, лучшая из семи команд, прошедших в финал, отправилась на Всероссийские соревнования в Анапу. Не менее важной задачей, по словам Вячеслава Свиридова, председателя Тамбовского регионального отделения «Юность России», стало выявление физической подготовленности обучающихся в свете разработанных в регионе нормативов сдачи на золотой и серебряный значки ГТО.

В мае 2013 г. в областном центре прошел большой смотр физической подготовленности учащейся молодежи к будущей сдаче норм ГТО. В марте 2014 г. по инициативе главы города Алексея Кондратьева состоялся первый городской фестиваль комплекса ГТО, а полгода спустя на главной спортивной арене Тамбова собралось около двухсот пятиклассников из 20 школ областного центра для участия в первых пробных соревнованиях по сдаче норм ГТО. Николай Забавников, председатель отделения ДОСААФ России Тамбовской области, заметил тогда, что требования к спортсменам, по сравнению с советским комплексом, стали строже. Несмотря на это, около 50\% участников выполнили нормативы ГТО по серебряному уровню и стали первыми в регионе обладателями специальных жетонов. В это же время в рамках программы поэтапного внедрения физкультурно-спортивного комплекса соревнования стартовали в среднепрофессиональных учебных заведениях.

Накануне 2015 г. в областном центре было объявлено об официальной апробации испытаний и норм ГТО. В качестве инновационной площадки был выбран МАОУ «Лицей №28 им. Н. А. Рябова» г. Тамбова. Ученики 1-х - 6-х классов на протяжении учебного года подтягивались, отжимались, метали гранаты, стреляли, бегали и плавали. «На водной дистанции порядка $30 \%$ ребят выполнили норматив на золотой значок ГТО», - констатировала Надежда Елизарова, инструктор-методист ДЮСШ №6.

На протяжении 2015 г. готовились к сдаче норм ГТО и трудовые коллективы Тамбовщины. В августе на традиционной городской спартакиаде 12 команд трудящихся испытали себя на силу, ловкость и выполнение других элементов комплекса ГТО. Победителем признана команда завода «Пигмент».

В атмосфере всеобщей спортивной подготовки не устояли от соблазна испытать себя на прочность и сотрудники Управления по физической культуре, спорту и туризму администрации Тамбовской области. На стадионе «Спартак» около 40 госслужащих под руководством начальника структурного подразделения успешно сдали нормы ГТО. Руководитель управления Михаил Белоусов лично возглавил группу госслужащих активистов и выполнил все нормативы в соответствии с золотым уровнем. 
С большим удовольствием на предложение принять участие в индивидуальном спортивном эксперименте откликнулся Управляющий Тамбовского регионального отделения Фонда социального страхования РФ Андрей Пилипенко. Упражнение на гибкость (касание пола пальцами рук при наклоне вперед из положения стоя с прямыми ногами) далось испытуемому с необычной легкостью. Сгибания ног в коленях не зафиксировано, результат удержан пальцами обеих рук больше двух секунд. Выбор между отжиманиями, подъемом гири и подтягиваниями на турнике выпал в сторону последнего. Без особых усилий молодой руководитель выполнил 5 подтягиваний средним прямым хватом, касаясь верхом груди перекладины, сводя при этом лопатки, в нижней точке полностью выпрямляя руки. Самым сложным, по признанию Андрея Пилипенко, стал тест на выносливость. Конечный результат - три километра за 16 минут 5 секунд. Таким образом, три обязательных к выполнению испытания были выполнены успешно.

Однако при всей видимой легкости физических испытаний, предлагаемых школьникам, студентам и работающим тамбовчанам, есть одно неоспоримое «но». Все те, кто прекрасно зарекомендовал себя в процессе сдачи норм физкультурно-спортивного комплекса, неизменно ведут активный образ жизни. Так, управляющий Фондом социального страхования трижды в неделю занимается плаванием, теннисом и футболом. Если бы не занятия в спортивном зале, выполнить нормы ГТО было бы гораздо сложнее, признался Андрей Пилипенко. Начальник областного управления по физической культуре, спорту и туризму Михаил Белоусов - кандидат в мастера спорта по спортивному туризму - до сих пор практикует частые семейные походы на байдарках по реке Ворона. Тамбовская ученица Ксения Авдеева, ставшая победителем на I Всероссийском фестивале ГТО в Белгороде, имеет второй спортивный разряд по полиатлону. Не исключение и яркие результаты других тамбовских школьников, демонстрирующих высокие результаты при сдаче норм ГТО.

По данным доклада, представленного в администрацию Тамбовской области депутатом Тамбовской областной Думы Владимиром Андросовым, результаты тестовых соревнований по сдаче норм всероссийского физкультурноспортивного комплекса ГТО выглядят несколько удручающе: «Из 2100 учеников 5-6 классов в сдаче участвовало 200 человек, из них 144 выполнили требования. Стоит отметить, что участниками соревнований стали самые подготовленные дети своих школ. Из этого можно сделать вывод - максимум $20 \%$, а это около 400 человек, способны сдать нормативы и $80 \%$, напротив, абсолютно не подготовлены к испытаниям. Данные другого спортивного мероприятия под названием «Все в спорте», проведенного под эгидой «Единой России» в феврале 2013 г. также демонстрируют неутешительные статистические данные по ученическим навыкам владения лыжами. Экспертные заключения таковы $-60 \%$ школьников не могут стоять на лыжах, $30 \%$ в определенной степени владеют навыками ходьбы и только $10 \%$ могут заявить о хорошем уровне подготовки...». Несмотря на подобные негативные результаты, основными школьными отметками по физкультуре по-прежнему являются «4» и «5». Вывод депутата - учителя физкультуры умышленно завышают детям оценки по предмету. Отсутствие заинтересованности у школьников в обучении сказывается на низкой физической подготовке. При этом реализация комплекса ГТО станет своеобразным стимулом к полноценному физическому развитию для детей и их родителей и позволит вос- 
питать здоровое поколение тамбовчан. По сути, введение комплекса ГТО - это стимул заняться физкультурой многим жителям региона, независимо от возраста и социального статуса.

Другая сторона вопроса - поощрения и всевозможные льготы, которыми некоторые инициаторы хотят наградить россиян за сдачу норм ГТО. В числе таковых - дополнительные дни к отпуску или финансовое поощрение работающих граждан, прибавка к стипендии для студентов и дополнительные бонусы для абитуриентов при поступлении в профессиональные учебные заведения. Так, по этому поводу высказался молодой и успешный тамбовский руководитель, управляющий Фондом социального страхования Андрей Пилипенко: «Каждый человек должен заниматься своим здоровьем для самого себя, а не ради конкретной выгоды. Среди наших сотрудников уже сегодня есть желающие пройти испытания новым физкультурно-спортивным комплексом «Готов к труду и обороне». В наших рядах - много тех, кто регулярно занимается спортом. Нередко проводим Дни здоровья с эстафетами и состязаниями. Думаем о введении физкультминуток. Двигательная активность в процессе трудового дня действительно необходима. Активный образ жизни поможет каждому справиться с испытаниями модернизированного комплекса ГТО и, к примеру, пополнить коллекцию старых значков ГТО со школы, института или армии...». К слову, коллекция подобных значков собрана и представлена в Музее спорта на базе ТГУ им. Г. Р. Державина. Уникальная спортивная экспозиция, инициатором которой стал обладатель многочисленных значков ГТО, известный в спортивных кругах тамбовчанин Анатолий Сычев, открылась в 2012 г. Представлен в коллекции и значок - комплекс ГТО от 1931 г.

Официально жители Тамбовской области начнут сдавать нормы ГТО с 2016 г. Тогда же за выполнение нормативов самые ловкие, сильные и умелые станут поощряться значками спортивного комплекса «Готов к труду и обороне». Какими будут результаты - покажет время. А пока, согласно данным, предоставленным специалистами Управления физической культуры, спорта и туризма администрации Тамбовской области, по состоянию на январь 2015 г. около 315 тысяч человек в регионе регулярно занимаются спортом: это треть населения. Еще пять лет назад эта цифра была вдвое меньше. Таким образом, с каждым годом число приверженцев здорового образа жизни на Тамбовщине растет. Вредные привычки уходят на задний план, расставляя акценты на правильные приоритеты: ЗОЖ, хорошее самочувствие и приятный внешний вид со здоровым румянцем на щеках.

Для воспитания крепкого и здорового поколения тамбовчан необходимо заинтересовывать ребят с раннего возраста. Всевозможные спортивные секции и введенный в школах третий час урока физкультуры с заинтересованным в результатах преподавателем будут этому только способствовать. Как вариант развитие альтернативных видов спорта, популярных сегодня среди молодежи. Уже третий раз в Тамбове проходит фестиваль «Спорт улиц». В этом году около 200 профессионалов и любителей продемонстрировали свои экзотические навыки в скейтбординге, воркауте, паркуре, велосипедном спорте.

В целом сегодня на Тамбовщине уделяется большое внимание развитию системы детско-юношеского спорта: проводятся знаковые спортивно-массовые соревнования «Кросс наций», «Лыжня России», «Оранжевый мяч», «Российский 
Азимут», областной День здоровья и спорта, летние Сельские игры, Универсиада, Спартакиада среди дошкольных учреждений и др. В предстоящем периоде спортивные функционеры обещают продолжить работу по увеличению охвата разных категорий населения массовыми видами спорта и развитию спортивной инфраструктуры. На эти цели только в 2011-2014 гг. из федерального бюджета было привлечено в регион 1,63 млрд. рублей, с учетом софинансирования из областной казны были возведены более 40 объектов спортивной инфраструктуры.

О становлении сети физкультурно-спортивных площадок на местах говорил и Президент РФ Владимир Путин, обсуждая на заседании Совета по физической культуре и спорту введение комплекса ГТО. «Работа обещает быть серьезной, - отметил глава государства, - но мы должны с ней справиться!».

1. Антонюк С.Д., Макарова Л.Н., Мукина Е.Ю., Мистрюкова М.Н. Обоснование пространства двигательной культуры личности на основе принципа интеграции // Вестник Тамбовского государственного технического университета. 2006. T. 12. №2. C. 577-582.

2. Кабаева Т. ГТО. Перезагрузка // Делюкс. 2015. №5. С. 15-17.

\title{
Жуковская Т.В. \\ О нахождении множества достижимости линейной управляемой функционально- дифференциальной системы
}

\author{
Zhukovskaia T.V. \\ On finding an attainable set of a linear functional \\ differential equation control system
}

Тамбовский государственный технический университет Tambov State Technical University

Рассматривается задача нахождения множества достижимости для управляемой линейной функционально-дифференциальной системы. Исследование использует представление общего решения линейного абстрактного функиионально-дифференциального уравнения (ЛАФДУ) через оператор Грина. Приводится алгоритм приближенного нахождения общего решения ЛАФДУ. Оиенивается расстояние по Хаусдорфу между точным множеством достижимости и его приближением, основанном на аппроксимации оператора Грина. Приведень примеры нахождения множества достижимости для обыкновенного дифференциального уравнения второго порядка и уравнения первого порядка с запаздыванием. 
We consider a problem of finding an attainable set of a linear functional differential equation control system. Our research is based on a representation of the general solution of a linear abstract functional differential equation by Green's operator. We introduce an algorithm of finding an approximate general solution of a linear abstract functional differential equation. The Hausdorff distance between an exact attainable set and its approximation is estimated. Our method of estimating exploits an approximation of Green's operator. Some examples of finding an attainable set of a second-order ordinary differential equation and a first-order delay differential equation with lateness are presented.

Ключевые слова: управляемая система; множество достижимости; краевая задача; оператор Грина; функиия Коши; приближенное решение.

Key words: control system; attainable set; boundary value problem; Green's operator; Cauchy's function; approximate solution.

Множеством достижимости называют множество всех таких состояний, в которые можно привести динамическую систему при помощи допустимого управления из начальной точки (начального состояния) за заданный промежуток времени. Мы рассмотрим задачу нахождения множества достижимости в следующей постановке: предполагаем, что динамическая система описывается линейным абстрактным функционально-дифференциальным уравнением (ЛАФДУ), а состояние системы определяется значениями на решении этого уравнения заданных функционалов. Исследование основано на полученных Н. В. Азбелевым и его учениками результатах теории ЛАФДУ [1]. Аналогичный подход применялся в [6] при исследовании задачи оптимального управления для ЛАФДУ.

Пусть заданы банаховы пространства $D, B, Y$, множество $\mathfrak{U} \subset Y$; пусть определены линейные ограниченные отображения $\mathcal{L}: D \rightarrow B, H: Y \rightarrow B, l_{1}: D \rightarrow$ $\mathbb{R}^{n}, l_{2}: D \rightarrow \mathbb{R}^{p}$ и вектор $\alpha \in \mathbb{R}^{n}$. Будем предполагать, что оператор $\mathcal{L}$ нётеров и ind $\mathcal{L}=n$. Пусть при любом $f \in B$ «начальная» краевая задача

$$
\mathcal{L} x=f, l_{1} x=\alpha
$$

однозначно разрешима.

Рассматривается управляемая система

$$
\mathcal{L} x=H u, l_{1} x=\alpha .
$$

Для каждого допустимого управления

$$
u \in \mathfrak{U}
$$

на соответствующем решении $x \in D$ задачи (2) определим значение $l_{2} x \in$ $\mathbb{R}^{p}$. Искомое множество достижимости есть совокупность полученных таким образом векторов. Обозначим это множество через $\mathfrak{D}$.

В задачах управления движением в качестве $D, B$ удобно выбирать пространства абсолютно непрерывных и, соответственно, суммируемых (в некоторой степени) функций, определенных на промежутке времени $[0, T]$, в качестве $Y$ - также пространство суммируемых функций. Тогда множество $\mathfrak{U} \subset Y$ содержит суммируемые функции, удовлетворяющие некоторым ограничениям (например, их значения должны принадлежать заданному множеству $U$ ). В таких системах управления $\mathcal{L}$ есть дифференциальный оператор, функционал $l_{1}$ опре- 
деляется равенством $l_{1} x=x(0)$ (то есть задача (1) - это задача Коши для системы обыкновенных дифференциальных уравнений), а функционал $l_{2}-$ равенством $l_{2} x=x(T)$. В современных математических моделях наряду с обыкновенными дифференциальными уравнениями используются уравнения с сосредоточенным и распределенным запаздыванием, интегро-дифференциальные и другие типы функционально-дифференциальных уравнений, то есть $\mathcal{L}-$ некоторый функционально-дифференциальный оператор. В задачах управления экономической динамикой рассматриваются интегральные функционалы $l_{i} x=$ $\int_{0}^{T} \boldsymbol{\ell}_{i}(s) x(s) d s, i=1,2$. Исследуемая здесь система управления (2),(3) охватывает перечисленные и многие другие модели.

Для нахождения множества $\mathfrak{D}$ воспользуемся следующим представлением [1, с. 105] решения краевой задачи (1):

$$
x=G f+X \alpha,
$$

где $X \in D^{n}$ - фундаментальная система решений однородного уравнения $\mathcal{L} x=0$, а линейный ограниченный оператор $G: B \rightarrow D$ - оператор Грина «начальной» краевой задачи. Используя это соотношение, получаем

$$
\begin{aligned}
& x=G H u+X \alpha, l_{2} x=l_{2} G H u+l_{2} X \alpha, \\
& \quad \mathfrak{D}=\left\{l_{2} G H u+l_{2} X \alpha, u \in \mathfrak{U}\right\}=l_{2} G H \mathfrak{U}+l_{2} X \alpha .
\end{aligned}
$$

Пример 1. Пусть задано $T<\frac{\pi}{2}$. Рассмотрим управляемую систему

$$
\mathcal{L} x \doteq \ddot{x}+x=u(t), x(0)=0, \dot{x}(0)=0, t \in[0, T],
$$

где управление удовлетворяет ограничению

$$
u(t) \in[0,1], t \in[0, T] .
$$

Полагаем, что $B=Y \doteq L([0, T], \mathbb{R})$ - пространство суммируемых на $[0,1]$ функций с нормой $\|y\|_{L}=\int_{0}^{T} y(s) d s ; D \doteq W^{2}([0, T], \mathbb{R})$ - пространство дважды дифференцируемых функций таких, что их первая производная абсолютно непрерывна, а вторая производная суммируема, с нормой $\|x\|_{W^{2}}=|(x(0), \dot{x}(0))|+$ $\|\ddot{x}\|_{L}$. Множество $\mathfrak{U}$ здесь содержит измеримые функции, удовлетворяющие неравенству (7). Для системы (6) имеем

$$
\begin{gathered}
(\mathcal{L} x)(t)=\ddot{x}(t)+x(t),(H u)(t)=u(t), \\
l_{1}: W^{2} \rightarrow \mathbb{R}^{2}, l_{1} x=(x(0), \dot{x}(0)) .
\end{gathered}
$$

Пусть функционал $l_{2}: W^{2} \rightarrow \mathbb{R}$ задан равенством $l_{2} x=x(T)$. Для рассматриваемой управляемой системы определим множество достижимости. Запишем в виде (4) решение задачи (6)

$$
x(t)=\int_{0}^{t} \sin (t-s) u(s) d s .
$$

Заметим, что функция Коши $\mathcal{G}(t, s)=\sin (t-s)$ неотрицательна, поэтому множество достижимости

$$
\mathfrak{D}=\left\{\int_{0}^{T} \sin (T-s) u(s) d s, u(s) \in[0,1]\right\}=[0,1-\cos T] .
$$

Пример 2. Пусть задано число $p>0$. Рассмотрим управляемую систему с запаздыванием

$$
\mathcal{L} x \doteq \dot{x}(t)-p x\left(\frac{t}{2}\right)=u(t), x(0)=0, t \in[0, T],
$$

где управление удовлетворяет ограничению

$$
u(t) \in[-1,1], t \in[0, T] .
$$


Здесь удобно выбрать следующие банаховы пространства: как и выше, $B=Y \doteq L([0, T], \mathbb{R}) ; D \doteq A C([0, T], \mathbb{R})$ - пространство абсолютно непрерывных функций, имеющих суммируемую производную, с нормой $\|x\|_{A C}=|x(0)|+$ $\|\dot{x}\|_{L}$. Множество $\mathfrak{U}$ здесь содержит измеримые функции, удовлетворяющие неравенству (9). Для системы (8) имеем

$$
(\mathcal{L} x)(t)=\dot{x}-p x\left(\frac{t}{2}\right),(H u)(t)=u(t), l_{1}: A C \rightarrow \mathbb{R}, l_{1} x=x(0) .
$$

Пусть функционал $l_{2}: W^{2} \rightarrow \mathbb{R}$, определяющий конечное положение системы, задан равенством $l_{2} x=x(T)$. Для рассматриваемой управляемой системы определим множество достижимости. Используя функцию Коши начальной задачи (8) (см. [2]), получим

$$
x(t)=\int_{0}^{t} \sum_{k=0}^{\infty} p^{k} \chi_{\left[0, \frac{t}{2^{k}}\right]}(s) \frac{2^{\frac{k(k-1)}{2}}}{k !}\left(\frac{t}{2^{k-1}}-2 s\right)^{k} u(s) d s .
$$

Здесь функция Коши

$$
\mathcal{G}(t, s)=\sum_{k=0}^{\infty} p^{k} \chi_{\left[0, \frac{t}{2^{k}}\right]}(s) \frac{2^{\frac{k(k-1)}{2}}}{k !}\left(\frac{t}{2^{k-1}}-2 s\right)^{k},
$$

как и в примере 1 , неотрицательна, поэтому множество достижимости есть отрезок $\mathfrak{D}=[-d, d]$, где

$$
d=\int_{0}^{T} \sum_{k=0}^{\infty} p^{k} \chi_{\left[0, \frac{T}{2^{k}}\right]}(s) \frac{2^{\frac{k(k-1)}{2}}}{k !}\left(\frac{T}{2^{k-1}}-2 s\right)^{k} d s .
$$

Применение описанной схемы требует нахождения оператора Грина (соответственно, оператора Коши для уравнений с вольтерровыми операторами в функциональных пространствах с «обычным» начальным условием $x(0)=\alpha$ ) и фундаментального решения однородного уравнения. Однако точно получить требуемые величины можно лишь для некоторых частных функциональнодифференциальных уравнений. Для широкого применения данного подхода к управляемым функционально-дифференциальным системам можно воспользоваться приближенными методами нахождения оператора Грина и фундаментального решения однородного уравнения. Для скалярных функциональнодифференциальных уравнений с вольтерровыми отображениями такие алгоритмы предложены в работах [4; 5].

Обсудим правомерность использования в формуле (5) приближенных значений оператора Грина и фундаментальной системы решений.

Пусть задана последовательность операторов $G_{j}: B \rightarrow D$ и последовательность векторов $X_{j} \in D^{n}, j=1,2, \ldots$. Определим последовательность множеств

$$
\mathfrak{D}_{j}=l_{2} G_{j} H \mathfrak{U}+l_{2} X_{j} \alpha, j=1,2, \ldots .
$$

Очевидно, что если множество $\mathfrak{U}$ ограничено и имеют место сходимости операторов

$$
\left\|G_{j}-G\right\|_{B \rightarrow D} \rightarrow 0,\left\|X_{j}-X\right\|_{D^{n}} \rightarrow 0
$$

то для расстояния по Хаусдорфу $h_{D}\left[\mathfrak{D}_{j}, \mathfrak{D}\right]$ в пространстве $D$ между «точным» множеством достижимости (5) и его приближением (10) справедливо

$$
\begin{gathered}
h_{D}\left[\mathfrak{D}_{j}, \mathfrak{D}\right] \leq\left\|l_{2}\right\|_{B \rightarrow \mathbb{R}^{p}}\left(\left\|G_{j}-G\right\|_{B \rightarrow D}\|H\|_{Y \rightarrow B}\|\mathfrak{U}\|_{Y}+\right. \\
\left.+\left\|X_{j}-X\right\|_{D^{n}}|\alpha|_{\mathbb{R}^{p}}\right) \rightarrow 0 .
\end{gathered}
$$


В заключение приведем предложенный в [4; 5] алгоритм, позволяющий численно находить общее решение (и, следовательно, оператор Грина и фундаментальную систему решений) скалярного уравнения вида

$$
\mathcal{L} x \doteq \dot{x}+V x=f(t), \quad t \in[0, T] .
$$

Здесь линейный ограниченный оператор $V: A C([0, T], \mathbb{R}) \rightarrow L([0, T], \mathbb{R})$ является вольтерровым.

Определим оператор

и запишем уравнение (9) в виде

$$
K: L \rightarrow L,(K y)(t)=V \int_{0}^{t} y(s) d s,
$$

$$
\dot{x}+K \dot{x}+A x(0)=f,
$$

где $A(\cdot)=V e, e(t)=1$, при п.в. $t \in[0, T]$. Пусть спектральный радиус $\rho(K)$ оператора $K$ меньше 1 . Из вольтерровости оператора $V$ следует, что оператор $K$ также является вольтерровым. Так как $\rho(K)<1$, то задача Коши для уравнения (12) с начальным условием

$$
x(0)=\alpha
$$

при любых $f \in L, \alpha \in \mathbb{R}^{n}$ однозначно разрешима, и ее решение определяется равенством

$$
x(t)=X(t) \alpha+\int_{0}^{t} \mathcal{G}(t, s) f(s) d s .
$$

Здесь $\mathcal{G}(t, s)$ - функция Коши.

Метод основан на нахождении такого отображения $P: L \rightarrow L$, что для произвольного $y \in L$ величина $\|y-P y\|_{L}$ достаточно мала, и для «приближенного уравнения»

$$
\dot{x}+K P \dot{x}+A x(0)=f,
$$

функция Коши, а, следовательно, и оператор Коши, и фундаментальное решение однородного уравнения, выписываются в явном виде.

Построим такое отображение $P$. Для этого выберем некоторое натуральное число $N$ и действительные числа $t_{j}, j=\overline{1, N}$, удовлетворяющие неравенствам $0<t_{1}<t_{2}<\cdots<t_{N}=T$. Рассмотрим функции $z_{j} \in L, j=\overline{1, N}$, такие, что $z_{j}(t)=0$ при п.в. $t \in\left[0, t_{j-1}\right]$. Определим матрицы $\tau, g$ размерности $N \times N$ с элементами

$$
\tau_{i j}=\int_{t_{i-1}}^{t_{i}} z_{j}(t) d t, \quad g_{i j}=\int_{t_{i-1}}^{t_{i}}\left(K z_{j}\right)(s) d s .
$$

Заметим, что при $j>i$ выполнено $\tau_{i j}=g_{i j}=0$.

Если предположить, что $\tau_{i i} \neq 0$ при любом $i$, то матрица $\tau$ обратима, обозначим $\eta=\tau^{-1}$. Для элементов этой матрицы при $j>i$ выполнено равенство $\eta_{i j}=0$. Определим матрицу $\sigma=g \eta$. Построим отображение $P: L \rightarrow L$, ставящее в соответствие каждому $y \in L$ элемент

$$
P y=\sum_{j=1}^{N} \mathrm{o} \xi_{j} z_{j},
$$

с такими коэффициентами $\xi_{j}$, что справедливо соотношение

$$
\int_{0}^{t_{i}} y(s) d s=\int_{0}^{t_{i}}(P y)(s) d s, \quad i=\overline{1, N} .
$$

Из последнего условия найдем коэффициенты $\xi_{j}, j=\overline{1, N}$. Положим $x_{i}=$ $\int_{0}^{t_{i}} y(s) d s$. Тогда 


$$
\int_{\square a}^{t_{i}} \sum_{j=1}^{N} \xi_{j} z_{j}(s) d s-\int_{\square a}^{t_{i-1}} \sum_{j=1}^{N} \xi_{j} z_{j}(s) d s=\sum_{j=1}^{N} \xi_{j} \tau_{i j}=x_{i}-x_{i-1} .
$$

Следовательно,

$$
\xi_{i}=\sum_{j=1}^{i} \eta_{i j}\left(x_{i}-x_{i-1}\right)
$$

и

$$
P y=\sum_{i=1}^{N} \text { o } \sum_{j=1}^{i} \mathrm{o} \eta_{i j}\left(x_{i}-x_{i-1}\right) z_{j} .
$$

Функция Коши уравнения (14), в котором отображение $P: L \rightarrow L$ определяется равенством (15), находится следующими рекуррентными соотношениями

$$
\begin{aligned}
& \mathcal{G}\left(t_{1}, s\right)=\left\{\begin{array}{c}
\frac{1}{1-\eta_{11} g_{11}} \text { при } s \in\left[0, t_{1}\right], \\
0 \text { при } s \notin\left[0, t_{1}\right],
\end{array}\right. \\
& \mathcal{G}\left(t_{i}, s\right)=\left\{\begin{array}{cc}
\frac{1}{1-\eta_{i i} g_{i i}}\left(1+\sum_{j=1}^{i} \mathrm{o} \mathcal{G}\left(t_{j}, s\right)\left(\sigma_{i j}-\sigma_{i j+1}\right)\right) & \text { при } s \in\left[0, t_{i}\right], \\
0 & \text { при } s \notin\left[0, t_{i}\right],
\end{array}\right. \\
& i=\overline{2, N} \text {. }
\end{aligned}
$$

Задача нахождения множества достижимости для нелинейного функционально-дифференциального уравнения гораздо сложнее, т. к. для такого уравнения нет представления общего решения, аналогичного соотношению (4). Однако для некоторых конкретных уравнений разработаны численные методы, позволяющие решать эту задачу (см., например, [3; 7]).

1. Азбелев Н. В. Введение в теорию функционально-дифференциальных уравнений. М.: Наука, 1991. 280 с.

2. Борзова М. В. Некоторые интегрируемые в квадратурах линейные функционально-дифференциальные уравнения // Вестник Тамбовского университета. Серия: Естественные и технические науки. 2015. Т. 20. Вып. 5. C. 1079-1083.

3. Жуковский Е. С. О параметрическом задании решения дифференциального уравнения и его приближенном построении // Известия высших учебных заведений. Математика. 1996. Т. 407. №4. С. 31-35.

4. Жуковская Т. В. Вольтерровость операторов и численное решение функционально-дифференциальных уравнений: дисс. ... канд. физ.-мат. наук: 01.01.02. Пермь, 1990. 140 с.

5. Жуковская Т. В. Интерполяция функции Коши // Вестник Тамбовского университета. Серия: Естественные и технические науки. 2002. Т. 7. Вып. 1. С. 110-111.

6. Жуковская Т. В. О применении $\mathrm{W}$-метода Азбелева в исследовании задачи оптимального управления для линейного функциональнодифференциального уравнения // Теория управления и математическое моделирование. Тезисы докладов Всероссийской конференции с международным участием, посвященной памяти профессора Н. В. Азбелева и профессора Е. Л. Тонкова. Удмуртский государственный университет. Ижевск, 2015. С. 55-57. 
7. Жуковская Т. В., Молоканова Е. А., Стуров Д. Л. О вертикальных асимптотах интегральных кривых обыкновенного дифференциального уравнения // Вестник Тамбовского государственного технического университета. 2011. T. 17. №.3. C. 736-743.

\title{
Кондракова Е.Ю., Харченко В.Ю. Экспресс-методика определения константы активности фталоцианинового катализатора
}

\author{
Kondrakova E.Yu., Kharchenko V.Yu. \\ Express-method of determining constants \\ the activity of the phthalocyanine catalyst
}

Тамбовский государственный технический университет Tambov State Technical University

Представлены результаты разработки конструкиии и режима работы самовсасывающей мешалки. Предложена установка для определения константы активности фталоцианинового катализатора. Показана возможность использования в методике доступных реагентов и сокращения времени анализа в 2,5..3,0 раза.

The paper presents the results of design and operation mode of the self-sucking stirrer. Installation to determine the constant activity of the phthalocyanine catalyst is proposed. The possibility of using the methodology available reagents and reduce the analysis time of 2.5..3.0 times is shown.

Ключевые слова: меркаптаны; константа активности фталоцианинового катализатора; самовсасывающая мешалка.

Key words: mercaptans; the constant activity of the phthalocyanine catalyst, self-priming stirrer.

Проблема переработки углеводородного сырья, используемого в нефтяной и газовой промышленностях в огромных количествах, в настоящее время стоит очень остро в виду постоянно ужесточающихся требований к качеству продукта. Анализ состава углеводородного сырья [1] показывает, что в нефти и газоконденсате присутствует достаточное количество меркаптанов, которые приводят к повышению скорости коррозии оборудования, ухудшению качества продуктов нефтепереработки, а также влекут за собой потенциальную угрозу здоровью людей и окружающей среде. 
Меркаптаны обладают высокой токсичностью, летучестью и неприятным запахом даже в очень низких концентрациях. Высокая коррозионная активность низших алифатических меркаптанов уменьшается с ростом углеродной цепи. Меркаптаны - сильные нервные яды, обладают наркотическим эффектом, вызывают паралич мышечных тканей. К тому же происходит адаптация людей к запаху в широком интервале концентраций. Немаловажным является и то, что начиная с момента добычи нефти негативное воздействие серосодержащих соединений продолжается и при хранении, транспортировке и переработке нефти.

С ростом потребностей населения в углеводородном сырье возникает важная проблема обеспечить заводы и предприятия по его переработке установками и реактивами для очистки сырья от серосодержащих примесей.

Для очистки нефтепродуктов применим достаточно простой и эффективный способ удаления меркаптанов. Он заключается в экстракции меркаптанов раствором щелочи, окислении образующихся меркаптидов кислородом, содержащемся в пропускаемом через реактор газе. Процесс идет в присутствии катализатора до нерастворимых в щелочи дисульфидов. Последние отделяются от раствора щелочи. Реакция идет по уравнению:

$$
4 \mathrm{RSNa}+\mathrm{O}_{2}+2 \mathrm{H}_{2} \mathrm{O} \stackrel{\text { KAT }}{\longrightarrow} 2 \mathrm{RSSR}+4 \mathrm{NaOH}
$$

На практике процесс демеркаптанизации нефти осуществляется двумя способами. Первый основан на применении катализатора в растворенной форме в водно-щелочном растворе. Во втором способе применяется катализатор, который наносят на твердый носитель (графит, кокс, углеродистые волокна).

Гетерогенный способ обессеривания более сложен и энергоемок, так как необходимо использовать специально подготовленную подложку в качестве носителя.

Обычно носители с высокой адсорбционной емкостью имеют небольшую механическую прочность. Поры пористых носителей часто закупориваются нафтенами. Для восстановления катализатора должна быть предусмотрена в технологической схеме систематическая промывка его растворителем с дальнейшим извлечением из него веществ, адсорбированных катализатором во время основного процесса.

Наибольшую термостойкость и стабильность в щелочных средах, а также высокую каталитическую активность проявляют фталоцианиновые комплексы металлов переменной валентности (кобальта, железа, меди).

Скорость химической реакции жидкофазного окисления сероводорода и меркаптанов при других равных условиях зависит от активности используемого катализатора и от количества кислорода, который проходит через межфазную границу газ/жидкость, то есть от гидродинамики процесса. В свою очередь, гидродинамика процесса определяется как скоростью вращения мешалки или амплитудой и частотой качания реактора, так и геометрией газоподводящего барботера (диаметром отверстий) и в целом всего реактора.

Применение различных методик оценки каталитической активности связано с использованием достаточно сложного специального лабораторного оборудования, дорогостоящих реактивов и вспомогательных веществ (аргона). Все они требуют высокой квалификации экспериментатора как аналитика и достаточно трудоемки, что создает определенные сложности для их применения. 
Для оценки каталитической активности фталоцианинового катализатора были разработаны установка и экспресс-методика определения константы его активности с использованием доступных реагентов и кислорода воздуха в качестве окислителя [2].

В основу разработанной методики легла реакция окисления сульфида натрия кислородом воздуха с образованием элементарной серы по уравнению 2 .

$2 \mathrm{Na}_{2} \mathrm{~S}+\mathrm{O}_{2}+2 \mathrm{H}_{2} \mathrm{O} \stackrel{\text { KAT }}{\longrightarrow} \mathrm{S}_{2}+4 \mathrm{NaOH}$

Возможно протекание процесса по двум механизмам. Лимитирующей стадией процесса в диффузионной области является стадия массопереноса кислорода в зону реакции, которая зависит от физических свойств фаз и гидродинамики.

В кинетической области скорость окисления меньше скорости массопередачи кислорода и поэтому лимитирует скорость всего процесса. Таким образом, именно эта область пригодна для оценки каталитической активности катализатора, которую возможно определить по количеству сульфида натрия, вступившего в реакцию [3].

Но в описанных в настоящее время методиках достижение выполнения измерений в кинетической области приводит к определенным экспериментальным трудностям, так как необходимо покачивать реактор или продувать воздух или кислород через анализируемый раствор.

Из классических работ в области перемешивания известно, что за телом, перемещающимся в жидкой фазе, создается область пониженного давления, в которой осуществляется интенсивное перемешивание. Эти закономерности были положены в основу разработанной установки для определения константы активности катализатора и соответствующей методики.

На рис. 1 представлена установка, основным элементом которой является самовсасывающая мешалка 1 , помещенная в термостатированный реактор 2 диаметром 68 мм. и объемом $250 \mathrm{~cm}^{3}$.

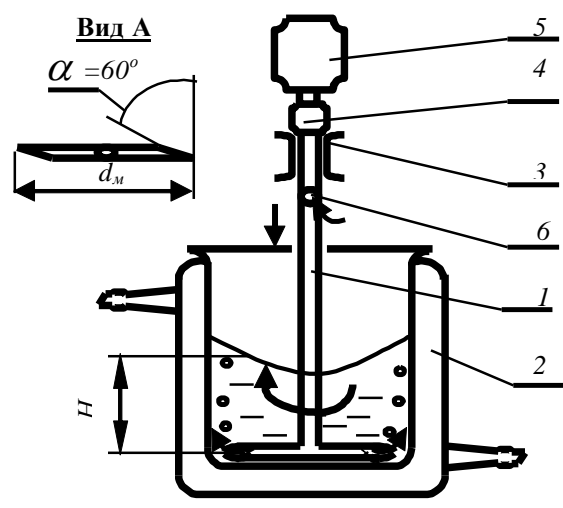

Рис. 1. Схема установки для определения константы активности катализатора:

1 - мешалка самовсасывающая,

2 - термостатированный реактор,

3 - подшипник, 4 - муфта,

5 - электродвигатель,

6 - отверстие для забора воздуха 
Вал мешалки изготовлен из стеклянной трубки, наружный диаметр которой $d_{\mathrm{T}}=6$ мм. В нижней части трубки в качестве лопасти приварена Тобразно другая трубка аналогичного диаметра. Внутренние полости при этом образуют единый канал. Концы трубки срезаны под углом по ходу вращения мешалки. В верхней части вертикального вала находится отверстие 6. Попав в него, воздух проходит через полый вал и лопасть и поступает в зону пониженного давления за крутящейся мешалкой.

Так происходит подача кислорода в зону интенсивного перемешивания жидкой фазы. В процессе всплытия пузырьков идет дополнительное перемешивание и насыщение окислителем.

В ходе экспериментов были подобраны условия протекания реакции в кинетической области изменением геометрии реактора и мешалки (изменялись диаметр мешалки и углы скоса лопасти). Это гарантирует получение постоянных, достоверных результатов в анализируемом диапазоне концентраций растворов и активностей катализатора.

При отработке методики проводили опыты при постоянной скорости вращения мешалки, равной $24 \mathrm{c}^{-1}$ (1440 об/мин), были использованы растворы сульфида натрия с концентрацией $\mathrm{C}_{\mathrm{Na}_{2} \mathrm{~s}}=0,03 \ldots 0,14$ моль/дм ${ }^{3}$ при температуре $20 \ldots 40{ }^{\circ} \mathrm{C}$, в присутствии катализатора с концентрацией $\mathrm{C}_{\text {кат }}=(1,0 \ldots 10,0) \cdot 10^{-6}$ моль/дм ${ }^{3}$

За константу активности фталоцианинового катализатора $K$ при условии протекания процесса окисления в кинетической области принимали константу скорости реакции 2. Вычисляли её по методу наименьших квадратов:

$$
K=a / 60
$$

где $a=\left(n \cdot \Sigma \tau_{i} \cdot Y i-\Sigma \tau_{i} \cdot \Sigma Y_{i}\right) /\left(\Sigma \tau_{i}{ }^{2}-\left(\Sigma \tau_{i}\right)^{2}\right)$;

$\tau$ - время окисления, мин.;

$Y=\ln C$

$C$ - массовая доля сульфидной серы в пробе, \% .

В коническую колбу объёмом $250 \mathrm{~cm}^{3}$ помещали $50 \mathrm{~cm}^{3}$ дистиллированной воды, $5 \mathrm{~cm}^{3}$ йода с концентрацией 0,05 моль/дм ${ }^{3}$ и $2 \mathrm{~cm}^{3}$ однопроцентной уксусной кислоты. Не останавливая мешалку, отбирали пробы через 1, 2, 4, 6, 8, 10 минут пипеткой объёмом $2 \mathrm{~cm}^{3}$. Непосредственно после отбора пробы помещали в колбу и встряхивали. Последующее окисление сульфида натрия за счёт растворённого кислорода прекращалось. Остаток сульфида натрия при этом окислялся по уравнению:

$$
\mathrm{Na}_{2} \mathrm{~S}+\mathrm{I}_{2} \rightarrow \mathrm{S}+2 \mathrm{NaI}
$$

Избыток йода титровали тиосульфатом натрия и определяли содержание недоокисленной серы.

$$
\mathrm{I}_{2}+2 \mathrm{Na}_{2} \mathrm{~S}_{2} \mathrm{O}_{3} \rightarrow 2 \mathrm{NaI}+\mathrm{Na}_{2} \mathrm{~S}_{4} \mathrm{O}_{6}
$$

В качестве выходных параметров в экспериментах использовали константу активности катализатора, коэффициент вариации $\omega=S_{n} / K$ и среднюю квадратичную ошибку

$$
S_{n}=\sqrt{\sum_{1}^{n}\left(\bar{K}-K_{i}\right)^{2} /(n-1)} .
$$

При выполнении экспериментов была обнаружена зависимость константы активности фталоцианинового катализатора от диаметра мешалки $d_{\mathrm{M}}$, скоса кон- 
цов мешалки и глубины погружения оси лопасти мешалки, равной высоте просасывания $H$. Для уменьшения влияния $H$ мешалку во всех опытах располагали на расстоянии 5 мм от дна реактора. В ходе визуальных наблюдений было установлено, что просасывание воздуха в принятых условиях начинается при меньшем диаметре и происходит более интенсивно при скосе концов мешалки под углом $\alpha=60^{\circ}$. При определении константы активности вывод был подтвержден (табл. 1). Все последующие опыты, кроме оговоренных специально, проводились при $\alpha=60^{\circ}$.

Таблица 1. Влияние глубины погружения мешалки и угла скоса ее концов на константу активности катализатора

\begin{tabular}{l|c|c|c|c|c|c|c|c}
\hline \multirow{2}{*}{$\begin{array}{l}H, \\
\text { мм }\end{array}$} & \multirow{2}{*}{$\alpha,{ }^{\circ}$} & \multicolumn{6}{|c}{ Константа активности $K \cdot 10^{4}, \mathrm{c}^{-1}$, при диаметре мешалки $d$, мм } \\
\cline { 3 - 9 } & & 15 & 20 & 25 & 30 & 35 & 40 & 45 \\
\hline \multirow{4}{*}{30} & 30 & 8,12 & 12,31 & 17,33 & 18,99 & 20,09 & 20,71 & 20,89 \\
\cline { 2 - 9 } & 45 & 9,28 & 13,92 & 18,73 & 20,22 & 20,78 & 21,40 & 21,62 \\
\cline { 2 - 9 } & 60 & 11,13 & 16,41 & 20,61 & 21,39 & 21,62 & 21,70 & 21,54 \\
\cline { 2 - 9 } & 75 & 10,41 & 14,14 & 18,90 & 20,92 & 21,13 & 21,48 & 21,44 \\
\hline \multirow{4}{*}{50} & 30 & 6,34 & 11,03 & 13,89 & 16,83 & 17,54 & 19,33 & 20,68 \\
\cline { 2 - 9 } & 45 & 6,81 & 11,90 & 15,14 & 17,54 & 17,89 & 19,67 & 21,27 \\
\cline { 2 - 9 } & 60 & 8,12 & 13,71 & 18,78 & 20,42 & 20,89 & 21,31 & 21,59 \\
\cline { 2 - 9 } & 75 & 7,82 & 13,62 & 16,33 & 18,41 & 19,14 & 20,50 & 21,48 \\
\hline
\end{tabular}

Константа активности в исследованном интервале концентраций реагентов возрастает при увеличении диаметра мешалки с 15 до 30 мм. Далее она остается постоянной (в соответствии с рис. 2).

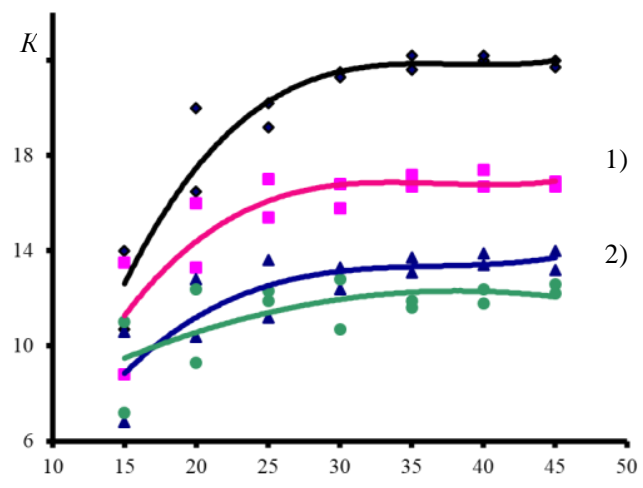

Рис. 2. Зависимость константы активности от диаметра мешалки при различных концентрациях сульфида натрия $\left(\mathrm{C}_{\mathrm{Na}_{2}} \mathrm{~s}\right.$, [моль/дм $\left.\left.{ }^{3}\right]\right)$

$$
\begin{aligned}
& \text { и катализатора ( } \left.\left.\mathrm{C}_{\text {кат, }} \text { [моль/дм }{ }^{3}\right]\right) \text { : } \\
& 1-\mathrm{C}_{\mathrm{Na}_{2}} \mathrm{~s}=0,14 ; \mathrm{C}_{\mathrm{kaT}}=1 \cdot 10^{-5} ; 2-\mathrm{C}_{\mathrm{Na}_{2}} \mathrm{~s}=0,14 ; \mathrm{C}_{\text {кат }}=1 \cdot 10^{-6} \text {; } \\
& 3-\mathrm{C}_{\mathrm{Na}_{2}} \mathrm{~s}=0,03 ; \mathrm{C}_{\text {кат }}=1 \cdot 10^{-5} ; 4-\mathrm{C}_{\mathrm{Na}_{2}} \mathrm{~s}=0,03 ; \mathrm{C}_{\text {кат }}=1 \cdot 10^{-6}
\end{aligned}
$$

Относительная погрешность измерения уменьшается от $45 \%$ при диаметре мешалки 15 мм до 3,5 \% при диаметре 35 мм и более.

Увеличение температуры окисления с $20^{\circ} \mathrm{C}$ до $40^{\circ} \mathrm{C}$ приводит к некоторому уменьшению константы активности. 
В табл. 2 приведены расчетные значения высоты всасывания мешалки $H$ при различных ее диаметрах, выполненные при предположении о равенстве гидростатического давления $P_{н}$ на глубине погружения $H$ оси лопасти мешалки и перепада давления $\Delta P$ между передней и задней сторонами мешалки, рассчитанному по модифицированному критерию Эйлера $E u_{\mu}$, значения которого находили по известным зависимостям от критерия Рейнольдса модифицированного для аппарата с гладкими стенками [4].

В таблице в качестве базы сравнения приведены константы активности катализатора $K$, определённые в тех же условиях для растворов с концентрациями сульфида натрия $\mathrm{C}_{\mathrm{Na}_{2} \mathrm{~s}}=0,14$ моль/дм ${ }^{3}$ и катализатора $\mathrm{C}_{\text {кат }}=$ $1 \cdot 10^{-5}$ моль/дм ${ }^{3}$ при глубине погружения мешалки $H_{1 \text { изм. }}=30$ мм и $H_{2}$ изм. $=50$ мм.

Расчетные значения высоты всасывания $H$ в опытах $3\left(H_{3}=28,1\right.$ мм) и 5 $\left(H_{5}=48,9\right.$ мм) соответствуют фактическим глубинам погружения мешалки $H_{1 \text { изм }}$ $=30$ мм и $H_{2}$ изм. $=50$ мм. В этих опытах константа активности катализатора достигает постоянных значений. Это свидетельствует о протекании процесса в кинетической области. Таким образом, возможно применение предложенной методики расчета для определения размеров реактора и мешалки, а также необходимого объема анализируемой массы в методике нахождения константы каталитической активности.

Таблица 2. Влияние диаметра мешалки на высоту всасывания

\begin{tabular}{|c|c|c|c|c|c|c|}
\hline $\begin{array}{c}\text { № } \\
\text { опыта }\end{array}$ & $\begin{array}{c}\text { Диаметр } \\
\text { мешалки, } \\
\text { мм }\end{array}$ & $\begin{array}{c}\text { Критерий Рейноль- } \\
\text { дса модифициро- } \\
\text { ванный }\end{array}$ & $\begin{array}{c}\text { Критерий Эйлера } \\
\text { модифицирован- } \\
\text { ный }\end{array}$ & $\begin{array}{c}H_{\text {расч. }} \cdot 10^{3}, \\
\text { м }\end{array}$ & \multicolumn{2}{|c|}{$K \cdot 10^{4}, \mathrm{c}^{-1}$} \\
\cline { 4 - 7 } & 20 & 9600 & 1,02 & 11,6 & $H_{1}$ изм. & $H_{2 \text { изм. }}$ \\
\hline 2 & 25 & 15000 & 1,0 & 18,4 & 13,71 \\
\hline 3 & 30 & 21600 & 0,9 & 28,1 & 21,39 & 20,42 \\
\hline 4 & 35 & 29400 & 0,85 & 35,8 & 21,62 & 20,89 \\
\hline 5 & 40 & 38400 & 0,8 & 48,9 & 21,70 & 21,31 \\
\hline 6 & 45 & 48600 & 0,78 & 58,4 & 21,54 & 21,59 \\
\hline
\end{tabular}

Сходимость расчетных и экспериментальных данных также подтверждают полученные в дальнейшем результаты.

Таким образом, предложенная методика нахождения каталитической активности фталоцианинового катализатора, в роли которого выступают производные фталоцианина кобальта, меди, железа, применяемого для очистки нефтепродуктов, сточных вод от меркаптанов, сульфидов и сероводорода, основанная на использовании самовсасывающей мешалки, приводит к энерго- и ресурсосбережению за счет сокращения времени анализа в $2,5 . .3,0$ раза и отказа от потребления дефицитных реагентов. К тому же использование самовсасывающей мешалки допустимо и в других процессах, в которых рассматривается возможность рецикла газообразных веществ в реакционную массу.

1. Дытнерский Ю. И. Процессы и аппараты химической технологии. Учебник для вузов. Часть 1. М.: Химия, 1995. 400 с. 
2. Кондракова (Харченко) Е. Ю., Рапопорт Ю. М. Разработка методики определения каталитической активности водорастворимых производных фталоцианина кобальта // Труды ТГТУ: Сб. науч. ст. молодых учёных и студентов. Тамбов, 2004. Вып. 15. С. 9-12.

3. Кондракова (Харченко) Е. Ю., Рапопорт Ю. М., Харченко В. Ю. Совмещенный процесс получения фталоцианина кобальта из производных о-фталевой кислоты и ее ангидрида // Вестник ТГТУ. 2006. Т. 12. №4 С. 1018.

4. Мазгаров А. М., Вильданов А. Ф. Химические основы процесса демеркаптанизации // Транспорт, хранение и переработка меркаптансодержащих нефтей и газоконденсатов. Казань: ВНИИУС, 1993. 321 с.

\title{
Протасов Д.Н. Построение модели кредитно-инвестиционных ресурсов малого предприятия
}

\author{
Protasov D.N. \\ Modeling of small enterprise investment-credit resourses
}

Тамбовский государственный технический университет Tambov State Technical University

Исследуются экономико-математические модели, позволяющие изучать динамику развития малого предприятия в зависимости от выбранных инвестииионных стратегий. Оченивается погрешность полученного решения.

The paper studies economic and mathematical models enabling to investigate the dynamics of industrial enterprise growth based on the preferred investment strategies. The error of the produced solution is estimated.

Ключевые слова: динамика развития; погрешность решения дифференииального уравнения; экономико-математические модели.

Keywords: growth dynamics; error in differential equation solution; economic and mathematical model.

При постоянно трансформирующейся ситуации в экономике страны, изменении системы взаимосвязей между многими экономическими показателями полная экономическая самостоятельность предприятий, принципиально другая налоговая система требуют новых исследований экономики для применения адекватных экономико-математических методов и моделей, позволяющих изучать динамику развития малых предприятий. Это необходимо для учета внеш- 
них возмущений, оказывающих влияние на внешние факторы, такие как: учет кредитов, налоговые льготы и субсидии для промышленных предприятий, влияние внешних факторов с импульсным возмущением (изменяющийся курс валют, рост цен на сырье, спрос, инфляция и т.д.).

Рассмотрим математическую модель, показывающую взаимосвязь между такими агрегированными переменными, как объем выпуска продукции, стоимость основных производственных фондов предприятия, темпы их прироста, чистая и общая прибыль, налоговые отчисления и т.д. [2, с. 137]. Эта модель адаптирована к условиям внешней среды и предназначена для малых и промышленных предприятий, функционирующих в условиях, описываемых в той же системе предпосылок, которая исследуется в модели M1 [1, с. 232]. Для этого применяются нелинейные виды производственных функций вместо однофакторных производственных функциональных зависимостей.

Динамическая адаптированная модель М2 основана на совокупности гипотез 1-4 модели M1 [1, с. 232]. Для этого вместо линейной производственной функции (гипотеза 5) применяются нелинейные виды однофакторных производственных функций, в том числе:

1) степенная - для анализа функционирования нового созданного малого предприятия, освоившего не занятую, свободную рыночную область и имеющего высокие предпосылки для развития;

2) показательная - имеющая некоторые ограничения по производству (асимптоты) и затухающими темпами роста, для малого предприятия, с некоторыми ограничениями по спросу.

Уравнение (1) описывает динамику развития основных производственных фондов, с учетом непредвиденных внешних факторов и возмущений (инфляция, рост цен на сырье и т.д.), за счет собственных оборотных средств и внешних финансовых инвестиций. В уравнении влияние импульсных возмущений показывается с помощью введения обобщенной функции $\delta(t)$, которая оказывает внешнее воздействие в определенный момент времени $t_{0}$, на основные производственные фонды.

Используя предпосылки 1-5 модели М2 получаем систему соотношений:

$$
\begin{gathered}
P(t)=f A(t) \\
M^{o \sigma}(t)=(1-c) P(t) \\
M(t)=M^{o \sigma}(t)-N(t) \\
N(t)=\tau_{1} P(t)+\tau_{2} K_{\Lambda}(1-\xi) M(t) \\
d A / d t=\hat{a} P(t)+I(t)+\alpha \delta(t)
\end{gathered}
$$

где $A(t)$ - стоимость основных производственных фондов; $P(t)$ - выпуск продукции в момент $t$ в стоимостном выражении; $f$ - показатель фондоотдачи; $M^{\text {об }}(t)$ - общая прибыль малого предприятия; $N(t)$ - сумма налоговых отчислений; $M(t)$ - чистая прибыль малого предприятия; $c$ - удельная себестоимость в стоимостном выражении выпуска продукции; $\tau_{1}, \tau_{2}-$ ставки налогообложения на объем выпуска и прибыль соответственно; $I(t)$ - объем внешних инвестиций; 
$\xi$ - доля чистой прибыли, отчисляемой на реинвестирование, $0 \leq \xi \leq 1$; $K_{\Lambda}={ }^{M(t)} / M^{\text {об }(t)}-$ коэффициент, характеризующий соотношение общей и чистой прибыли предприятия; $\hat{a}(t)=\left(1-c-\tau_{1}\right) \xi(t) / 1+\tau_{2} K_{\lambda}(1-\xi(t))[2$, с. 141$] ; \alpha-$ величина внешних возмущений.

При использовании уравнения $d A / d t=\hat{a} P(t)+I(t)+\alpha \delta(t)$ и обозначении выпуска продукции в случае степенной производственной функции $P(t)=\gamma[A(t)]^{m}$ задается основное уравнение учитывающей внешние возмущения динамики малого предприятия, имеющее вид:

$$
d A / d t=\bar{a}[A(t)]^{m}+I(t)+\alpha \delta(t), \text { где } \bar{a}=\gamma \hat{a} .
$$

Анализ уравнения (2) выявил, что его невозможно решить для некоторых видов правых частей. Это уравнение целесообразно решать с помощью численных методов.

Уравнение (2) разрешимо для случая $I(t)=\beta A(t)$ : случай линейного дифференциального уравнения, при котором поток финансовых вложений должен быть пропорционален динамике основных фондов промышленного предприятия с коэффициентом пропорциональности $\beta(0<\beta<1)$. Реализуемая следующая кредитно-финансовая стратегия инвестиционной поддержки определяется так: чем крупнее предприятие, тем больше инвестиций в него вкладывается. При этом уравнение (2) принимает вид:

$$
d A / d t=\bar{a}[A(t)]^{m}+\beta A(t)+\alpha \delta(t) .
$$

Анализ уравнения динамики показателя $A(t)$ из уравнения (3) с помощью приближенных методов показывает, что рост основных производственных фондов предприятия определяется в данной модели структурными параметрами объекта $\bar{a}$, их начальным состоянием $A_{0}$, а также соотношением коэффициента роста инвестиций $\beta$, показателем эффективности производства $\chi$ и величиной внешних возмущений $\alpha$. Для малых и промышленных предприятий также используются виды функции, которые могут отображать процесс насыщения производства продукции.

Степенная производственная функция $P(t)$ описывает основные производственные фонды и является частным случаем функции Кобба-Дугласа с заданным видом:

$$
P(t)=\gamma A(t)^{m} L^{\lambda}, m+\lambda=1,
$$

где $L$ - трудовые ресурсы, $m$ и $\lambda$ - коэффициенты эластичности основных фондов и труда, $\gamma$ - известный параметр этой функции.

В случае показательной производственной функции динамика развития малого предприятия часто характеризуется определенной нелинейностью: сначала могут наблюдаться высокие показатели прироста, которые затем понижаются. При этом в модели используются различные виды функций, отражающие процесс насыщения рынка произведенной продукцией, например:

$$
P(t)=P_{0}+\hat{p}\left(1-\mathrm{e}^{-A(t)}\right),
$$

где $P_{0}=P(0)-$ начальный объем производства, $\hat{p}-$ предел насыщения рынка, $P(t)=P(0)+\hat{p}$ при $t \rightarrow \infty$. 
Функция (4) отображает процесс возрастания объемов производства малого предприятия до некоторого предела насыщения рынка (асимптоты, определяемой внешними ограничениями): например, спросом продукции, максимально возможным уровнем оптимизации труда работников и т. д. Значительное падение объемов производства в условиях рыночной экономики практически всегда означает его сворачивание и переориентирование на новый вид продукции. Поэтому случаи понижения объемов выпуска продукции в заданной модели рассматриваться не будут.

Используя полученное уравнение (3), отображающее связь между производственной функцией и динамикой основных производственных фондов, при привлечении внешних инвестиций, получим:

$$
\begin{array}{r}
d A / d t=\tilde{a}_{1}-\tilde{a}_{2} \mathrm{e}^{-A(t)}+I(t)+\alpha \delta(t), \\
\text { где } \tilde{a}_{1}=\hat{a}\left(P_{0}+\hat{p}\right) \text { и } \tilde{a}_{2}=\hat{a} \hat{p} .
\end{array}
$$

Если известна динамика объемов внешних инвестиций, заданная одним из заданных следующих выражений: 1) $I(t)=I_{0}=$ const ; 2) $I(t)=\beta_{1} \mathrm{e}^{\beta_{2} t}$, то из нелинейного дифференциального уравнения (5), подставляя данные выражения, получаем следующие варианты динамики роста основных производственных фондов:

1) Для постоянных инвестиций $I(t)=I_{0}=$ const . Тогда данное уравнение (5) приобретает вид:

$$
d A / d t+\tilde{a}_{2} \mathrm{e}^{-A(t)}=\tilde{a}_{1}+I_{0}+\alpha \delta(t) .
$$

Для однородного дифференциального уравнения $d A / d t+\tilde{a}_{2} e^{-A(t)}=0$ решение имеет вид:

$$
e^{A(t)}+\tilde{a}_{2} t=C(t) \text { или } A(t)=\ln \left(C(t)-\tilde{a}_{2} t\right),\left(C>\tilde{a}_{2} t\right) .
$$

Для определения $C(t)$ исследуем неоднородное дифференциальное уравнение: $\frac{C^{\prime}(t)-\tilde{a}_{2}}{C(t)-\tilde{a}_{2} t}+\tilde{a}_{2} \frac{1}{C(t)-\tilde{a}_{2} t}=\tilde{a}_{1}+I_{0}+\alpha \delta(t)$.

В результате преобразований получаем:

$$
A(t)=\ln \left[\frac{\tilde{a}_{2}}{\tilde{a}_{1}+I_{0}+\alpha \delta(t)}+C \mathrm{e}^{\left(\tilde{a}_{1}+I_{0}+\alpha \delta(t)\right) t}\right],
$$

где $C$ - произвольная постоянная, получаемая с помощью известного нам начального условия.

2) Для возрастающих с темпом роста $\beta_{2}$ инвестиций $I(t)=\beta_{1} \mathrm{e}^{\beta_{2} t}$ уравнение (5) принимает вид:

$$
d A / d t+\tilde{a}_{2} \mathrm{e}^{-A(t)}=\tilde{a}_{1}+\beta_{1} \mathrm{e}^{\beta_{2} t}+\alpha \delta(t) .
$$

Решение данного однородного дифференциального уравнения $d A / d t+\tilde{a}_{2} e^{-A(t)}=0$, имеет вид: $A(t)=\ln \left(C(t)-\tilde{a}_{2} t\right), \quad\left(C>\tilde{a}_{2} t\right)$. Применив необходимые преобразования, окончательно получаем:

$$
A(t)=\ln \left(\frac{-\tilde{a}_{2}}{\beta_{2}} e^{-\alpha \theta(t)-\tilde{a}_{1} t}\left(e^{\frac{\beta_{1}}{\beta_{2}} e^{\beta_{2} t}}+\alpha \theta(t)\right) \sum_{i=0}^{n} \frac{\left(-\frac{\beta_{2}}{\beta_{1}}\right)^{n} e^{\beta_{2} n t}}{n !\left(n-\frac{\tilde{a}_{1}}{\beta_{2}}\right)}+C e^{\frac{\beta_{1}}{\beta_{2} \beta_{2} t}+\tilde{a}_{1} t+\alpha \theta(t)}\right),
$$


где С определяется по начальному условию $A(0)=A_{0}$.

Исследование уравнения (5) для заданных вариантов внешнего инвестирования (постоянное и растущее по нелинейному закону) имеет логарифмический вид роста основных производственных фондов малого предприятия.

Пусть задана достаточно гладкая функция $f:[0, T] \times R^{s} \rightarrow R^{s}$. Исследуется влияние возмущений на решение заданной дифференциальной задачи Коши:

$$
y^{\prime}(t)-f(t, y(t))=0, \text { где } t \in[a, b], y(a)=y_{0} .
$$

Предполагается, что функция $f$ будет удовлетворять условию Липшица $[3$, c. 48] по $y$, то есть существует такая постоянная величина $L$, такая что:

$$
\left\|f\left(t, y_{1}\right)-f\left(t, y_{2}\right)\right\| \leq L\left\|y_{1}-y_{2}\right\|
$$

при всех $t \in[a, b]$ и всех $y_{1}, y_{2}$ из интересующей нас области. Это условие обеспечивает существование и единственность решения задачи Коши (6).

Предположим, что величина $z(t)$ удовлетворяет дифференциальному уравнению:

$$
z^{\prime}(t)-f(t, z(t))=\alpha \delta(t),
$$

где $z(a)=y_{0}+\alpha \delta_{0}, t \in[a, b]$, и где $\alpha$ мало.

Определив $z(t)=y(t)+\alpha e(t)+O\left(\alpha^{2}\right)$ и применяя теорему Тейлора, из (7) получаем:

$$
\begin{aligned}
& y^{\prime}(t)+\alpha e^{\prime}(t)-f(t, y(t))-f_{y}(t, y(t)) \alpha e(t)=\alpha \delta(t)+O\left(\alpha^{2}\right), \\
& y(a)+\alpha e(a)=y(t)+\alpha \delta_{0}+O\left(\alpha^{2}\right) .
\end{aligned}
$$

Тогда функция погрешности $e(t)$ должна удовлетворять линейному дифференциальному уравнению:

$$
e^{\prime}(t)-f_{y}(t, y(t)) e(t)=\alpha \delta(t), e(a)=\delta_{0},
$$

Следовательно, если у и $z$ удовлетворяют уравнениям (6) и (7), а погрешность $e(t)$ - уравнению (9), то справедливо соотношение (8).

Погрешность приближенного решения задачи (6) удовлетворяет полученному уравнению. Решение задачи (6) представимо в виде:

$$
e(t)=E(a, t) \delta_{0}+\int_{a}^{t} E(u, t) \delta(u) d u, E(u, t)=\exp \left[\int_{u}^{t} f_{y}(t, y(t)) d t\right]
$$

Рассматривая дифференциальное уравнение, получаем, что если имеется система $s$ уравнений, то $f_{y}(t, y(t))$ представляет собой матрицу Якоби функции $f$ размерности $(s \times s)$. Аналогично матрицей является и $E(u, t)$. В этом случае экспонента определяется с помощью бесконечного, всегда сходящегося ряда.

Из выражения (10) видно, что влияние внешнего возмущения $\delta(t)$ в точке $u$ зависит от вида функции $E(u, t)$, которая должна быть меньше или больше единицы и быть убывающей или возрастающей функцией. Тогда если дифференциальное уравнение имеет вид $y^{\prime}=\lambda y$, где $f_{y}=\lambda$, тогда $E(u, t)=e^{\lambda(t-u)}$. Если же $\lambda>0$, то влияние погрешности вблизи точки $u$ на полную погрешность в точке $\mathrm{t}$ растет с увеличением $\mathrm{t}$, если же $\lambda<0$, то происходит противоположное. Для других видов уравнений возможны другие, более сложные типы поведения погрешностей.

Функция $e(t)$, которая интересует нас, должна удовлетворять линейному дифференциальному уравнению: 


$$
e^{\prime}(t)-f_{y}(t, y(t)) e(t)=\alpha \delta(t), e(a)=\delta_{0}
$$

Необходимо знать $s^{2}$ элементов матрицы Якоби $E(u, t)$ для того, чтобы определить погрешность $e(t)$. Необходимый объем работы становится очень большим, за исключением того случая, когда матрица Якоби уже известна. Это бывает в некоторых методах интегрирования жестких уравнений. Поэтому мы должны определить такую локальную погрешность, которую можно оценить без особого труда.

Это поведение наглядно представляется интегральными кривыми дифференциального уравнения. Множество интегральных кривых $y(t)=\left\{y_{1}(t), \ldots, y_{s}(t)\right\}$ уравнения $y^{\prime}(t)-f(t, y(t))=0 \quad$ - это множество решений задачи Коши: $y^{\prime}(t)-f(t, y(t))=0$, где $t \in[a, b], y(a)=y_{0}$, для всех значений $y_{0}$. Влияние импульсного возмущения состоит в том, чтобы сместить решение с одной из этих кривых на соседнюю кривую.

Необходимо рассмотреть случай при $t=t_{0}$, в которой функция имеет разрыв и является кусочно- непрерывной, чтобы избежать точек $(t, y)$, в которых $f_{y}^{\prime}(t, y), f_{y}^{\prime \prime}(t, y), f_{y}^{\prime \prime \prime}(t, y), \ldots$. не определена.

Пусть функция $f(t, x)$ удовлетворяет условиям [4, с. 75]:

1) $f(t, y)$ непустое замкнутое множество; (11)

2) Функция $f(t, y)$ непрерывна на отрезках $\left[0, t_{0}\right)$ и $\left[t_{0}, T\right]$ и полунепрерывна сверху в точке $t_{0}$ :

$$
\left(h\left|f\left(t_{1}, y_{1}\right), f(t, y)\right| \rightarrow 0, t_{1} \rightarrow t, y_{1} \rightarrow y\right), t_{0} \in[0, T] ;
$$

3) существует такая суммируемая функция $\mathrm{k}(\mathrm{t})$, что для

$$
\forall t \in[0, T], h\left|f\left(t_{1}, y_{1}\right), f(t, y)\right| \leq k(t)\left|y_{1}-y\right| .
$$

Теорема 1. Пусть $f(t, y)$ удовлетворяет условиям (10-13) при $t \in[0, T]$, функция $\mathrm{y}(\mathrm{t})$ непрерывна на отрезках $\left[0, t_{0}\right)$ и $\left[t_{0}, T\right]$ и полунепрерывна сверху $t_{0} \in[0, T]$. Функция $p(t)$ суммируема, $\left|x(0)-y_{0}\right| \leq \varepsilon, \quad p\left(x^{\prime}(t), f(t, x(t))+\beta \delta(t)\right) \leq p(t)+(\beta-\alpha) \delta(t)$ почти всегда.

Тогда существует такое решение $y(t)$ задачи:

$$
y^{\prime}(t)=f(t, y(t))+\alpha \cdot \delta(t),
$$

где $t \in[0, T], t_{0} \in[0, T], y(0)=y_{0} \quad \delta(t)=\theta^{\prime}(t), \theta(t)=\left\{\begin{array}{l}1, \text { при } t-t_{0} \geq 0 ; \\ 0, \text { при } t-t_{0}<0 ;\end{array}\right.$ что выполняется $|y(t)-x(t)| \leq \xi(t),\left|y^{\prime}(t)-x^{\prime}(t)\right| \leq k(t) \xi(t)+p(t)$ почти всегда при:

$$
\xi(t)=\varepsilon e^{m(t)} / e^{\alpha \theta\left(t-t_{0}\right)}+\left|\int_{a}^{t} e^{m(t)-m(s)} p(s) d(s)\right|, m(t)=\left|\int_{a}^{t} k(r) d r+\alpha \theta\left(t-t_{0}\right)\right| .
$$

1. Протасов Д. Н. Развитие модели кредитно инвестиционных ресурсов промышленного предприятия // Вопросы современной науки и практики. Университет им. В. И. Вернадского. 2009. №1. С. 231-238.

2. Хачатрян С. Р. Методы и модели решения экономических задач. М.: Экзамен, 2005. 384 с. 
3. Холл Д., Уатт Д. Современные численные методы решения обыкновенных дифференциальных уравнений. М.: Мир, 1989. 312 с.

4. Филиппов А. Ф. Дифференциальные уравнения с разрывной правой частью. М.: Наука, 1985. 225 с.

\title{
Пучков Н.П. Формирование компетенции на основе использования математического стиля мышления при решении контекстных задач
}

\author{
Puchkov N.P. \\ Forming the competence on the basis of the mathematical \\ thinking while solving the contextual tasks
}

Тамбовский государственный технический университет Tambov State Technical University

Обосновывается возможность использования результатов формирования у обучаюшихся математического стиля мышления как основы формирования многих компетенций, прописанных в образовательных стандартах.

The paper argues for the possibility to use the students' level of mathematical thinking as a basis for the formation of many competences prescribed in the educational standards.

Ключевые слова: математический стиль мышления; компетенщии; контекстные задачи; современные проблемы обучения.

Keywords: mathematical thinking; competences; contextual tasks; modern methodological problems.

В настоящее время преподаватели математики вузов столкнулись с ситуацией, выраженной системой характерных признаков, имеющих форму явных противоречий:

1. Необходимость получения студентами математических знаний, соответствующих (одновременно) программам подготовки по ряду родственных направлений и достаточных для продолжения обучения в магистратуре в условиях, когда примерно в 1,5 раза сокращены сроки обучения математике в бакалавриате, по сравнению с уже отлаженным учебным планом для специалитета.

2. Необходимость формирования у студентов способностей использовать эти знания при изучении специальных дисциплин, в будущей профессии в усло- 
виях низкого уровня мотивации студентов к изучению математики как следствию ее невостребованности «в явном виде».

3. Необходимость подготовки специалистов способных, на достаточном уровне, самостоятельно мыслить, анализировать, заниматься научной, инновационной деятельностью в условиях наличия суженного спектра, как математических знаний, так и способностей получать эти знания, у первокурсников, приученных в школе к натаскиванию только на определенный тип задач, продекларированных в ЕГЭ. Такие выпускники средней школы готовы быть, в большей степени, офисными служащими, безропотно выполняющими определенные инструкции.

4. Необходимость для преподавателей осваивать новые методики, технологии обучения в условиях возросшего числа формальных показателей эффективности работы вузов, делегированных для выполнения преподавателями, а также возросшей аудиторной нагрузки преподавателей в связи с оптимизацией структуры вузов.

Наиболее болезненной и трудной для разрешения эта ситуация оказалась для опытных, имеющих большой стаж работы преподавателей, составляющих основной контингент ППС, т. к., по крайней мере, формально требовала заметной перестройки их традиционной деятельности, которую они считали и считают успешной. На процесс новой деятельности преподавателей негативно накладывается и чисто психологический эффект: внедрение компетентностного подхода (вместо знаниевого, как это декларируется) создает впечатление о том, что раньше требование профессиональной компетентности на выпускников вузов не распространялось, в вузах соответствующие способности не формировались, поэтому никакой определенной преемственности в технологии, методики обучения не просматривается.

Здесь хотелось бы сказать о том, что, постоянно рассуждая о преемственности при обучении студентов, мы не задумываемся о преемственности при загрузке работой преподавателей, хотя отсутствие последнего заметно влияет на качество обучения.

Для изменения взгляда на цель обучения, соответствующих методик и технологии естественно есть объективные причины, проявляющие себя как следствие изменения социально-экономической обстановки в стране, стремительно развивающейся мировой экономики и т. д. Поэтому нами рассматривается проблема как разрулить создавшуюся ситуацию наиболее эффективно, в частности, какие актуализировать педагогические механизмы, доступные для использования основному контингенту профессорско-преподавательского состава вузов.

На наш взгляд, таким механизмом, способствующим системному разрешению обозначенных выше противоречий, является формирование математического стиля (способа) мышления у обучающихся в процессе решения учебных, контекстных задач.

Такой вывод напрашивается как результат следующих исследований.

Рассуждая о математическом способе мышления весьма заманчиво использовать его определение, сформулированное известным немецким математиком Германом Вейлем: «Под математическим способом мышления я понимаю, во-первых, особую форму рассуждений, посредством которых математика про- 
никает в науки о внешнем мире - в физику, химию, биологию, экономику и т.д. и даже в наши размышления о повседневных делах и заботах, и, во-вторых, ту форму рассуждений, к которой прибегает в своей собственной области математик, будучи предоставленным самому себе» [1, с. 6].

В анализируемой нами ситуации актуальна первая часть определения, которая настраивает процесс преподавания математики на проникновение в другие науки, предметные области, профессиональную деятельность, т. е. на демонстрацию своей универсальности, что, как раз, и обозначено нами как первая проблема. Мы не даем здесь рецептов, как научиться математическому мышлению, для этого можно воспользоваться многочисленными литературными источниками, учитывая, что их изучение не представляет для преподавателей математики заметных сложностей; многое для них вообще очевидно. Эта статья ориентирована на стимулы и импульсы для творческого проведения учебных занятий, ориентированных на формирование компетенций, преподавателями, владеющими математическим стилем мышления.

Специфика математического мышления - не в его методах, а в объектах, в своеобразии его предметного содержания, поэтому научить математически мыслить вообще (в абстракции) невозможно, т. к. мышление как процесс получает свое наибольшее развитие в деятельности, а при изучении математики такой деятельностью является процесс решения учебных задач.

Овладеть математическим мышлением сложнее, чем овладеть суммой определенных математических знаний (т. к. требуется выработка у обучающихся умений эти знания анализировать, переносить на реальную практику, использовать для получения новых знаний, принятия конкретных решений, т.е. умений, лежащих в основе компетентности); активно развивать математическое мышление можно лишь при условии включения обучаемых в деятельную среду обучения.

Рассуждая о связи математического мышления и математических компетенций, прописанных в современных вузовских стандартах, можно обнаружить их заметное сходство, если рассмотреть основные характеристики математического мышления, выделенные полвека назад советским психологом Вадимом Андреевичем Крутецким и представленных в тексте его работы [2]:

1) способность к формализации математического материала, к отделению формы от содержания, абстрагированию от конкретных количественных отношений и пространственных форм и оперированию формальными структурами, структурами отношений и связей;

2) способность обобщать математический материал, вычленять главное, отвлекаясь от несущественного, видеть общее во внешне различном;

3) способность к последовательному, правильно расчлененному логическому рассуждению, связанному с потребностью в доказательствах, обоснованиях, выводах;

4) способность к обратимости мыслительного процесса (к переходу с прямого на обратный ход мысли);

5) способность к переключению от одной умственной операции к другой, свобода от сковывающего влияния шаблонов и трафаретов;

6) способность к пространственным представлениям, которая прямым образом связана с наличием такой отрасли математики, как геометрия. 
Мы видим здесь перечень способностей, который напоминает перечень компетенций, продекларированных, например, в действующих ФГОСах ВПО для направлений подготовки 080100, 090303, 140100, 140400, 230100 и др.:

ОК-1: способность к обобщению, анализу, восприятию информации, постановке цели и выбору путей её достижения.

ОК-9: способность к логическому мышлению, обобщению, анализу, критическому осмыслению информации, систематизации, прогнозированию, постановке исследовательских задач и выбору путей их решения на основании принципов научного познания.

ОК-12: способность и готовность к практическому анализу логики различного рода рассуждений, к публичным выступлениям, аргументации, ведению дискуссии и полемики.

ПК-1: способность собрать и проанализировать исходные данные, необходимые для расчета экономических и социально-экономических показателей, характеризующих деятельность хозяйствующих субъектов.

ПК-7: способность формировать законченное представление о принятых решениях и полученных результатах в виде отчета с его публикацией (публичной защитой).

Этот факт (наличия схожих конструкций) позволяет утверждать, что можно найти преемственность перехода от формирования математического стиля мышления к формированию компетенций.

Обнаружив такое сходство, мы ориентируем педагогов-математиков на использование существующих разработок методов формирования математического стиля мышления, как при составлении паспортов компетенций, так и при организации учебных занятий.

Математический стиль мышления ценен и сам по себе. Анализ литературных источников, посвященных математическому мышлению, обнаружил большой интерес к этому феномену как со стороны зарубежных: Г. Вейль, Ж. Пиаже, Ж. Адамар, А. Пуанкаре, так и советских/российских ученых: Л. К. Максимов, И. Я. Каплунович, Д. Д. Мордухай-Болтовский, А. И. Маркушевич, А. Я. Хипчин, В. А. Крутецкий и др.

Если обобщать их мнения, то характерные черты математического стиля (способа) мышления включают в себя:

- выделять условия и выводы, данные и искомые величины;

- находить общее, сравнивать и противопоставлять факты;

- абстрагироваться от конкретного содержания, переходить от конкретной ситуации к математической формулировке вопроса, к схеме, сжато характеризующей существо дела;

- четко формулировать проблемы, задания;

- соблюдать строгость изложения материала;

- улавливать нечеткость рассуждений;

- выдерживать полноценное логическое аргументирование;

- генерализовано понимать ситуацию, схватывать структурные отношения в обобщенном виде и т.п.

Овладев такими умениями, студент сможет самостоятельно успешно осваивать новый учебный материал не только по математике, а и по другим учебным дисциплинам, эффективно реализовать свои знания и, таким образом, упростить 
задачи преподавателя по содержательному наполнению аудиторных учебных занятий.

Формирование математического стиля мышления на учебных занятиях должно основываться на демонстрации преподавателем таких свойств математических знаний, как доказательность и неопровержимость, ориентация на истину, а не на пользу, связь с приложениями в естественных и гуманитарных науках, единство формального и содержательного и на использовании основных качеств математического мышления: ясность, точность, лаконичность и т.д.

Характерной чертой математического стиля мышления является однозначность высказываний. Преподаватели математики, постоянно сталкиваются с фактами свободного обращения обучаемых с различными терминами. Попытки «навести порядок» в этом процессе приводят к конфликтным ситуациям, и в этом есть объективные причины. Достаточно еще раз процитировать Германа Вейля: «Математика снискала себе дурную славу из-за разреженного воздуха абстракции, в котором она живет... В самом деле, первая трудность, с которой сталкивается человек..., когда его пытаются научить мыслить математически, состоит в том, что ему необходимо усвоить более прямой взгляд на вещи; его вера в слова должна быть поколебима, ему необходимо научиться мыслить конкретно и направлено» [1, с. 9]. И далее: «Слова - орудия опасные. Созданные для нашей повседневной жизни, они обладают привычным значением лишь при известных ограниченных обстоятельствах, но ... человек ... склонен распространять их на более широкие сферы, немало не заботясь о том, сохраняют ли те при этом твердую опору в реальности или нет» [1, с. 9].

Поэтому в процессе формирования математического стиля мышления непременно и непрерывно должно присутствовать приучение к осознанию важности того, что, выражаясь математически, каждое слово имеет свою область определения.

Пример того, как это может выглядеть на практике, приведен в работе [1, c. 10-11].

На наш взгляд, для реализации компетентностного подхода, а именно для проверки учебно-познавательной компетентности студентов технических специальностей при обучении математике, следует использовать контекстные задачи.

Под контекстными задачами, используемыми при изучении математики, мы понимаем задачи, целью которых является разрешение стандартной или нестандартной ситуации (предметной, межпредметной или практической) посредством нахождения соответствующего способа решения с обязательным использованием математических знаний. Основной особенностью таких задач является получение познавательного и профессионально-значимого для студентов результата.

Решение контекстных задач должно стать проявлением математического стиля мышления в деятельности.

Кроме того, решая такие задачи, студент убеждается в том, что многие математические понятия вытекают из реальной жизни, из практики, что повышает уровень мотивации к изучению математики.

Содержание контекстных задач не должно быть примитивным, создающим впечатление об аналогичном уровне потребности в математике; именно примитивным, а не простым. 
Хотя человек мыслит наиболее продуктивно, когда имеет дело со сложными объектами, простые задачи в курсе математики играют важную роль в формировании и развитии математического мышления; необходима лишь соответствующая форма организации занятий.

Читателям, желающим более детально познакомиться с результатами использования такого рода задач, следует обратиться к работам [3; 4].

Основываясь на вышеизложенном, мы в своей практической работе использовали определенный нами алгоритм математического мышления при решении задач математического моделирования, нахождения оптимальных решений, исследования количественных зависимостей, реализации вероятностных схем и т.п. Первые результаты реализации такой методики на примере образовательной области «Экономика» изложены нами в работе [5].

Заключение:

- Существует необходимость именно системного разрешения проблем перехода на многоуровневость образования и на компетентностный подход в обучении.

- Значимую роль при этом может сыграть учебный предмет «Математика», в процессе преподавания которого используются особые качества математического мышления и учебные контекстные задачи.

- Математический способ мышления следует рассматривать как такую форму рассуждений, посредством которых математика проникает как в науки о внешнем мире, так и в различные производственные ситуации.

- Преподавателям математики не следует бояться трудностей формирования компетенций, т. к. их содержательное наполнение во многом повторяет характеристики математического мышления, формирование, развитие которого в школе, в вузе с давних пор являлось одним из основных требований к организации учебного процесса.

1. Вейль Г. Математическое мышление: Пер. с англ. и нем. / Под ред. Б. В. Бирюкова и А.Н. Паршина. М.: Наука. Гл. ред. физ-мат. лит., 1989. 400 с.

2. Крутецкий В. А. Психология математических способностей школьников. М.: Из-во института практической психологии. 1998. 416 с.

3. Лебедева О. Е. Компетентностный подход в образовании // Школьные технологии. 2004. №5.

4. Павлова Л. В. Познавательные компетентностные задачи как средство формирования предметно-познавательной компетентности будущего учителя // Изв. гос. пед. ун-та им. А. И. Герцена. 2009. №113.

5. Пучков Н. П. Математический аппарат как средство обучения экономике // Вестник ТГТУ. 2001. Т. 7. №4. С. 680-686. 


\title{
Толстых С.С., Подольский В.Е., Бабичев А.М., Толстых С.Г. \\ Вычислительная сложность решения \\ систем линейных алгебраических \\ уравнений: этап эксперимента
}

\author{
Tolstyh S.S., Podolsky V.E., Babichev A.M., Tolstyh S.G. \\ The computational complexity of solving systems \\ of linear algebraic equations: a stage of experiment
}

Тамбовский государственный технический университет,
Tambov State Technical University

Исследуется зависимость однопроцессорной вычислительной сложности решения систем линейных алгебраических уравнений от размерности задачи и длины мантиссы в представлении вещественных чисел с плавающей точкой

Dependence of single-processor computing complexity of solving systems of the linear algebraic equations from dimensionality of the task and length of a mantissa in representation of floating-point numbers is analyzed.

Ключевые слова: вычислительная сложность; системы линейных алгебраических уравнений; плавающая точка; длинная арифметика.

Keywords: computing complexity; systems of linear algebraic equations; floating point; long arithmetic.

Работа выполняется в соответствии с Проектом № 1346 из реестра государственных заданий высшим учебным заведениям и научным организациям в сфере научной деятельности.

Решение систем линейных алгебраических уравнений (СЛАУ) - одна из важнейших задач вычислительной математики. Особую значимость она имеет как вспомогательная, в частности, при решении систем нелинейных уравнений (СНУ) методом Ньютона-Раффсона. Следует заметить также, что СНУ являются процедурной основой нелинейных разностных схем, которые используются в моделировании распределенных систем. При решении систем большой размерности, а также при плохой обусловленности, вполне обычном явлении при аппроксимации, например, могут возникнуть тенденции к повышению точности получаемых решений, к использованию длинной арифметики с плавающей точкой.

Исходя из вышеперечисленного, построение зависимостей времени счета от размерности СЛАУ и/или длины мантиссы является актуальной экспериментальной проблематикой, у которой не существует аналитических альтернатив.

Значительная доля заинтересованности авторов статьи - в построении сервисов управления крупноблочными вычислениями с облачным базированием: 
необходимо построить экспериментальные зависимости вычислительной сложности решения СЛАУ для оценки вычислительной емкости схем распределения сложной задачи по параллельно работающим компьютерам и кластерам [3; 4].

Решается СЛАУ вида

$$
\mathbf{A x}=\mathbf{b},
$$

где

$$
\begin{aligned}
\mathbf{A} & =\left(\begin{array}{llll}
a_{11} & a_{11} & \cdots & a_{1 n} \\
a_{21} & a_{22} & \cdots & a_{2 n} \\
\cdots & \cdots & \cdots & \cdots \\
a_{n 1} & a_{n 2} & \cdots & a_{n n}
\end{array}\right), \\
\mathbf{b} & =\left(\begin{array}{l}
b_{1} \\
b_{1} \\
\cdots \\
b_{n}
\end{array}\right)
\end{aligned}
$$

- соответственно, числовая матрица и вектор-столбец системы, составленные из вещественных чисел.

СЛАУ вида (1) делим на два класса:

1) с матрицей общего вида $\mathbf{A}$, когда

$$
\exists i, j \in\{\overline{1, n}\}: a_{i j} \neq a_{j i} ;
$$

2) с симметричной матрицей $\mathbf{A}$, когда

$$
\forall i, j \in\{\overline{1, n}\}: a_{i j}=a_{j i} \text {. }
$$

Класс (4) решается прямыми методами решения СЛАУ, класс (5) предназначен для итерационных методов. Дополнительным условием к (5) считаем, что $\mathbf{A}>0$ или более подробно

$$
\lambda_{i}(\mathbf{A})>0, i=\overline{1, n},
$$

где $\lambda_{i}(\mathbf{A})-i$-тое вещественное собственное число матрицы $\mathbf{A}$.

Для проведения вычислительных экспериментов было разработано специальное диалоговое Windows-приложение, часть возможностей которого охватывала тему данной статьи. Экранная форма начального состояния программы показана на рисунке 1.

Программа составлена с использованием Visual Studio 2013 (VS 2013) Academic Edition в виде окна диалога на языке $\mathrm{C}++$, откомпилирована с включенным режимом повышенного быстродействия по плавающей точке (опция /fp:fast) и в условиях глобальной оптимизации кода программы (опции /Ot и /GL). Для организации оконных взаимодействий используется стандартная библиотека MFC. Использовались готовые реализации численных методов решения СЛАУ на основе фонда Matiss v.3.0. Для вывода графиков в приложении предусмотрено дочернее окно класса CStatic.

Рассмотрим основные моменты сценария работы программы Dipole-SLAE (здесь SLAE - Systems of Linear Algebraic Equations) применительно к теме данной статьи.

Перед запуском теста пользователь выбирает точность арифметики с плавающей точкой: 
1) double - стандартный формат IEEE, 16 десятичных разрядов в мантиссе, порядок \pm 308 , ячейка 8 байт.

2) LongReal - 10-байтные вещественные числа, имеющие классовую поддержку с использованием ассемблера, на котором написаны все основные функции-члены класса. Используются команды сопроцессора, формат ячеек типа LongReal соответствует стандарту long double IEEE.

3) HReal - класс поддержки длинной арифметики с регулируемой длиной мантиссы (от 50 и выше).

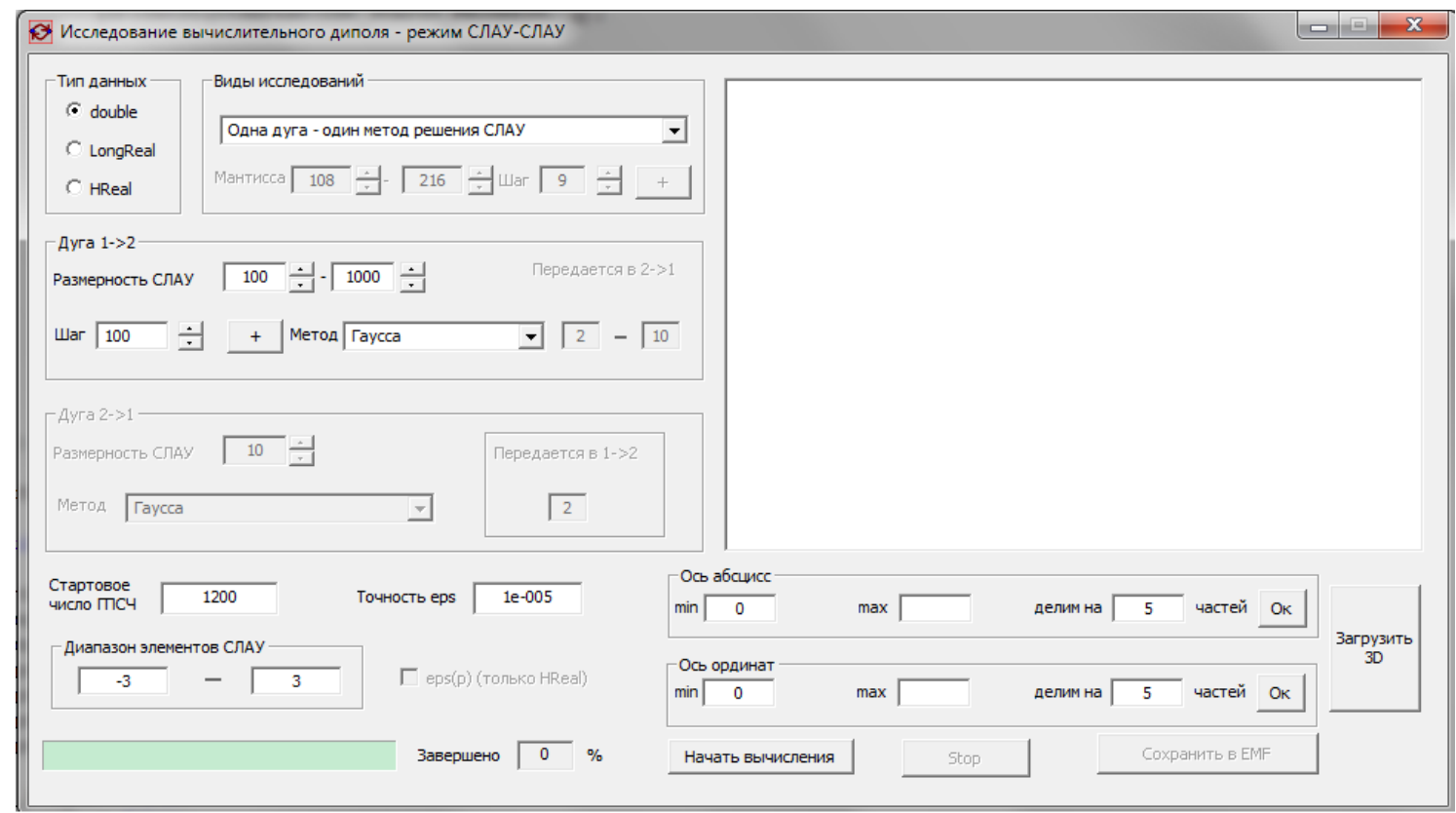

Рис. 1. MFC-приложение Dipole-SLAE

Далее в комбобоксе «Вид исследования» выбирается пункт «Одна дуга один метод решения СЛАУ». Поясним использование термина «дуга». Кроме исследования зависимостей времени счета задачи (1) от ее характеристик, программа Dipole-SLAE может быть использована в исследовании математической модели элементарного вычислительного комплекса со структурой в виде сильно связного орграфа, состоящего из пары дуг и пары вершин. Дуги ассоциируются с решением СЛАУ, размерности, и методы решения могут при этом варьироваться. Вершины орграфа (в режиме имитации) соответствуют распределительным серверам, осуществляющим передачу некоторого числа переменных, найденных в результате решения СЛАУ.

Для управления процессом генерации тестовых матриц в специальных текстовых полях окна диалога предусмотрено задание диапазона случайных чисел, из которых состоят матрицы, а также стартового числа генератора псевдослучайных чисел с плавающей точкой, настраиваемого на выбранную точность представления.

Check-box “eps(p)” используется для управления точностью решения СЛАУ итерационными методами. В прямых методах эта возможность отсутствует: они работают с максимально возможной точностью. Предусмотрены два режима задания точности: вручную (Check-box не включен) в специальном поле ввода и автоматически - равной $10 \mu$, где $\mu$ - машинный ноль, согласованный с длиной мантиссы класса HReal. Алгоритм для генерации машинных нулей бази- 
руется на проверке равенства «HReal $(1, \mathrm{p})+\mathrm{mu}==\operatorname{HReal}(1, \mathrm{p}) »$ и показан на рисунке 2 (Здесь «==» бинарное отношение «равно»).

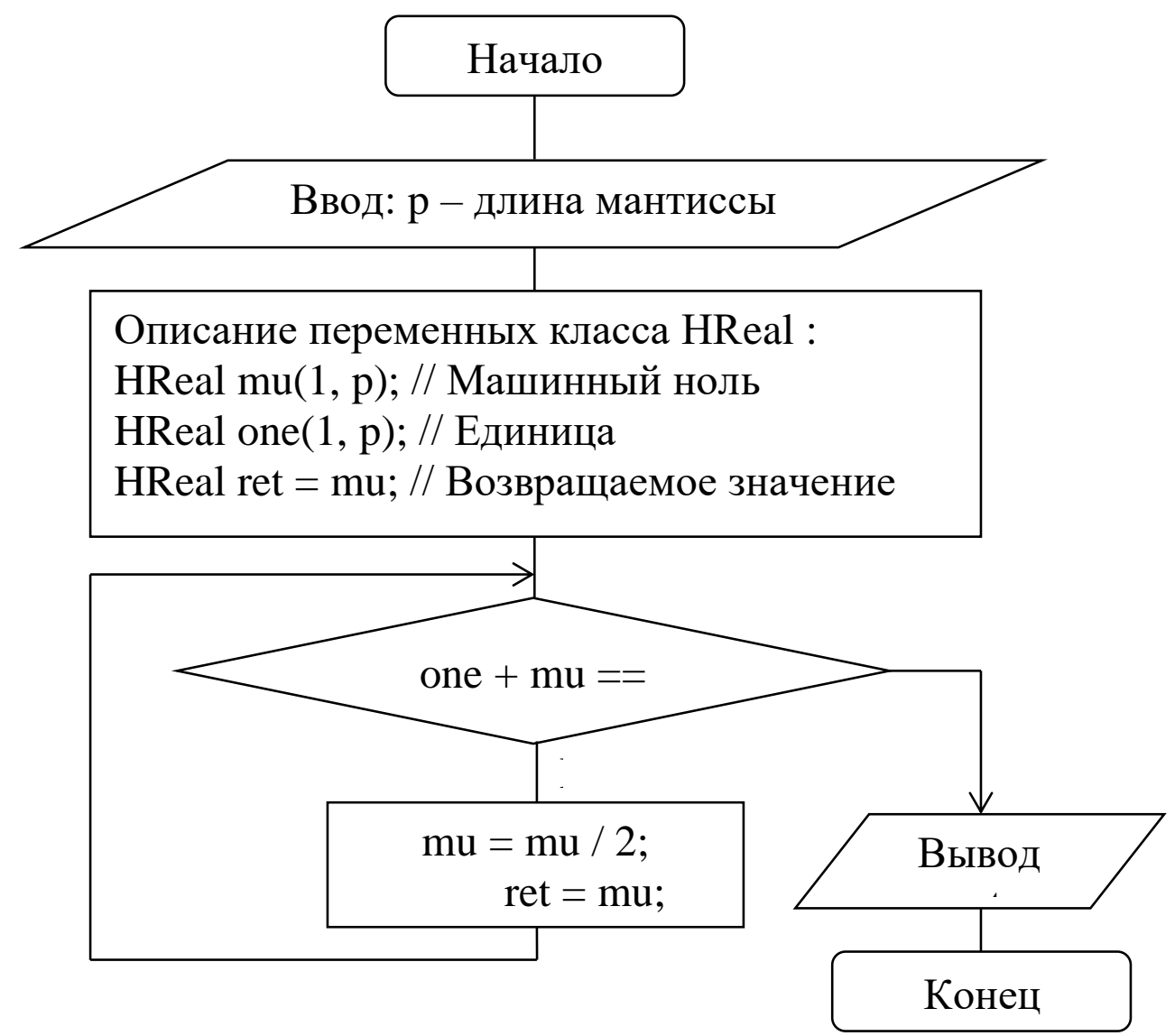

Рис. 2. Блок-схема алгоритма нахождения машинного нуля в класcе HReal

Для вариантов точности double и LongReal элемент управления “eps(p)" не работает, т.е. возможности автоматического задания точности работы итерационных методов для этих представлений чисел с плавающей точкой в программе нет, только вручную.

Таким образом, для прямых методов

$$
\begin{aligned}
& \left.a_{i j}=\Xi_{\min }+\tilde{\xi}\right] i, j\left[\left(\Xi_{\max }-\Xi_{\min }\right),\right. \\
& \left.b_{i}=\Xi_{\min }+\tilde{\xi}\right] i\left[\left(\Xi_{\max }-\Xi_{\min }\right), i=\overline{1, n}, j=\overline{1, n},\right.
\end{aligned}
$$

где $\tilde{\xi}] \bullet[\in[0,1]$ - генератор равномерно распределенных псевдослучайных вещественных чисел в диапазоне $[0,1] ; \Xi_{\min }, \Xi_{\max }-$ пределы, выбираемые перед началом вычислительного эксперимента. Для вещественных чисел стандартного типа double использовался стандартная функция $\operatorname{rand}()$ компилятора $\mathrm{C}++\mathrm{c}$ дискретизацией $2^{-15}$. Для 10-байтных чисел класса LongReal также используется линейный конгруэнтный ГПСЧ, но с увеличенной длиной отрезка неповторяемости за счет перехода с 2-х (стандартный $\operatorname{rand}())$ на 8-байтные целые типа unsigned _ int64, поэтому дискретизация достигла $2^{-63}$.

Генерирование чисел $\tilde{\xi}] \bullet[$ типа HReal осуществляется по следующему алгоритму:

1. Вход: $\left[\Xi_{\min }, \Xi_{\max }\right]-$ пределы генерации; $p$ (число десятичных разрядов в мантиссе). 
2. Инициализация вспомогательной строки $s=" .0 "$.

3. Цикл по десятичным разрядам мантиссы $i=1 . . p$.

4. Генерация псевдослучайной цифры мантиссы $j=\operatorname{rand}() \% 10$.

5. $s=s .(“ 0 ”+j)$ (конкатенация с символьным представлением цифры $j$ ).

6. Конец цикла по $i$.

7. Выход: $\Xi_{\min }+(1 \cdot s)\left(\Xi_{\max }-\Xi_{\min }\right)$.

Выражение $(1 \cdot s)$ является формальным обозначением преобразования данных по схеме «строка символов $\rightarrow$ число класса HReal». Обратное преобразование по схеме «число типа int $\rightarrow$ строка символов» формализуется как (“" 0 ” $+j$ ), где $j$ - преобразуемое в строку число (в данном случае это цифра от 0 до 9). Целочисленная операция «х \% у» взята из $\mathrm{C}++$ и означает «остаток от деления».

При исследовании вычислительной сложности итерационных методов решения СЛАУ матрица А также состоит из псевдослучайных чисел, но чтобы обеспечить сходимость итераций, формируется симметричная, положительноопределенная матрица. Легче всего обеспечить эти свойства, добиваясь выполнения правил диагонального преобладания по следующему алгоритму:

1. Вход: $n$ - размерность матрицы; $\left[\Xi_{\min }, \Xi_{\max }\right]$ - (пределы генерации); $\gamma$ корректирующий множитель, $\gamma>1$ (чем больше $\gamma$, тем меньше показатель обусловленности формируемой матрицы - отношение наибольшего по модулю собственного числа матрицы к наименьшему, тоже по модулю).

2. Цикл $i=1 . . n-1$.

3. Цикл $j=i+1 . . n$.

4. $\left.a_{j i}=a_{i j}=\Xi_{\min }+\tilde{\xi}\right] i, j\left[\left(\Xi_{\max }-\Xi_{\text {min }}\right)\right.$.

5. Конец циклов по $j, i$.

6. Цикл $i=1 . . n$.

7. $a_{i i}=\gamma \sum_{\substack{j=1, j \neq i}}^{n}\left|a_{i j}\right|$

8. Конец цикла по $i$.

9. Выход: симметричная и положительно-определенная матрица $\mathbf{A}=\left(a_{i i}\right)_{n \times n}$.

Вектор $\mathbf{b}=\left(b_{i}\right)_{n \times 1}$ в задаче (1) некритичен, полагаем $b_{i}=1, i=\overline{1, n}$.

При организации замеров времени счета конкретной СЛАУ важно добиться воспроизводимости результатов, что обеспечивается, прежде всего, заданием одного и того же стартового числа для ГПСЧ при формировании тестовой СЛАУ. Кроме этого, в условиях функционирования многозадачной операционной системы, надо максимально освободить процессор от посторонних вычислений: снять резидентные программы, исключить какие-либо обращения к компьютерным сетям и т.п. К сожалению, полностью освободить процессор от посторонних вычислений зачастую невозможно, поэтому необходим специальный алгоритм усреднения времени решения задачи (1), суть которого состоит в постепенном порционном увеличении числа обращений к процедуре решения задачи (1), не меняя исходных данных для этой задачи. Увеличение числа порций обращений происходит вплоть до момента, когда оно перестанет оказывать влияние на среднее время счета. Назовем замер времени счета одной порции одной 
итерацией. В основе алгоритма будет сглаживание полученных порционных замеров времени. Размер порции равен числу решений полностью идентичных задач, и, выражаясь тенденциями, можно утверждать, что для «небольших» задач этот размер всегда больше, чем для «крупных». Под термином «крупный» может подразумеваться либо большая размерность (1), либо большая длина мантиссы.

Введем обозначение method(•) - процедура решения (1). Без ограничения общности, отметим, что время счета измеряется по стандартному таймеру компилятора $\mathrm{C}++$ с дискретизацией 1 микросекунда.

Итак, сформулируем алгоритм сглаживания замеров времен счета в вычислительном эксперименте по изучению вычислительной сложности решения СЛАУ в условиях действия помех, связанных с нежелательной загрузкой процессора посторонними вычислениями.

1. Вход: $n$ - размерность СЛАУ; $\mathbf{A}=\left(a_{i i}\right)_{n \times n}, \mathbf{b}=\left(b_{i}\right)_{n \times 1}$ - параметры решаемой задачи (1); $\varepsilon$ - точность решения (только для итерационных методов решения СЛАУ); $p$ - длина мантиссы (только для класса HReal); $\delta$ - процент относительной ошибки измерения времени счета (в условиях отсутствия помех любая порция продублированных обращений к процедуре method(•) занимает неизменное время процессора, и тогда $\delta=0) ; N_{z}^{\max }$ - лимит числа итераций с нулевым временем счета: если лимит превышен, полагаем, что дальнейшие замеры следует прекратить и считать нулевое время результатом вычислительного эксперимента; $\Delta N$ - размер порций; $t^{*}-$ критическое время счета при однократном обращении к method(•): если фиксируется превышение этого значения, влиянием разброса показателей при измерении времени пренебрегаем, и размер порции становится минимальным, т.е. $\Delta N:=1$.

2. Блок инициализации.

2.1. $N=0, t=0$ - обнуляем общее количество обращений к процедуре method(•) и время, за которое они были сделаны;

2.2. $t_{0}=0$, обнуляем суммарное время обращения к процедуре method(•) на предыдущей итерации и всех предшествующих ей итерациях;

2.3. $t_{1}=\infty$, аналогично п. 2.2, предварительно полагаем суммарное время обращения к method(•) на последующей итерации включительно равным машинной бесконечности, чтобы, по меньшей мере, одна итерация была сделана обязательно. Соответственно, соседним итерациям назначаются индексы 0 и 1.

2. Обнуляем число замеров с нулевым временем счета $n_{z}=0$.

4. Начало итерационного цикла.

5. Для двух соседних итераций находим расхождение по времени счета в его абсолютном выражении $\Delta t:=\left|t_{1}-t_{0}\right|$, а для нахождения относительного расхождения определяем

$$
t_{\max }:=\max \left\{t_{0}, t_{1}\right\} .
$$

6. Если обнаружено, что $t_{\max }=0$, то увеличиваем счетчик замеров с нулевым временем счета $n_{z}:=n_{z}+1$, и, если оно превысило допустимый предел $n_{z}>n_{z}^{\max }$, полагаем, что $t:=0$ и выходим из итерационного цикла. В противном 
случае, когда $t_{\max }>0$, проверяем условие сходимости итераций: $100\left(\Delta t / t_{\max }\right) \leq \delta$. При выполнении этого условия выходим из итерационного цикла.

7. Полагаем $t_{0}:=t_{1}$, итерации продолжаются.

8. Цикл $q=1 . . \Delta N$, в котором происходит $\Delta N$-кратное обращение к процедype method $(\bullet)$.

9. Фиксируем время $t_{\text {prev }}=\operatorname{clock}()$ (здесь $\operatorname{clock}()-$ время, исчисляемое от начала работы программы, в микросекундах).

10. Решаем задачу (1): раскрывая абстрактор «॰», делаем обращение к процедуре $\operatorname{method}(n, \mathbf{A}, \mathbf{b}, \mathbf{x}, p)$; здесь $\mathbf{x}-$ вектор решения СЛАУ.

11. Фиксируем текущее время $t_{\text {next }}:=\operatorname{clock}()$.

12. Общее время счета получает приращение $t:=t+t_{\text {next }}-t_{\text {prev }}$.

13. Конец цикла по $q$.

14. $N:=N+\Delta N-$ общее количество обращений к процедуре method(•) получает приращение и, соответственно, уточняется время счета, затрачиваемое на одно обращение к процедуре $\operatorname{method}(\cdot): t_{1}=t / N$.

15. Проверяем: не слишком ли велико время однократного обращения к процедуре $\operatorname{method}(\bullet)$, а именно $t_{1}>t^{*}$ ? Если превышение обнаружено, нет смысла производить усреднение, достаточно однократного обращения к процедуре $\operatorname{method}(\bullet):$ устанавливаем $\Delta N:=1$.

16. Конец итерационного цикла.

17. Находим искомое усредненное время обращения к тестируемой процедуре: $\bar{t}=t / N$.

18. Выход: $\bar{t}:=\bar{t} / 1000$ - усредненное время решения задачи (1) в миллисекундах.

Результаты исследования делим на три класса: 1) прямые; 2) итерационные; 3) смешанные методы решения СЛАУ. Первый класс представлен обычным методом Гаусса и методом Гаусса с выбором главного элемента. Второй класс: методы Гаусса-Зейделя, наискорейшего спуска, сопряженных градиентов, минимальных невязок. В классе смешанных методов представлен лишь один - метод Краута с вращениями.

Дадим список возможных зависимостей, используемых при аппроксимации экспериментальных данных:

Таблица 1. Зависимости, использованные для аппроксимации

\begin{tabular}{|l|l|c|}
\hline \multicolumn{1}{|c|}{ Типы данных } & \multicolumn{1}{|c|}{ Вид зависимости } & Номер \\
\hline double, LongReal & $\bar{t}(n)=\alpha n^{3}$ & (8) \\
\cline { 2 - 3 } & $\bar{t}(n)=\alpha n^{2}$ & (9) \\
\cline { 2 - 3 } & $\bar{t}(n)=\alpha n^{2}+\beta n+\gamma$ & (10) \\
\cline { 2 - 3 } & $\bar{t}(n)=\alpha n^{3}+\beta n^{2}+\gamma n+\delta$ & (11) \\
\hline \multirow{2}{*}{ HReal } & $\bar{t}(n, p)=\alpha p^{2} n^{3}+\beta p n^{3}+\gamma p^{2} n^{2}+\delta p n^{2}$ & (12) \\
\cline { 2 - 3 } & $\bar{t}(n, p)=\alpha p^{2} n^{2}+\beta p n^{2}+\gamma p^{2} n+\delta p n$ & (13) \\
\hline
\end{tabular}


Формулы (12), (13) могут быть переписаны и в сепарабельном виде, но с позиций аппроксимации выгоднее записать именно в таком, развернутом виде. Для аппроксимации зависимостями (8)-(11) применялось сингулярное разложение, цель которого - исключить отрицательные коэффициенты полиномов [5].

В Таблицах 2-5 содержатся результаты аппроксимации (выборочно).

Таблица 2. Результаты аппроксимации для метода Гаусса

\begin{tabular}{|l|c|c|c|c|c|c|}
\hline \multicolumn{5}{|c|}{ Метод Гаусса } & \multirow{2}{*}{ Формула } & $\sigma$ \\
\cline { 1 - 4 } & $\alpha$ & $\beta$ & $\gamma$ & $\delta$ & & \\
\hline double & $2,46 \mathrm{e}-9$ & & & & $(8)$ & 0,0158 \\
\hline LongReal & $8.97 \mathrm{e}-9$ & & & & $(8)$ & 0,0087 \\
\hline HReal & $1,83 \mathrm{e}-10$ & $6,63 \mathrm{e}-9$ & $1,43 \mathrm{e}-9$ & $1,21 \mathrm{e}-7$ & $(12)$ & 0,0153 \\
\hline
\end{tabular}

Таблица 3. Результаты аппроксимации для метода Краута с вращениями

\begin{tabular}{|l|c|c|c|c|c|c|}
\hline & $\alpha$ & $\beta$ & $\gamma$ & $\delta$ & Формула & $\sigma$ \\
\hline double & $1,97 \mathrm{e}-8$ & & & & $(8)$ & 0,0885 \\
\hline LongReal & $1.05 \mathrm{e}-7$ & & & & $(8)$ & 2,2805 \\
\hline HReal & $1,04 \mathrm{e}-9$ & $4,93 \mathrm{e}-8$ & $9,35 \mathrm{e}-10$ & $1,07 \mathrm{e}-7$ & $(12)$ & 0,0746 \\
\hline
\end{tabular}

Таблица 4. Результаты аппроксимации для метода Гаусса-Зейделя

\begin{tabular}{|l|c|c|c|c|c|c|}
\hline & $\alpha$ & $\beta$ & $\gamma$ & $\delta$ & Формула & $\sigma$ \\
\hline double & $8,63 \mathrm{e}-8$ & & & & $(9)$ & 0,0006 \\
\hline LongReal & $3,37 \mathrm{e}-7$ & $1,54 \mathrm{e}-5$ & $5,84 \mathrm{e}-8$ & & $(10)$ & 0,0025 \\
\hline HReal & $1,47 \mathrm{e}-8$ & $7,57 \mathrm{e}-7$ & $2.18 \mathrm{e}-7$ & $4.62 \mathrm{e}-6$ & $(13)$ & 0,0504 \\
\hline
\end{tabular}

Таблица 5. Результаты аппроксимации для метода минимальных невязок

\begin{tabular}{|l|c|c|c|c|c|c|}
\hline & $\alpha$ & $\beta$ & $\gamma$ & $\delta$ & Формула & $\sigma$ \\
\hline double & $1,28 \mathrm{e}-7$ & & & & $(9)$ & 0,0006 \\
\hline LongReal & $5,22 \mathrm{e}-7$ & $5,92 \mathrm{e}-5$ & 0 & & $(10)$ & 0,0063 \\
\hline HReal & $3,41 \mathrm{e}-8$ & $4,42 \mathrm{e}-7$ & $2,91 \mathrm{e}-7$ & $5,76 \mathrm{e}-5$ & $(13)$ & 0,0153 \\
\hline
\end{tabular}

Результаты в Таблицах 2-5 были получены при следующих входных данных: для построения одномерных зависимостей вида $\bar{t}(n)=f(n)$ размерность $n$ варьировалась в пределах $[100,1000]$ с шагом 100. Для двумерных зависимостей, соответствующих типу данных HReal, $p \in[\overline{108,216}]$ с шагом 9, $n \in[\overline{10,100}]$ с шагом 10. Для всех итерационных методов точность $\varepsilon$ поиска решения СЛАУ для точности double принималась равной $10^{-5}$, для LongReal $-\varepsilon=10^{-6}$, для точности HReal опыты проводились с фиксированной точностью $\varepsilon=10^{-18}$. Из результатов, которые частично приведены в Таблицах 2-5, были сделаны следующие выводы:

1. Метод Краута с вращениями значительно выделяется среди прочих весьма значительным временем счета, что, однако, не умаляет его заявленных достоинств при решении плохо обусловленных СЛАУ, собственно, именно для таких систем он и предназначен.

2. Все итерационные методы имеют очевидные преимущества перед прямыми методами по времени счета, однако наиболее простой метод ГауссаЗейделя оказался неожиданно самым выгодным среди них (ряд таблиц здесь не 
приводятся), несмотря на невысокую скорость сходимости. Объяснение этому кроется в большой вычислительной нагрузке изощренных итерационных методов по вспомогательным векторно-матричным вычислениям.

Отдельно проводились исследования сепарабельности аппроксимирующих зависимостей, так, на рисунке 3 в качестве одного из экспериментальных доказательств приведена зависимость времени счета задачи (1), решаемой методом Гаусса в классе HReal - варьировалась длина мантиссы, а размерность СЛАУ оставалась постоянной, равной 30. В этом и всех других подобных экспериментах оказалось, что время зависит от длины мантиссы квадратично. На рисунке 4 приведена зависимость времени счета от двух аргументов. Исследования показали достаточную устойчивость замеров времени в условиях слабых вычислительных помех.

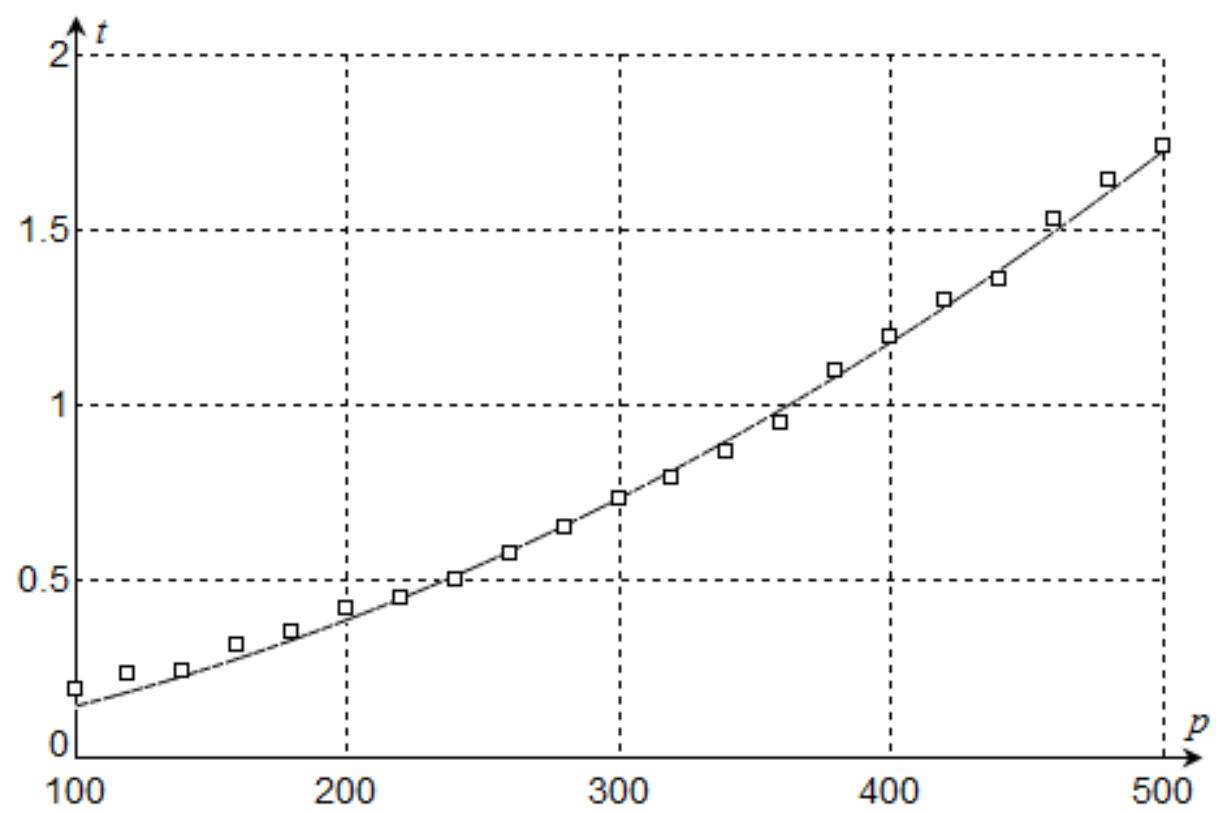

Рис. 3. Зависимость $\bar{t}=\bar{t}(p)$ в методе Гаусса

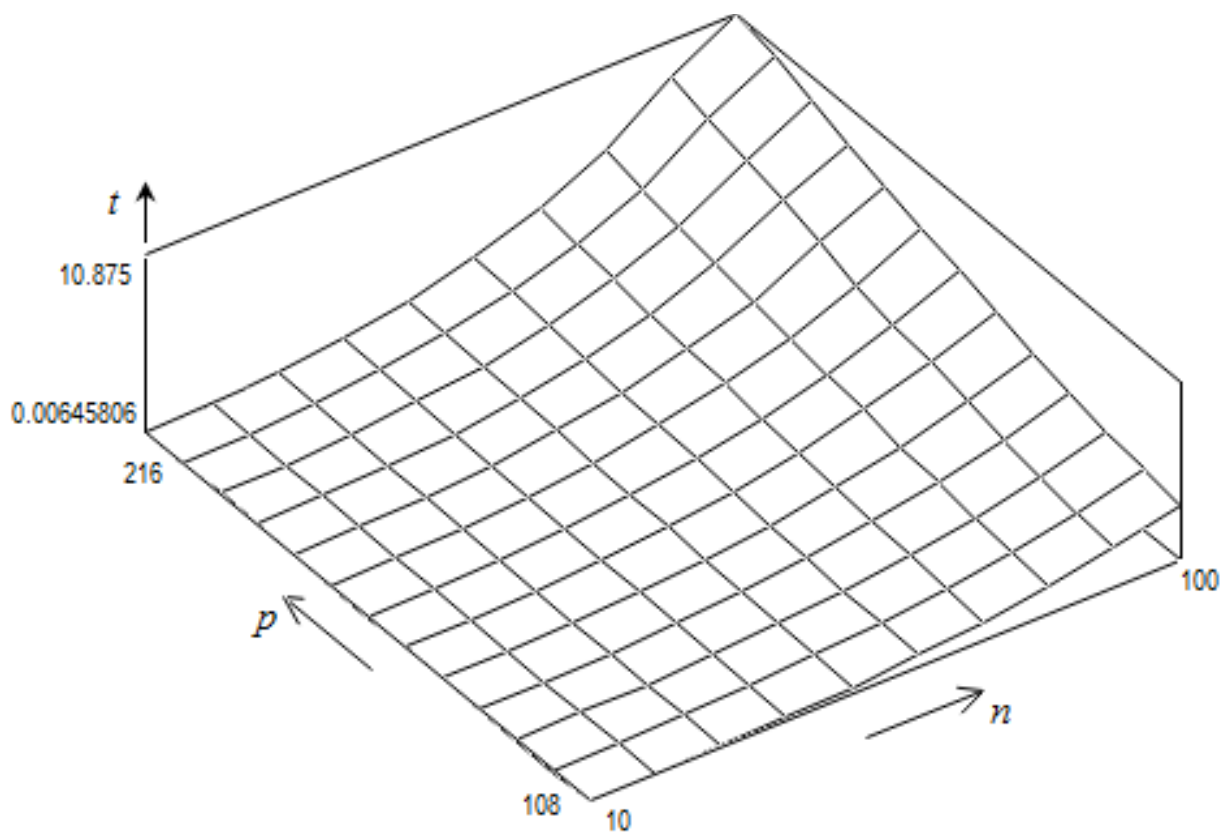

Рис. 4. Зависимость $\bar{t}=\bar{t}(n, p)$ в методе Гаусса 


\title{
Bblвoдbl
}

Для ряда известных методов решения СЛАУ получены экспериментальные зависимости времени счета от размерности задачи и длины мантиссы в условиях действия вычислительных помех. Это начало большого этапа исследования классических методов вычислений, выступающих в роли вычислительной нагрузки в режимах крупноблочных распределенных вычислений.

1. Бабичев А. М., Подольский В. Е. Основные подходы к разработке системы удаленного администрирования сетевых клиентов на основе вебтехнологий // Вопросы современной науки и практики. Университет им. В. И. Вернадского. №3 (41). 2012. С. 42-46.

2. Муромцев Ю. Л., Погонин В. А., Гребенников Р. В. Анализ энергосберегающего управления многомерными объектами // Вестник ТГТУ. 2007. Т. 13. №4. С. 838-845.

3. Толстых С. С., Подольский В. Е. Оценка сложности крупноблочных облачных вычислений, использующих арифметику повышенной точности // Труды Института системного программирования РАН. Т. 26. Вып. 5. 2014. С. 29-64.

4. Подольский В. Е., Толстых С. С. Повышение эффективности региональных образовательных компьютерных сетей с использованием элементов структурного анализа и теории сложности. М.: Машиностроение, 2006. 176 с.

5. Eckart, C., Young, G. The approximation of one matrix by another of lower rank // Psychometrika. 1936. №1. P. 211-218.

\section{Толстых С.С., Подольский В.Е., Бабичев А.М., Толстых С.Г. Структурно-параметрическая минимизация орграфа облачной вычислительной системы}

\author{
Tolstyh S.S., Podolsky V.E., Babichev A.M., Tolstyh S.G. \\ Structural-parametrical minimization of digraph \\ of cloud computing system
}

Тамбовский государственный технический университет Tambov State Technical University

Предложены концепцуии и алгоритм структурно-параметрической минимизачии орграфа облачной вычислительной системь.

The concept and algorithms of structural-parametric minimization digraph cloud computing system is proposed. 
Ключевые слова: облачная вычислительная система; орграф; минимизащия.

Keywords: cloud computing system; digraph; minimization.

Работа выполняется в соответствии с Проектом № 1346 из реестра государственных заданий высшим учебным заведениям и научным организациям в сфере научной деятельности.

Орграф облачной вычислительной системы (OBC) может содержать элементы, способствующие увеличению времени вычисления оценки сложности [25], что негативно сказывается на применении этих оценок в режиме online. К таким элементам, мешающим анализу сложности, относятся ветви вычислений, выполняемых последовательно, и скрытые параллельные ветви вычислений (терминология и обозначения взяты из нашей работы [1]). На рисунке 1 показаны: пример орграфа $(G)$, содержащего избыточные элементы, и результат структурно-параметрической минимизации (СПМ) - орграф $G$.

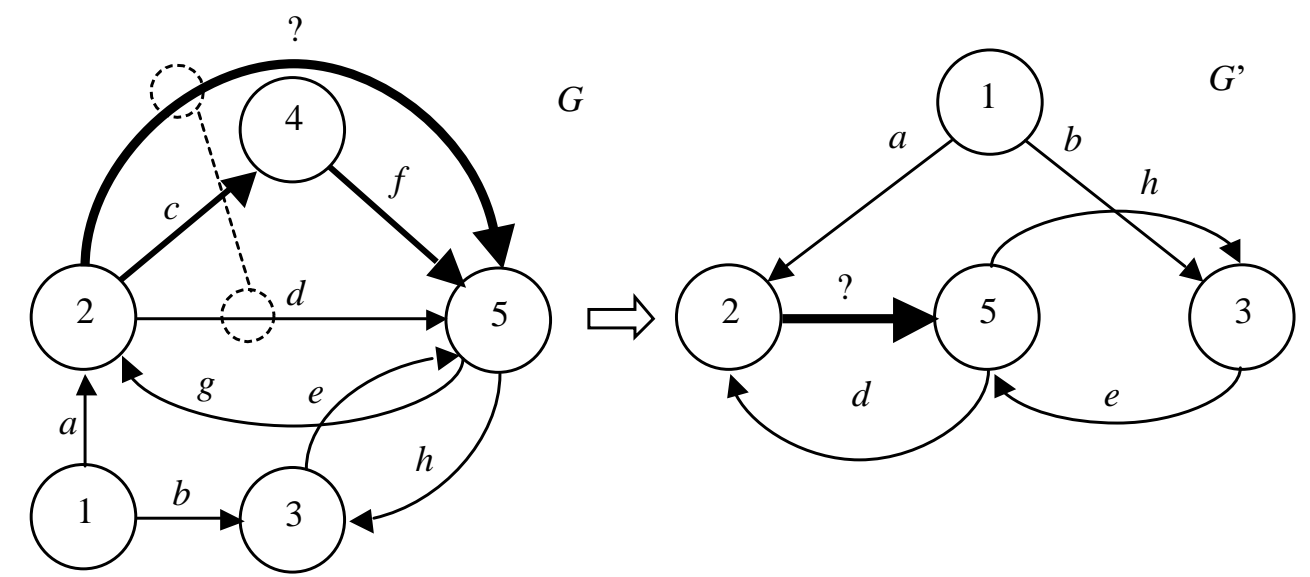

Рис. 1. Пример орграфа ОВС с избыточными элементами

Транзитивный вычислительный поток $2 \rightarrow 4 \rightarrow 5$ (дуги выделены утолщенными линиями) заменяется обобщенной дугой $2 \Rightarrow 5$, ее параметричность показана на рисунке 1 в виде вопросительного знака - требуется определить, каким образом она будет оцениваться. Через обобщенную дугу (такие дуги выделены двойной линией) $2 \Rightarrow 5$ проходит вычислительный поток, выполняемый параллельно потоку вычислений в изначальной дуге $2 \rightarrow 5$ орграфа ОВС (отмечено кружочками и соединяющей их точечной линией): у этих дуг совпадают начальная и конечная вершины. В результате получается дерево вычислений $G$ ' с вершиной «1», из которой выходят параллельные потоки $1 \rightarrow 2$ и $1 \rightarrow 3$. Орграф $G$, содержит точку сочленения «5». Обобщенная дуга $2 \Rightarrow 5$ в орграфе $G$, помимо транзитивной ветви $2 \rightarrow 4 \rightarrow 5$, содержит изначально скрытую параллельную ветвь расчетов в дуге $2 \rightarrow 5$ орграфа $G$. Параметричность обобщенной дуги орграфа $G$ ' также показана в виде вопросительного знака.

Оценка сложности параллельных вычислительных потоков должна учитывать характер их выполнения на ЭВМ: если эти потоки обрабатываются в параллельном режиме, оценка сложности должна быть согласована с критической линией, сложность которой максимальна. На рисунке 2 приводится иллюстрация к вышесказанному. 


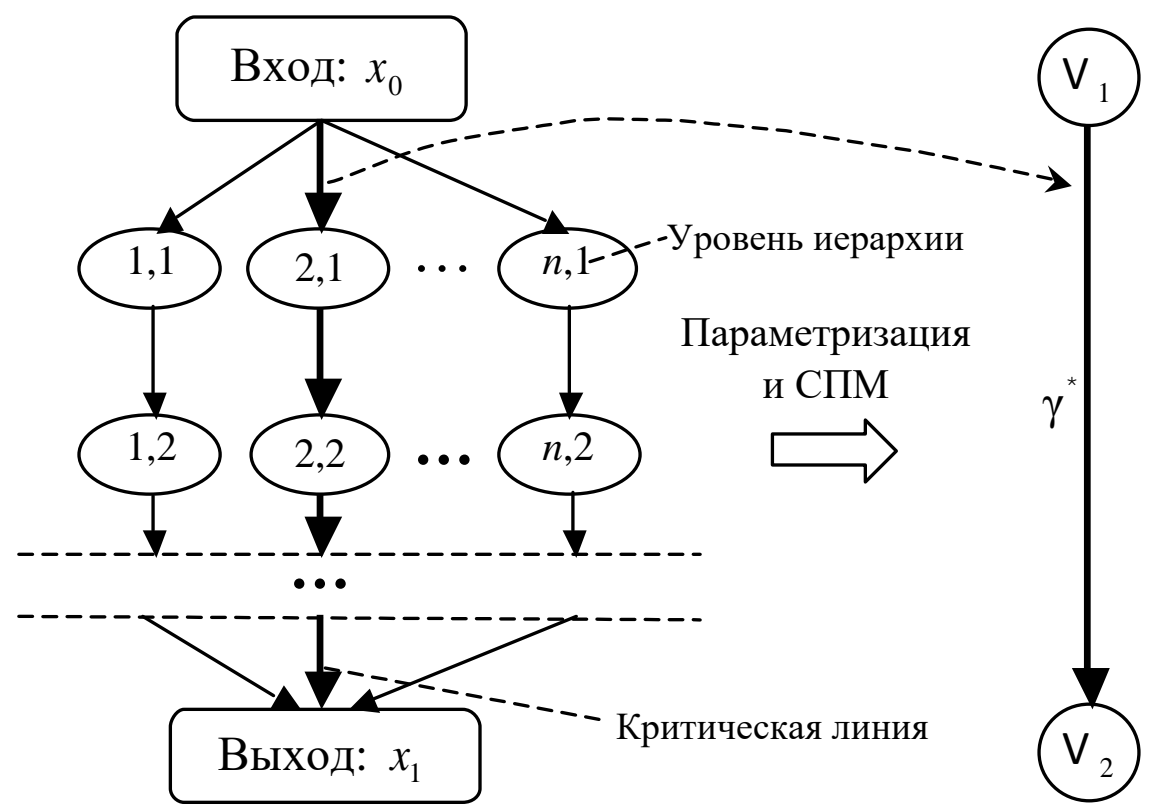

Рис. 2. Параллельные вычислительные потоки

На уровне концепций результат параметризации можно рассматривать как весовой кортеж, являющийся свойством обобщенной дуги $\bigvee_{1} \rightarrow V_{2}$, т.е.

$$
\gamma^{*}=\left(\left(\begin{array}{c}
\left(\gamma_{1,1}, \gamma_{1,2}, \ldots, \gamma_{1, p_{1}}\right) \\
\left(\gamma_{2,1}, \gamma_{2,2}, \ldots, \gamma_{2, p_{2}}\right) \\
\ldots \\
\left(\gamma_{n, 1}, \gamma_{n, 2}, \ldots, \gamma_{n, p_{n}}\right)
\end{array}\right), \gamma_{s}, \gamma_{r}\right), \gamma_{s}=\sum_{i=1}^{n} \min _{1 \leq j \leq p_{i}} \gamma_{i, j}, \gamma_{r}=\max _{1 \leq i \leq n} \sum_{j=1}^{p_{i}} \gamma_{i, j} .
$$

Для дальнейшего изложения метода СПМ потребуется определение.

Определение 1-вещественно-функиионального кортежа.

Кортеж $A=\left(a_{1 . . N}, \lambda\left(a_{1 . . N}, \mathbf{p}\right)\right)$ называется 1-вещественно-функциональным и имеет скалярное значение $\lambda\left(a_{1 . . N}, \mathbf{p}\right) \in R^{\geq 1}$ во всех арифметических операциях над элементами класса $R^{\geq 1}$.

Здесь: $a_{1 . . N}-$ элементы кортежа; $\lambda\left(a_{1 . . N}, \mathbf{p}\right)-$ безымянный функциональный контент кортежа $A ; \mathbf{p}$ - числовой вектор, управляющий вычислением значения кортежа.

Как показано на рисунке 3, транзитивную ветвь из $\mathrm{m}^{*}$ вершин, представляющих раздаточные серверы, можно представить как последовательность отображений $\varphi_{i}: \mathbf{x}_{i-1} \rightarrow \mathbf{x}_{i}, i=1 . . m^{*}$, при этом $\mathbf{x}_{0}-$ вектор входных, а $\mathbf{x}_{m^{*}}-$ вектор выходных переменных. Каждое из отображений $\varphi_{i}$ имеет соответствующую вычислительную нагрузку, оцениваемую параметричностью $\gamma_{i}$ на стадии параметризации. Далее, на стадии СПМ происходит стягивание транзитивной ветви в обобщенную дугу с параметричностью $\gamma^{*}$. 
Учитывая, что обобщенная дуга $d^{*}$ является частью сильно связного орграфа $G^{\prime}$, параметричность этой дуги $\gamma^{*}$ - суть 1-вещественно функциональный кортеж

$$
\gamma^{*}=\left(\gamma_{1}^{*}\left(d_{1 . . m^{*}}\right), \gamma_{2}^{*}\left(d_{1 . . m^{*}}\right), \lambda\left(\gamma_{1}^{*}, \gamma_{2}^{*}, \mathbf{p}\right)\right),
$$

где $\mathbf{p}=\left(p_{1}\right)-$ формально, в соответствии с Определением 4, вектор, фактически же - число $p_{1}=1$ 国; «1» соответствует значению $\lambda\left(\gamma_{1}^{*}, \gamma_{2}^{*}, \mathbf{p}\right)=\gamma_{1}^{*}\left(d_{1 . m^{*}}\right)$, «0»- значению $\lambda\left(\gamma_{1}^{*}, \gamma_{2}^{*}, \mathbf{p}\right)=\gamma_{2}^{*}\left(d_{1 . m^{*}}\right)$. Функтор $\gamma_{1}^{*}\left(d_{1 . . m^{*}}\right)$ вычисляет параметричность обобщенной дуги $d^{*}$ в случае, когда она подлежит разрыву, а $\gamma_{2}^{*}\left(d_{1 . m^{*}}\right)-$ в случае, когда обобщенная дуга $d^{*}$ не разрывается, но участвует в формулах оценки сложности при разрыве других дуг.

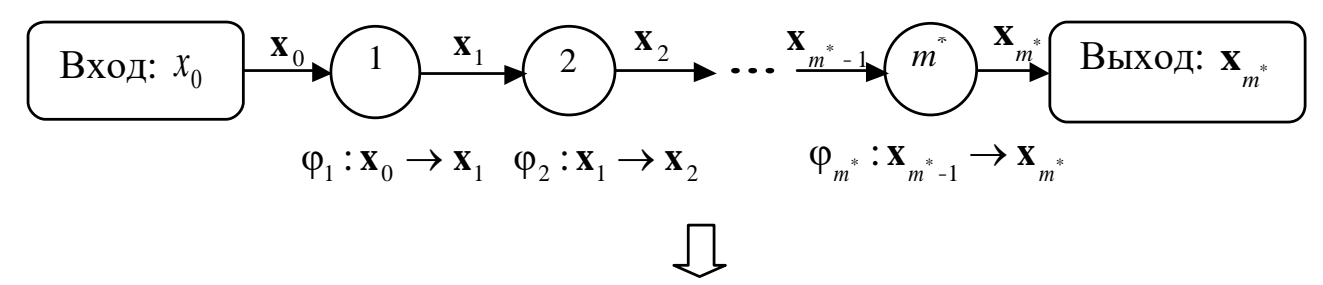

Параметризация

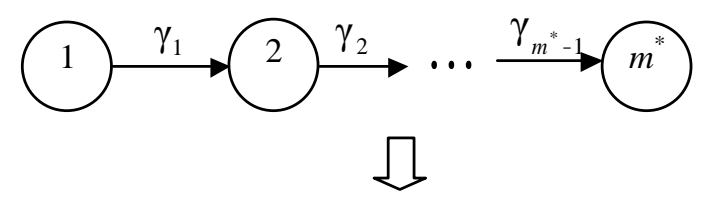

СПМ

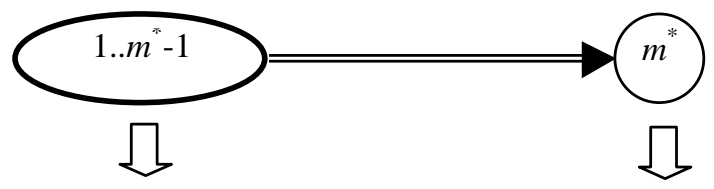

Сложность упрощения

Остаточная сложность разрыва
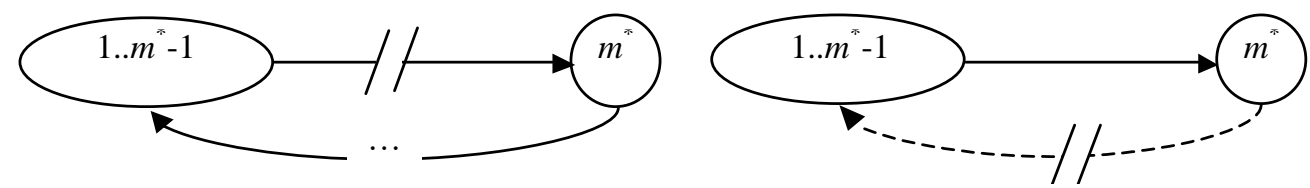

Рис. 3. Иллюстрация к формулам (2)-(4)

Для уточнения и дальнейшей конкретизации (2) были приняты следующие допущения:

1) Сложность упрощения при разрыве обобщенной дуги равна минимальной параметричности в транзитивной ветви

$$
\gamma_{1}^{*}\left(d_{1 . . m^{*}}\right)=\min _{1 \leq i \leq m^{*}} \gamma_{i} ;
$$

2) Остаточная сложность обобщенной дуги в случае разрыва иной дуги равна сумме параметричностей дуг перед стягиванием

$$
\gamma_{2}^{*}\left(d_{1 . m^{*}}\right)=\sum_{i=1}^{m^{*}} \gamma_{i}
$$


Вернемся к рисунку 1 - отметим важное обстоятельство: скрытая параллельность вычислений, будучи выявлена, может способствовать включению в обобщенные дуги других обобщенных дуг, а это свидетельство в пользу итерационного построения процедурной модели, реализующей описываемый метод СПМ.

Есть еще одно важное обстоятельство: оно иллюстрируется на рисунке 4 при замене транзитивной ветви обобщенной дугой в орграфе $G$ ' не должна появляться реверсивная петля. В примере на рисунке 4 транзитивная ветвь $1 \rightarrow 2 \rightarrow 3 \rightarrow 6$ заменяется обобщенной дугой $1 \cdot 6$, параллельно ей расположена транзитивная ветвь $1 \rightarrow 4 \rightarrow 5 \rightarrow 6$. В итоге формируется обобщенная дуга, которую совместно с изначально существующей дугой $6 \rightarrow 1$ можно сократить по признаку транзитивности до одной дуги, превратив в петлю. Однако ранее нами было принято, что орграфы не содержат петель, поэтому в итоге получается орграф $G^{\prime}$, в котором вершина 6 является точкой сочленения.

Структурно-параметрическая минимизация (СПМ) на уровне концепций может быть поделена на два уровня: а) верхний - структурный и б) нижний параметрический. Верхний уровень уже обозначен, нижний - частично, для транзитивных ветвей и, на концептуальном уровне, - для скрытых параллельных ветвей.

Далее потребуется предикат, который ставит в соответствие атомарное true последовательности дуг $D^{*}$, когда они идут транзитивно, одна за другой, причем первая дуга последовательности $D^{*}$ может иметь смежные к ней дуги только в своей начальной вершине $\left(\underline{d}_{1}^{*}\right)$, а последняя - в конечной вершине $\left(\bar{d}\left|D^{*}\right|\right)$. Предикат формализуется следующим образом:

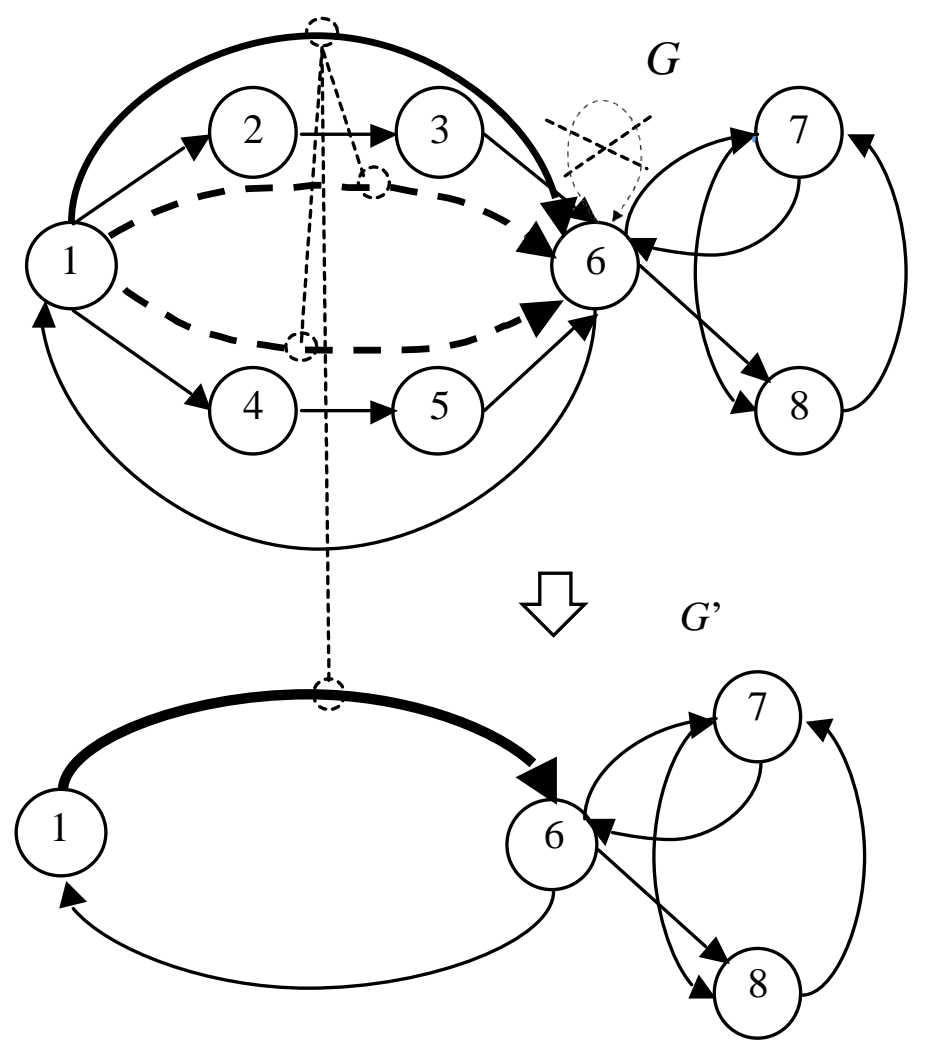

Рис. 4. Иллюстрация к недопустимости петель при стягивании транзитивных ветвей вычислений 


$$
\mathrm{E}\left(D^{*}\right)=\left(\begin{array}{l}
\left|D^{*}\right|=\left|I=\left(i_{1 . . m^{*}}\right)\right|=m^{*}, \bar{d}_{i_{j}}^{*}=\underline{d}_{i_{j+1}}^{*} \\
\underline{d}_{1}^{*} \neq \bar{d}_{m^{*}} \\
\wedge \\
\nexists d \in D: \bar{d}_{i_{j}}^{*}=\underline{d} \vee \bar{d}_{i_{j}}^{*}=\bar{d}, j=1 . .\left|D^{*}\right|-1
\end{array}\right) \Rightarrow \text { true M false. }
$$

Обобщенную дугу $d^{*}$, возникающую в результате стягивания транзитивной ветви, определяем с помощью операторного уравнения

$$
d^{*} \mathrm{k}\left(\left(\underline{d}^{*} \rightarrow \bar{d}^{*}\right) \mathrm{C}\left(\begin{array}{l}
\underset{i=1}{m^{*}}\left(d_{i} \in D^{*}: \mathrm{E}\left(D^{*}\right)=\text { true }\right), \\
\gamma^{*} \in(37), \underline{d}^{*}=d_{1} \in D^{*}, \bar{d}^{*}=d_{m^{*}} \in D^{*}
\end{array}\right)\right),
$$

где утверждается, что обобщенная дуга представлена начальной вершиной $\underline{d}^{*}$ и конечной вершиной $\bar{d}^{*}$, дуга конкретизируется последовательностью сцепленных друг за другом дуг орграфа $G$, ее параметричность вычисляется по формуле (2), а начало и конец совпадают с начальной вершиной первой и конечной вершиной последней дуги в кортеже $D^{*}$.

Для формирования процедурной модели СПМ запишем предикат, позволяющий выявить скрытую параллельность обобщенной дуги $d^{*}$ орграфа $G$ и изначальной дуги $d_{k} \in D, k=1 . . m$

$$
\mathrm{G}\left(d^{*}, d_{k}\right)=\left(\underline{d}_{1}^{*}=\underline{d}_{k} \wedge \bar{d}_{m^{*}}^{*}=\bar{d}_{k}\right) \Rightarrow \text { true M false, }
$$

склеивание параллельных дуг оформим в виде двуместной операции «њ»

$$
d^{*} \pm d_{k}:\left(d^{*}, d_{k}\right) \rightarrow\left(\underline{d}_{k} \rightarrow \bar{d}_{k}\right) \mathrm{c}\left(\left(d^{*}, d_{k}\right) \mathrm{К}\left(\gamma^{*} \mathrm{k} \gamma^{*}+\left(\gamma_{k} \mathrm{~d} d_{k} \in G^{\prime}\right)\right)\right) .
$$

Применение СПМ предполагает, что в нашем распоряжении уже имеется классическая матрица контуров. Следует отметить важное свойство дуг, входящих в транзитивную ветвь: в матрице $\breve{\mathbf{C}}(G)=\left(\breve{c}_{i j}(G)\right)_{K \times m}$ столбцы этой матрицы, соответствующие искомой ветви, одинаковы, т. к. все дуги ветви входят в одни и те же контуры орграфа. Это свойство позволяет ускорить поиск транзитивных дуг. Однако условие равенства столбцов в данном случае не является достаточным, как это продемонстрировано на рисунке 5.

В орграфе $G$ всего одна транзитивная ветвь $3 \rightarrow 5 \rightarrow 4$, соответственно столбцы матрицы, соответствующие дугам ветви, как можно видеть идентичные. Столбцы матрицы, соответствующие дугам $2 \rightarrow 3$ и $4 \rightarrow 1$, идентичные, но это не транзитивная ветвь. Таким образом, матрица контуров позволяет выявить некоторый набор дуг $D^{*}$, который может быть выстроен в транзитивную ветвь, но необходима дополнительная проверка с помощью предиката $\mathrm{E}\left(D^{*}\right)$. Если набор дуг, предположительно, - транзитивная ветвь, при подстановке в предикат $\mathrm{E}\left(D^{*}\right)$ дает значение предиката, равное false, этот набор дуг еще может представлять собой транзитивную ветвь, если из него исключить ряд дуг. 


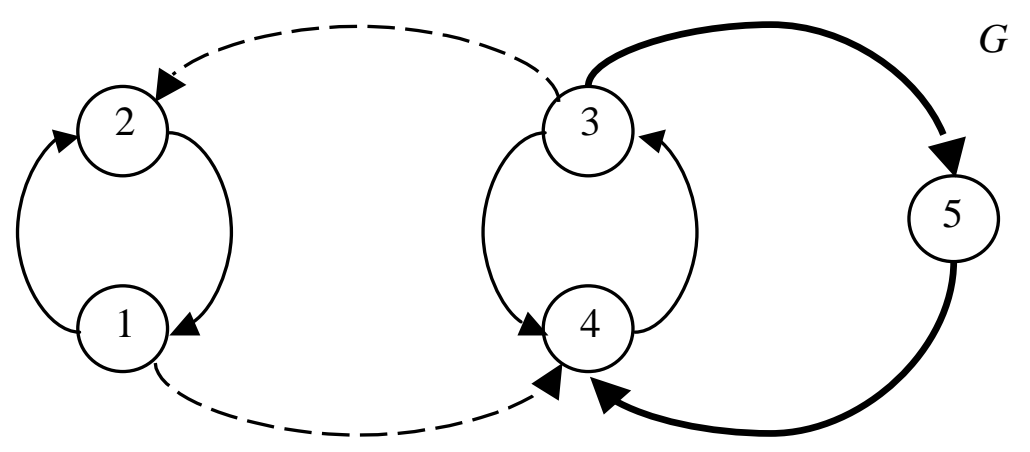

$$
\mathbf{C}(G)=\begin{array}{|l|l|l|l|l|l|l|l|}
\hline 1 & 2 & 2 & 3 & 3 & 4 & 4 & 5 \\
\hline 2 & 1 & 3 & 4 & 5 & 1 & 3 & 4 \\
\hline 1 & 1 & & & & & & \\
\hline & & & 1 & & & 1 & \\
\hline 1 & & 1 & 1 & & 1 & & \\
\hline 1 & & 1 & & 1 & 1 & & 1 \\
\hline & & & & 1 & & 1 & 1 \\
\hline
\end{array}
$$

Рис. 5. Пример установления факта транзитивности

Введем в рассмотрение функтор, возвращающий минимальный по мощности кортеж дуг $\breve{D}^{*}$, без которых кортеж $D^{*}$ становится транзитивной ветвью

$$
\breve{E}\left[D^{*}\right] \equiv\left(\exists \breve{D}^{*} \in D^{*} \Xi\left(D^{*} \backslash \breve{D}^{*}\right)=\text { true } \wedge\left|\breve{D}^{*}\right|=\min _{\circ}\left|\breve{D}^{*}\right|\right) \Rightarrow \breve{D}^{*} \mathrm{M} \varnothing .
$$

На рисунке 6 показана иллюстрация действий, производимых функтором $\breve{E}\left[D^{*}\right]$.

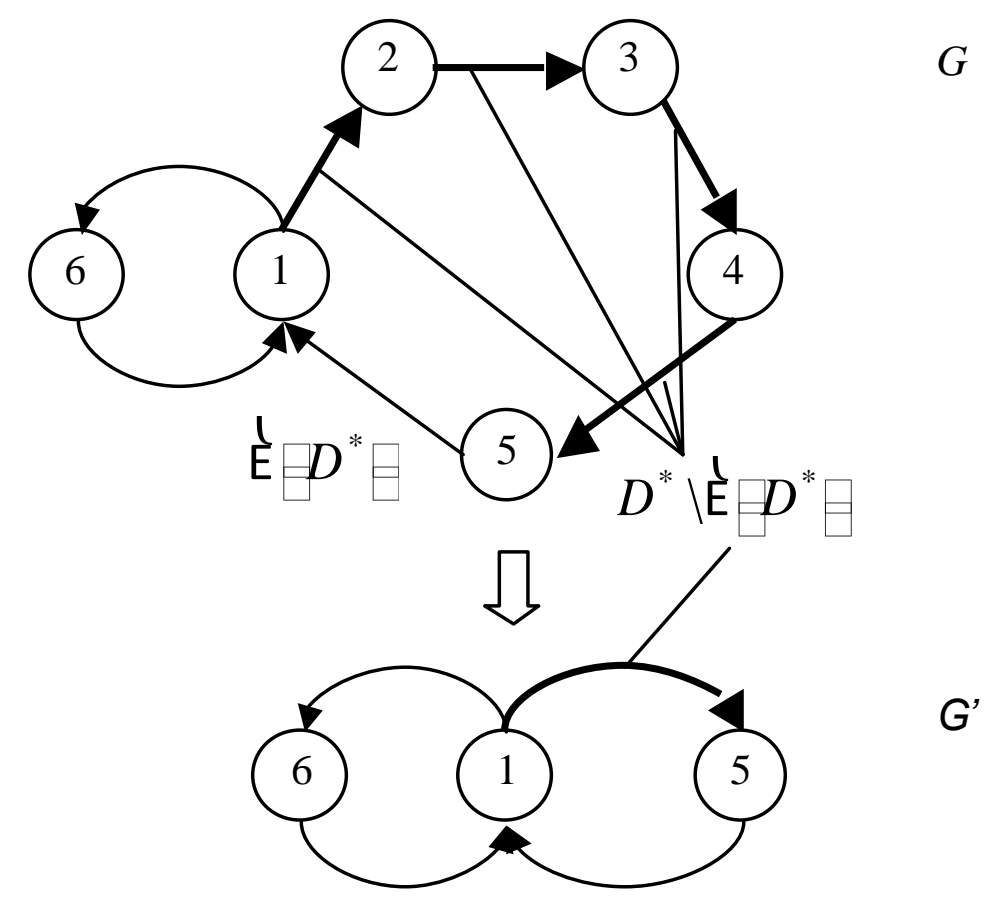

Рис. 6. Иллюстрация к функтору $\breve{E}\left[D^{*}\right]$ 
Орграф $G$ содержит кольцо $1 \rightarrow 2 \rightarrow 3 \rightarrow 4 \rightarrow 5 \rightarrow 1$, которое отвергается предикатом $\mathrm{E}\left(D^{*}\right)$ в качестве претендента на транзитивную ветвь, т.к. при стягивании она превращается в петлю. В данном примере значением функтора является кортеж, состоящей лишь из одной дуги $5 \rightarrow 1-$ достаточно удалить только эту дугу, чтобы выявить транзитивную ветвь $1 \rightarrow 2 \rightarrow 3 \rightarrow 4 \rightarrow 5$, чтобы прийти к орграфу $G$, и это будет результатом СПМ.

Сформулируем процедурную модель метода СПМ на рекурсивной основе.

1. Вход $\operatorname{StrMin}(G): G=(V, D, \Gamma)-$ орграф ОВC; $\breve{\mathbf{C}}(G)=\left(\breve{c}_{i j}(G)\right)_{K \times m}-$ классическая матрица контуров, соответствующая орграфу $G$.

2. Инициализируем возвращаемое значение StrMin - орграф $G^{\prime} \mathrm{k} G$.

3. Обнуляем кортеж дуг, составляющих транзитивную ветвь:

$$
D^{*} \mathrm{k} \varnothing, m^{*} \mathrm{k} \varnothing \text {. }
$$

4. Инициализируем булев массив $p D^{*}=\left[p D_{j}^{*} \mathrm{k}\right.$ false, $\left.j=1 . . m\right]$. Если $p D_{j}^{*}=$ true, столбец с номером $j$ считается «рассмотренным» и пропускается.

5. Цикл по не «рассмотренным» столбцам матрицы $\breve{\mathbf{C}}(G)$,

$$
j=(1 . . m) \wedge p D_{j}^{*}=\text { false } .
$$

6. Цикл по остальным столбцам матрицы $\breve{\mathbf{C}}(G)$, кроме столбца с номером

$$
j: v=1 . . j-1 . . j+1 . . m \wedge p D_{v}^{*}=\text { false } .
$$

7. Проверяем идентичность столбов $\breve{c}_{i j}=\breve{c}_{i v}, i=1 . . K$ ? Если они идентичны, добавляем дугу в кортеж $D^{*} \mathrm{k} \quad D^{*} \cup\left\{d_{++m^{*}}^{*} \mathrm{k} d_{D^{*}=\varnothing \Rightarrow j \mathrm{Mv}}\right\}$ и помечаем соответствующий столбец как «рассмотренный»: $p D_{D^{*}=\varnothing \Rightarrow j \mathrm{Mv}}^{*}=$ true .

8. Конец цикла по $v$.

9. Конец цикла по $j$.

10. Тестируем найденный кортеж на транзитивность $\mathrm{E}\left(D^{*}\right)=$ true ? Если тестирование прошло удачно, переходим на п. 12.

11. Применяем функтор $\breve{\mathrm{E}}\left[D^{*}\right]$ : если $\breve{\mathrm{E}}\left[D^{*}\right] \neq \varnothing$, полагаем $D^{*} \mathrm{k} D^{*} \backslash \breve{\mathrm{E}}\left[D^{*}\right]$, в противном случае процедурная модель заканчивает свою работу.

12. Исключаем транзитивную ветвь из результатного орграфа $G^{\prime} \mathrm{k} G^{\prime} \backslash \lambda G\left(\circ, D^{*}, \circ\right)$ и находим обобщенную дугу $d^{*}$ из решения операторного уравнения (41), добавляем информацию в результатный орграф $G^{\prime} \mathrm{k} G^{\prime} \cup \lambda G\left(\circ,\left\{d^{*}\right\}, \circ\right)$.

13. Проверяем наличие скрытой параллельной ветви, открываем цикл по перебору дуг орграфа $G^{\prime}$, всех, кроме $d^{*}, k=1 . .\left|G^{\prime}\right|_{2}, d_{k} \neq d^{*}$.

14. Дуга $d_{k}$ содержит параллельные вычисления с обобщенной дугой $d^{*} ?$ $\mathrm{G}\left(d^{*}, d_{k}\right)=$ true ? Если «да», то склеиваем дуги $d^{*} \mathrm{k} d^{*} \pm d_{k}$.

15. Конец цикла по $k$.

16. Проверяем $G^{\prime} \neq G$ ? Если «да», то необходимо продолжить рекурсию: $G^{\prime} \mathrm{k} \operatorname{StrMin}\left(G^{\prime}\right)$. 


\section{7. Выход - орграф $G^{\prime}$.}

\section{Bblводbl}

В целях ускорения online-оценок вычислительной сложности ОВС разработаны концепции и алгоритм процедуры структурно-параметрической оптимизации орграфа ОВС. Результаты могут быть использованы для облачного управления распределенными вычислениями.

1. Толстых С. С., Подольский В. Е. Оценка сложности крупноблочных облачных вычислений, использующих арифметику повышенной точности. // Труды Института системного программирования РАН. 2014. Т. 26. Вып. 5. С. 29-64.

2. Толстых С. С., Толстых Т. Н. Эвристический алгоритм построения функций структурной сложности // Вестник ТГТУ. 1996. Т. 2 С. 45-48.

3. Толстых С. С., Федоров Р. В., Подольский В. Е. Построение критериев оценки структурной сложности в режиме адаптации к целям анализа. // Вопросы современной науки и практики. Университет им. В. И. Вернадского. 2008. Т. 2. №3 (13). С. 208-217.

4. Подольский В. Е., Толстых С. С. Использование критериев структурной сложности для имитационного моделирования региональных компьютерных сетей // Параллельные вычисления в задачах математической физики: Сб. ст. Ростов н/Д: Изд-во РГУ, 2005. С. 67-75.

5. Подольский В. Е., Толстых С. С. Повышение эффективности региональных образовательных компьютерных сетей с использованием элементов структурного анализа и теории сложности. М.: Машиностроение, 2006. 176 с.

\section{Харченко В.Ю. \\ Выбор метода решения задачи энергосберегающего управления при производстве строительных материалов}

Kharchenko V.Yu.

The choice of method of solving the problem of energy saving control in the manufacture of building materials

Тамбовский государственный технический университет Tambov State Technical University

Проведен анализ прочессов производства строительных изделий, таких как силикатный кирпич, керамический кирпич и железобетонные изделия. Для 
энергоемких стадий производства строительных изделий поставлена задача энергосберегающего управления и предложен метод ее решения.

The paper presents the analysis of the processes of production of building materials, such as a silicate brick, a ceramic brick and ferroconcrete products. For energy-intensive stages of production of building materials tasked with energy-saving control and the method of its solution.

Ключевые слова: строительные материаль; силикатный кирпич; керамический кирпич; железобетонные изделия; тепловая обработка; оптимальное управление.

Keywords: building materials; silicate bricks; ceramic bricks; ferroconcrete products; heat treatment; optimal control.

В настоящее время в связи с бурными темпами строительства различных объектов как никогда остро стоит вопрос производства большого количества строительных материалов высокого качества. С другой стороны, на предприятиях, производящих строительные материалы в условиях высокой конкуренции, необходимо снижение себестоимости производимых изделий при обеспечении заданных качественных показателей и объема выпускаемой продукции.

Себестоимость и качество строительных изделий всегда существенно зависят от технологии выполнения наиболее сложных, длительных и энергоемких процессов. При производстве силикатного кирпича (СК) таким процессом является процесс тепловой обработки в промышленных автоклавах; при производстве керамического кирпича (КК) - процесс сушки в камерных сушилках; при производстве железобетонных изделий (ЖБИ) - процесс тепло-влажностной обработки в пропарочных камерах $[1 ; 2 ; 5]$.

Все эти процессы имеют много общего. Они характеризуются слабой изученностью большинства физико-химических процессов, периодическим характером, распределенностью в пространстве и взаимосвязанностью многих выходных координат, сосредоточенностью управляющих воздействий. Вместе с тем до $80 \%$ энергозатрат при производстве приходится именно на эти стадии, т. к. все они проходят при повышенных температурах.

Поэтому применение эффективных алгоритмов при управлении этими процессами, обеспечивающих минимизацию энергозатрат при выполнении технологических условий и ограничений, приведет к снижению себестоимости продукции. Возникает следующая задача:

Определить программу изменения температуры среды в аппарате $t^{*}(\tau), \tau \in\left[0, \tau_{\kappa}\right]$, при которой суммарный расход теплоносителя минимальный

$$
I^{*}\left(t^{*}(\tau)\right)=\min \int_{0}^{\tau_{\kappa}} G^{B x}(t(\tau)) \cdot d \tau
$$

при выполнении уравнений связи в виде математической модели [5]

$$
y(\cdot)=M(t(\tau)),
$$

и технологических условий и ограничений. 
При тепловой обработке силикатного кирпича в промышленных автоклавах такими технологическими условиями и ограничениями являются [5]:

ограничения на температуру среды:

на мгновенный расход теплоносителя:

$$
T_{\min } \leq t(\tau) \leq T_{\max },
$$

$$
A_{\text {min }} \leq G^{6 x}(\tau) \leq A_{\max },
$$

на градиент температуры в изделиях:

$$
B_{\min } \leq \frac{\partial t_{u}(\tau)}{\partial x} \leq B_{\max },
$$

на температуру изделий в конечный момент времени:

$$
t_{u}^{n}\left(\tau_{\kappa}^{*}\right) \leq C_{\max },
$$

на прочность кирпича в конечный момент времени :

$$
R\left(\tau_{\kappa}^{*}\right)>D_{\min },
$$

на время процесса:

$$
\tau_{\kappa} \leq \tau_{\kappa}^{3 a d} .
$$

При сушке керамического кирпича в камерных сушилках [2]: ограничение на скорость подачи теплоносителя:

$$
V_{\text {min }} \leq V \leq V_{\max },
$$

на температуру среды:

$$
T_{\text {min }} \leq t(\tau) \leq T_{\text {max }},
$$

на температуру изделия в процессе сушки:

$$
t_{u}^{n}(\tau) \leq T_{\max },
$$

на остаточное влагосодержание изделия в конце сушки:

$$
U_{\text {min }} \leq u_{u} \leq U_{\max },
$$

на время процесса:

$$
\tau_{\kappa} \leq \tau_{\kappa}^{3 a d} .
$$

При тепло-влажностной обработке ЖБИ в пропарочных камерах [1]:

ограничения на температуру среды:

$$
T_{\min } \leq t(\tau) \leq T_{\max },
$$

на давление в пропарочной камере:

$$
P_{\text {min }} \leq p(\tau) \leq P_{\max },
$$

на температуру ЖБИ в конечный момент времени :

$$
t_{u}\left(\tau_{\kappa}^{*}\right) \leq C_{\max },
$$

на прочность бетона в конечный момент времени :

$$
R\left(\tau_{\kappa}^{*}\right)>D_{\min },
$$

на время процесса:

$$
\tau_{\kappa} \leq \tau_{\kappa}^{3 a d} .
$$

Вследствие чрезвычайной сложности математической модели, включающей в себя уравнения в частных производных и уравнения в обыкновенных производных, решение поставленной задачи оптимального управления является весьма сложной проблемой. Решение задач оптимизации с помощью известных 
методов принципа максимума Понтрягина [3] не представляется возможным изза большого числа уравнений системы. Невозможно использовать и другие методы оптимизации, например, динамическое программирование из-за чрезвычайно большой размерности пространства состояний [4].

Применение прямых методов без введения дополнительных упрощающих положений также невозможно из-за большого числа варьируемых переменных [2].

Проведенные исследования показали, что управление может быть представлено зависимостью температуры в аппарате от времени, характеризующейся конечным числом переключений рис. 1.

На рис. 1а изображена кривая изменения температуры, состоящая из трех участков. На участке нагрева и участке охлаждения скорости подъема и снижения температуры выбраны, исходя из опыта эксплуатации промышленного оборудования.

Кривая (рис. 1а) является 5-ти параметрической с параметрами $\tau_{1}, \tau_{2}, \tau_{3}$, $t_{1}, t_{2}$. Будем считать, что множество программ изменения температуры, отображаемых кривыми вида рис. 1a, составляют класс $\mathrm{A}_{1}$.

Более широкий класс составляют 8-ми параметрические кривые (рис. 2б). Множество двухступенчатых программ составляют класс $\mathrm{A}_{2}$.

По аналогии с классом $\mathrm{A}_{2}$ можно определить класс $\mathrm{A}_{3}$, состоящий из трехступенчатых программ изменения температуры в аппаратах (рис. 2в).

Определив класс функций, мы переходим к задаче параметрической оптимизации.

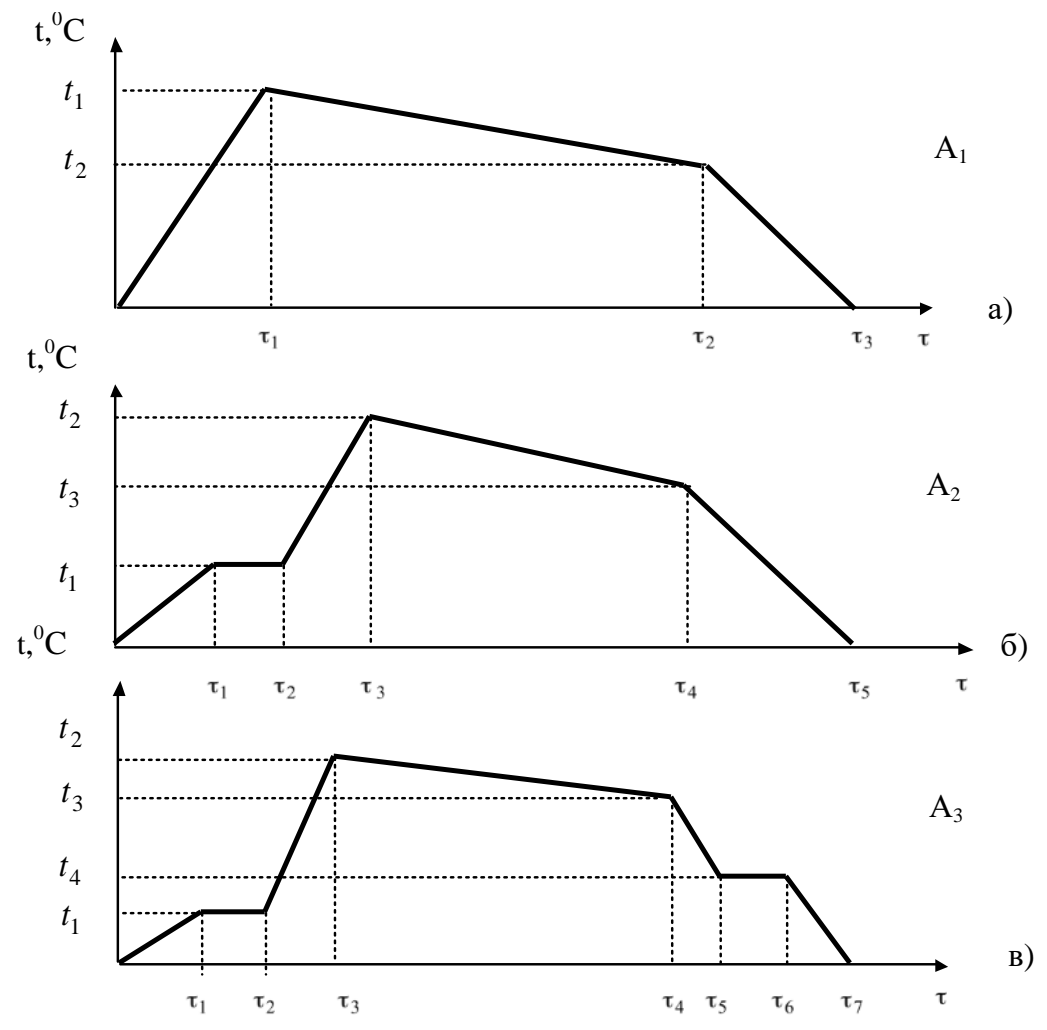

Рис. 1 Классы функций

Критерий в нашей задаче запишется следующим образом:

$$
I^{*}\left(t^{*}(\tau)\right)=\min _{t^{*}(\tau) \in A_{i}} \int_{0}^{\tau_{b}} G^{k x}(t(\tau)) \cdot d \tau
$$


Таким образом, например, при выборе класса функций $\mathrm{A}_{1}$ (рис. 2а) поиск ведется в пространстве переменных $\left(\tau_{1}, \tau_{2}, \tau_{3}, t_{1}, t_{2}\right)$ с использованием известных метода условной оптимизации [6].

1. Лагутин А. В. Математическое моделирование и оптимальное управление процессом тепловлажностной обработки: На примере производства железобетонных изделий: дисс. ... к. техн. наук: 05.13.07. Тамбов, 1999186 с.

2. Муромцев Ю. Л., Погонин В. А., Гребенников Р. В. Анализ энергосберегающего управления многомерными объектами // Вестник ТГТУ. 2007. T. 13. C. 838.

3. Прокопенко М. Н. Автоматизация технологического процесса сушки керамического кирпича на основе многосвязных однотипных систем управления: дисс. ... к. техн. наук: 05.13.06. Тамбов, 2007228 с.

4. Справочник по теории автоматического управления / Под ред. Красовского А. А. М.: Наука, 1987. 712 с.

5. Харченко В. Ю., Фролов С. В. Математическая модель процесса тепловой обработки силикатного кирпича в промышленных автоклавах / Тамбовский гос. техн. ун - т. Тамбов, 1997. 33 с.: 4 ил. Библиогр. 6 назв. Рус. Деп. в ВИНИТИ 04.04.97, №1081-В97. 1975.

6. Химмельблау Д. Прикладное нелинейное программирование. М.: Мир,

\title{
Шибкова В.П., Комендантов Г.А. Влияние атлетической гимнастики на формирование тела
}

\author{
Shibkova V.P., Komendantov G.A. \\ Influence of gymnastic on the body formation
}

Тамбовский государственный технический университет Tambov State Technical University

Рассматривается комплекс атлетической гимнастики. Утверждается, что атлетическая гимнастика стимулирует стремление к самовыражению через красоту тела.

The set of athletic gymnastics is considered. The author argues that the athletegymnastics stimulates the intension for the self-expression through the body beauty. 
Ключевые слова: рельефная мускулатура; красивые мышцьы; улучшение самочувствия.

Key words: relief muscles; beautiful muscles; improve health.

Всемирная организация здравоохранения, изучая здоровье людей, выделила причины, которые способствуют развитию различных заболеваний. Среди них основное значение имеют высокие темпы современной жизни; нервные стрессы и перенапряжение; избыточное несбалансированное питание, что приводит к ожирению; загрязнение воздушной и водной сред; алкоголизм; курение; наркомания. Поэтому важнейшей социальной задачей является оздоровление населения, так как половина факторов, которые определяют состояние здоровья современного человека, относится к его образу жизни. От правильного выбора занятий зависят результаты оздоровления организма. Атлетическая гимнастика - это традиционный вид гимнастики оздоровительно-развивающей направленности, которая сочетает силовую тренировку с разносторонней физической подготовкой, гармоническим развитием и укреплением здоровья в целом. В настоящее время наибольшую популярность имеют такие занятия, как боди-билдинг, культуризм, пауэрлифтинг, армрестлинг.

Боди-билдинг - это формирование мышечной мускулатуры, увеличение мышечных объемов. Те, кто занимается боди-билдингом, выступают на конкурсах и им присваиваются звания, например, «мистер Америка». Соревнования проводятся по определенным правилам, согласно которым оценивается, в первую очередь, силовая гармоничность.

Культуризм - это то же самое, что и боди-билдинг, с теми же принципами и правилами. Но культуризм был первым этапом в развитии боди-билдинга. Занятия культуризмом направлены на увеличение объемов отдельных мышечных групп. На конкурсах оценивается «самая широкая спина», «самые объемные бедра или шея» и т.д.

Пауэрлифтинг - это силовое троеборье, куда входят жим штанги лежа, приседание со штангой на плечах, тяга штанги в положение наклона вперед. Чтобы достичь максимального эффекта, необходимо выполнять упражнения в движении, а не в статических напряжениях.

Армрестлинг - это силовое единоборство на руках, проводится, сидя на стуле, хватом свободной рукой за специальную рукоятку и «кто кого перетянет». Главная задача армрестлинга - это положить руку соперника. Большая нагрузка ложится на мышцы спины, тазового пояса и ног.

В современном обществе всеми видами атлетической гимнастики занимаются также девушки и женщины.

Важнейшая черта атлетической гимнастики - за счет специальных упражнений у занимающихся формируются умения и навыки силовых перемещений собственного тела в различных режимах силовой нагрузки. Рассмотрим занятия атлетической гимнастикой с девушками как один из видов оздоровительной гимнастики, так как она находится на 3-м месте по ранговому выражению нагрузочности разных видов оздоровительных воздействий.

Почему-то у большинства девушек существует неправильное представление о женской атлетической гимнастике, что занятия с отягощением приведут к огромным мышцам. Это не так. В организме у девушек не вырабатывается гор- 
мон, который способствует росту мышечных структур, и поэтому развитие больших мышечных групп, по аналогии с мужчинами, невозможно. Занимаясь атлетической гимнастикой, девушка может ставить перед собой следующие задачи:

1) устранить те или иные дефекты фигуры;

2) сбросить лишний вес;

3) улучшить самочувствие;

4) повысить работоспособность;

5) иметь красивую осанку.

Но хорошую фигуру невозможно сформировать без силовых тренировок. Мышечная ткань активно сжигает калории даже в состоянии покоя, значит, чем больше ее масса, тем интенсивнее обмен веществ. Силовые упражнения помогут немного увеличить мышечную массу. Кроме того, с их помощью можно изменить фигуру, например, сделать грудь выше. А хорошо развитые мышцы спины не только улучшают осанку, но и зрительно делают талию тоньше.

Атлетической гимнастикой могут заниматься люди разного возраста (молодые, пожилые, юноши и девушки), но это должны быть практически здоровые люди, поскольку используются упражнения связанные с сильными напряжением. Атлетическая гимнастика удовлетворяет стремление людей иметь сильные красивые мышцы, рельефную мускулатуру. Она воспитывает у занимающихся привычку к систематическим выполнениям физкультурных упражнений, эффективно стимулирует стремление к самовыражению через красоту тела, служит средством активного отдыха.

Занимаясь регулярно атлетической гимнастикой, можно сформировать свое тело; добиться любых эффектов; улучшить прочность костей и связок; толщину хрящей и число капилляра в мышцах; улучшить здоровье и физическую подготовленность; увеличить гибкость, мощность и скорость; ослабить стресс, напряжение в повседневной жизни; контролировать вес и снижать жировую ткань; укреплять сердце; увеличивать уровень гемоглобина и количество красных кровяных телец. Занимаясь атлетической гимнастикой, можно снизить холестерин в организме.

Атлетическая гимнастика используется в группе специальных упражнений.

Первая группа - это упражнения без отягощений и предметов, что включает в себя продолжение сопротивления собственного тела: это, например, сгибание и разгибание рук в упоре лёжа, удержание напряженных рук в стороны.

Вторая группа - это упражнения силового характера. На снарядах, на перекладине, кольцах, брусьях выполняются упражнения в висе, в упоре, быстро и медленно. Эти упражнения задействуют разные группы мышц.

Третья группа - это упражнения с гимнастическими предметами определённой тяжести и эластичности; набивными мечами, эспандерами.

Четвёртая группа - это упражнения с отягощениями, например, гантелями, гирями, штангой. Упражнения с гантелями содержат различные симметричные и асимметричные движения руками в сочетание с наклонами, выпадами, приседаниями, позволяющими включить в работу большое количество мышечных групп и добиться достаточной нагрузки.

Пятая группа - это упражнения силового характера, которые выполняются в парах и в тройках: это простые и доступные упражнения, которые не требуют специальной технической подготовленности и выполняются в искусственно 
усложненных условиях. Один из партнеров создает определенное сопротивление действия для другого партнёра.

Шестая группа - это упражнения на тренажерах.

Начинать надо тренировки с одного подхода, когда мышцы привыкнут к нагрузке и окрепнут, можно переходить к увеличению подходов. Любой комплекс упражнений атлетической гимнастики состоит из подготовительной, основной и заключительной части.

Мы предлагаем следующий комплекс упражнений для начинающих заниматься атлетической гимнастикой.

Подготовительная часть состоит из упражнений без отягощений, чтобы разогреть мышцы: например, легкий бег, прыжки через скакалку, затем несколько упражнений на растяжку мышц.

Основная часть включает в себя упражнения с отягощениями:

1. Исходное положение (далее - И. п.) - стоя, ноги на ширине ступней, гантели в руках на уровне плеч. Жим гантелей до полного выпрямления рук.

Работающие мышцы - медиальный и тыльный дельтоид.

Повторения - 8-10 раз.

2. И. п. - стоя, ноги на ширине ступней, гантели в обеих руках, одновременно сгибание рук с гантелями, пока руки не окажутся у ваших плеч.

Работающие мышцы - бицепс, мышцы предплечья. Повторения - 8-10 раз.

3. И. п. - упор лежа, ладони на полу, пальцы смотрят вперед. Ноги и спина прямые. Сгибаем локти до касания грудью пола. Работающие мышцы - трицепс, бицепс, плечевая, мышцы и предплечья груди. Повторения - 10-15 раз (возможен облегченный вариант: отжимание с коленей).

4. И. п. - стоя, ноги врозь (или сидя ), держать гантели обеими руками за головой, локти согнуты и прижаты к голове. Разгибая руки, поднимаем гантели над головой. Сохраняем вертикальное положение плеч.

Работающие мышцы - трицепс, бицепс, мышцы предплечья.

Повторения - 8-10 раз.

5. И. п. - лежа на скамье, голова у края, плавно опускать руки с гантелями за голову, одновременно сгибая их в локтях. Повторения - 8-10 раз.

6. И. п. - стоя, ноги врозь, наклон вперед, тело почти параллельно полу, гантели в обеих руках прижаты к бокам. Разгибаем руки назад до параллели с полом.

Работающие мышцы - трицепс, бицепс, мышцы предплечья, грудные.

Повторения - 10-15 раз.

7. И. п. - лежа спиной на скамье, руки с гантелями согнуты в локтях, ноги согнуты в коленях. Поднимание гантелей вверх до полного выпрямления рук.

Работающие мышцы - передняя, малая, большая грудные, трапециевидная, бицепс, трицепс.

Повторение - 10-15 раз.

8. И. п. - лежа спиной на скамье, руки с гантелями выпрямлены над грудью. Разведение рук в стороны с гантелями. Работающие мышцы - передняя, малая, большая грудные, бицепс, трицепс. Повторения - 10-15 раз.

9. И. п. - ноги на ширине плеч, штанга лежит на полу. Наклонившись, беремся за штангу (одна рука сверху, другая снизу), медленно распрямляясь, поднимаем штангу от пола. 
Работающие мышцы - широчайшая, трапециевидная, ромбовидная, длинная спинная, ягодичная, квадрицепс.

Повторение - 8-10 раз.

10. И. п. - стоя, ноги врозь, руки с гантелями опущены вдоль туловища. Шаг вперед правой ногой как можно дальше, чтобы бедро оказалось параллельно полу. То же самое - с другой ноги.

Работающие мышцы - бицепс, квадрицепс, ягодичные.

Повторение - 8-10 раз.

11. И. п. - ноги на ширине плеч, в руках гантели. Приседание до уровня, когда бедра будут параллельно полу, затем поднимаясь из приседа, переходим на носки. Спину держим прямо.

Работающие мышцы - икроножная.

Повторение - 10-15 раз.

12. И. п. - ноги на ширине плеч, штанга (гриф штанги) на задней части шеи. Приседание со штангой, спина прямая.

Работающие мышцы - бицепс, квадрицепс, приводящие, тонкая, гребешковая, ягодичные, икроножная, камбаловидная.

Повторение - 8-10 раз.

Заключительная часть состоит из упражнений на расслабление и растяжку мышц.

1. И. п. - стоя, ноги на ширине плеч, руки согнуты, кисти обхватывают локти. Наклоняясь вперед, стараемся коснуться локтями пола. Делаем упражнение медленно, без резких движений.

2. И. п. - сидя на полу, ноги вместе. Тянемся медленно руками к пяткам и удерживаем тело в этом положение.

3. И. п. - сидя, ноги вперед. Перекат на спину, носками ног коснуться пола за головой.

4. И. п. - сидя на полу, ноги согнуты коленями в стороны, стопы вместе, руки на стопах. На счет «1»- с переходом на левое бедро опереться на левый локоть, правую ногу выпрямить вверх с помощью правой руки, «2-7» - пружинящие покачивания, «8» - и. п. То же другой ногой в другую сторону.

5. И. п. - то же. На счет «1-4» - наклон туловища вперед, руки вперед. «5$8 \gg$ - поставить руки на пол за спиной, прогнувшись.

Несколько советов - для занимающихся атлетической гимнастикой:

- полностью сконцентрируйтесь на упражнении, на той группе мышц, на которую его делаете;

- соблюдайте количество повторений, подходов;

- постепенно увеличивайте вес;

- учитесь дышать правильно при выполнение упражнений: при вдохе происходит движение (руки в стороны), при выдохе обратное движение (руки согнуты).

- между подходами - отдых по самочувствию.

Каждая девушка хочет быть красивой и каждая в глубине души не довольна своим телом. Регулярная физическая нагрузка поможет стать стройной. Без силовых тренировок невозможно сформировать хорошую фигуру. Занимайтесь атлетической гимнастикой, формируйте свое тело, и тогда успех будет обеспечен, вы обретете уверенность в себе. 
1. Антонюк С.Д., Макарова Л.Н., Мукина Е.Ю., Мистрюкова М.Н. Обоснование пространства двигательной культуры личности на основе принципа интеграции // Вестник Тамбовского государственного технического университета. 2006. T. 12. №2. С. 577-582.

2. Захаров Е.Н., Карасев А.В., Сафонов А.А. Энциклопедия физической подготовки. М.: Лептос, 1994. 2000.

3. Кеннеди Р. Базовые программы для массивных мышц. М.: Терра-спорт,

4. Кеннеди Р. Крутой культуризм. М.: Терра-спорт, 2000.

5. Керони С., Ренпен Э. Формирование тела со свободными отягощениями. М.: Терра-спорт, 2000.

6. Шестопалов С. Физические упражнения. Ростов н/Д: Проф-Пресс, 2001.

7. Павлов А. А. Бодибилдинг для начинающих. М.: РИПОЛ классик, 2008.

8. Физическая культура: Конспект лекций. М.: Приор-издат, 2006.

\title{
Шпагин С.В. \\ Комплексно-комбинированные занятия оздоровительной физической культурой для женщин различного возраста
}

\author{
Shpagin S.V. \\ Complex and combine lessons by sanitary physical \\ training for women of different age
}

Тамбовский государственный технический университет Tambov State Technical University

В статье дано теоретическое и экспериментальное обоснование эффективности применения комплексно-комбинированного типа организации занятий оздоровительной гимнастикой для учащейся молодежи. Продемонстрировано позитивное влияние продуктивного взаимодействия на удовлетворенность студенток занятиями оздоровительной гимнастикой; показана роль продуктивного педагогического взаимодействия между студентами и преподавателем на комплексно-комбинированных занятиях. Наглядно представлена роль комплексно-комбинированных занятий в формировании здорового образа жизни студенческой молодёжи.

The theoretical and experimental basis of effectiveness of complex and combine type of lessons organization by sanitary physical training for students is given in the 
paper. The positive influence of productive interaction on student women satisfaction by lessons of sanitary physical training is demonstrated. The role of productive pedagogical interaction between students and a teacher in complex and combine lessons is showed. The role of complex and combine lessons in development of students' healthy way of life is visually presented.

Ключевые слова: продуктивное педагогическое взаимодействие; оздоровительная гимнастика; студенческая молодежь; комплексно-комбинированные занятия.

Key words: productive pedagogical interaction; sanitary physical training; students; complex and combine lessons.

По проблеме педагогического взаимодействия в теории и методике оздоровительной физической культуры имеется значительный фонд знаний, неоднократно описанный в трудах отечественных и зарубежных ученых. Тем не мене, процесс физического воспитания в системе высшего образования изучен фрагментарно и требует дополнительного исследования $[2 ; 3 ; 4 ; 5]$. Недостаток адекватных форм организации физического воспитания является одной из основных причин, где педагогическое взаимодействие тренера и занимающихся могло бы проявить свой плодотворный резерв.

Целью проведенного исследования являлось опытно-экспериментальное и теоретико-методическое обоснование условий организации, содержания и структуры комплексно-комбинированных занятий оздоровительной физической культурой как в высших учебных заведениях, так и в оздоровительных секциях. Экспериментальную группу составил женский контингент [6;7].

Комплексно-комбинированные занятия оздоровительной физической культурой будут иметь эффект если подтвердится гипотеза исследования, заключающаяся в следующем:

- в занятиях будут использоваться как неурочные, так и урочные формы обучения;

- продуктивный подход тренера и занимающихся будет строиться на основе педагогического взаимодействия и организации занятий;

- продуктивное взаимодействие занимающихся и тренера будет основано на комплексе диагностических критериев эффективности.

168 студенток первого и второго курса (в возрасте 17-18 лет) выступали в качестве экспериментальной базы исследования, в том числе 25 студенток составляли контрольную и 23 студентки экспериментальную группу в процессе формирующего педагогического эксперимента. Женщины пенсионного возраста (55-65 лет), занимающиеся в секции физической культуры и оздоровительной гимнастики, составляли вторую базу общей численностью 54 человека.

Под плодотворным педагогическим взаимодействием в процессе комплексно-комбинированных занятий оздоровительной гимнастикой в вузе видится целесообразным восприятие личностного контакта студентов и преподавателя, который проявляется в двунаправленной коммуникации, посредством которой происходит трансформация физкультурной деятельности, установок и ценностных отношений к занятиям физической культурой в солидарность и согла- 
сие в понимании целей совместной физкультурно-оздоровительной работы. Это качественно повышает целенаправленность и продуктивность занятий [6; 7].

Под «продуктивностью» понимается нацеленность на положительный результат взаимодействия между педагогом и студентом и, как следствие, усвоение теоретических знаний и практических навыков оздоровительной работы, улучшение самочувствия, развитие двигательных способностей, ориентация на формирование здорового образа жизни, воспитание активной жизненной позиции и благоприятных социально-психологических установок.

Комплексно-комбинированное занятие, по объяснению Ю. В. Менхина и А. В. Менхина [2; 5], - форма организации процесса психофизического воспитания оздоровительно-развивающей направленности за счет использования обширного круга средств, влияющих на организм как на единый комплекс функциональных систем.

«Комплексность» подразумевает сочетание взаимосвязанных (однопорядковых, однокачественных) процессов или явлений. Фактически - это комплекс различных методов и средств в рамках установки развития двигательной сферы или данного вида оздоровительно-развивающей гимнастики.

Термин «комбинированность» предполагает агрегирование различных по возникновению, качеству, типу и нацеленности действия самостоятельных процессов или явлений. В раках проводимого исследования - это комплекс различных видов гимнастики, к которым относятся разные направления развития двигательной сферы или разнообразные системы оздоровления.

Предлагаются методические основы практического взаимодействия студентов и преподавателя в процессе работы комплексно-комбинированных занятий гимнастикой оздоровительно-развивающей направленности. Ключевым моментом исследования выступает увеличение продуктивности организации педагогического взаимодействия студентов и преподавателя в процессе комплекснокомбинированных занятий физической культурой и оздоровительной гимнастикой в рамках физического воспитания в высшем учебном заведении нефизкультурного направления.

В результате организации плодотворного взаимодействия преподавателя и студентов в процессе комплексно-комбинированных занятий оздоровительной гимнастикой является развитие устойчивой мотивации на необходимость в двигательной активности, польза занятий физической культурой, ориентация на здоровый образ жизни, укрепление здоровья, увеличение уровня работоспособности, стремление к реализации своих творческих способностей, что в целом эффективно отражается на общей успеваемости студентов.

Для организации взаимодействия студентов и преподавателя предлагается авторская комплексно-комбинированная программа занятий, которая была апробирована в ходе опытно-экспериментальной работы на группе студенток 1 и 2 курсов ФГБОУ ВПО «Тамбовский государственный технический университет». Урочная форма включала 2 занятия по 1ч. 30мин. (2 пары) в неделю. Неурочная форма включала в себя 2 вечерних занятия в неделю по 90 минут в рамках спортивно-оздоровительной группы «Шейпинг». Итого общая нагрузка составляла 8 ч. в неделю. Также девушки ежедневно в течение 15 мин. занимались утренней гигиенической гимнастикой в качестве самостоятельных занятий. 
Содержание занятий формировали упражнения из различных разделов оздоровительно-развивающей гимнастики: основная гимнастика - прыжковые упражнения, общеразвивающие упражнения, вольные упражнения, упражнения в равновесии, упражнения на гимнастических снарядах, акробатические упражнения, танцевально-хореографические упражнения с элементами художественной гимнастики, упражнения в тренажерном зале; атлетическая гимнастика упражнения с гантелями 2-3 кг., сгибание и разгибание рук в упоре лежа, подтягивания на низкой и высокой перекладинах; щейпинг - разминочные, основные и восстановительные упражнения на мышцы бедра, тазовой области, туловища и плечевого пояса; ритмическая гимнастика - умеренные движения головой, руками и туловищем в связке по 5-6 упражнений с музыкальным сопровождением, комбинация циклических действий (беговые упражнения, подскоки, прыжки, танцевальные шаги); аэробика (непрерывный вариант занятия) - различные разновидности шагов, бег на месте и с перемещениями, движения бедер в различных направлениях, махи ногами, выпады, подскоки со сменой положения ног, скрестные движения; стретчинг - упражнения на «растяжку» мышц внутренней, боковой и задней поверхностей бедер, туловища, спины, «гимнастика суставов»; элементы восточной оздоровительной гимнастики - ци-гун, ушу, хатха-йога; дыхательная гимнастика - элементы методики О. Лобановой, Е. Поповой, метода К. П. Бутейко, методики А. Стрельниковой. утренняя гигиеническая гимнастика - комплексные упражнения на основные мышечные группы и суставы в невысоком темпе.

Составлялись комплексно-комбинированные программы занятий в зависимости от цикла годичного периода, разнообразные по содержанию и структуpe, что позволяло дозировать психологическую и физическую нагрузку и управлять оздоровительным эффектом (табл. 1).

Таблица 1. Примерная программа комплекснокомбинированных занятий оздоровительной гимнастикой

\begin{tabular}{|c|c|c|c|c|}
\hline $\begin{array}{c}\text { Неделя } \\
\text { месяца }\end{array}$ & 1 занятие & 2 занятие & 3 занятие & 4 занятие \\
\hline 1 & $9,1,3,4,6$ & $9,1,4,5,7$ & $9,1,2,3,6$ & $9,1,4,6,7$ \\
\hline 2 & $9,1,3,4,6$ & $9,4,6,7$ & $9,1,2,3,8$ & $9,2,5,6$ \\
\hline 3 & $9,1,5,8$ & $9,2,4,7$ & $9,1,5,6,7$ & $9,2,4,6,8$ \\
\hline 4 & $9,1,3,8$ & $9,2,3,7$ & $9,4,6,7,9$ & $9,5,7,8$ \\
\hline
\end{tabular}

Основная задача анализа результатов опытно-экспериментальной работы оценка эффективности плодотворного взаимодействия студентов и преподавателя в процессе комплексно-комбинированных занятий оздоровительной гимнастикой. При организации комплексно-комбинированных занятий мы предполагали, что если в ходе их реализации будет зафиксирована возрастающая динамика данных показателей, то эта модель имеет эффект.

Определение удовлетворенности студенток занятиями физической культурой в виде комплексно-комбинированных занятий оздоровительной гимнастикой на основе вычисления индекса показывает, что до начала практической работы значимых различий в экспериментальной и контрольной группах не наблюдалось. В процессе комплексно-комбинированных занятий оздоровительной гимнастикой после внедрения нами модели организации продуктивного 
взаимодействия в экспериментальной группе выявлены изменения, в то время как в контрольной, где занятия велись по стандартным методикам, изменений не произошло (табл. 2).

Следовательно, удовлетворенность занятиями физической культурой по завершении опытно-экспериментальной работы в экспериментальной группе существенно увеличилась, вместе с тем в контрольной эти изменения были не столь значимы. Респонденты экспериментальной группы не только удовлетворены занятиями по физической культуре и оздоровительной гимнастике, стремятся посещать все занятия (заметно улучшилась посещаемость), но и высказывают желание, чтобы занятия и впредь проходили в комплекснокомбинированном виде.

Таблица 2. Удовлетворенность студенток занятиями физической культурой в виде комплексно-комбинированных занятий оздоровительной гимнастикой (в \% от числа опрошенных)

\begin{tabular}{|l|c|c|c|c|}
\hline \multirow{2}{*}{$\begin{array}{c}\text { Индекс удовлетво- } \\
\text { ренности }\end{array}$} & \multicolumn{2}{|c|}{ До эксперимента } & \multicolumn{2}{c|}{ После эксперимента } \\
\cline { 2 - 5 } & Э.Г. & К.Г. & Э.Г. & К.Г. \\
\hline Низкий & 15 & 14 & 2 & 10 \\
\hline Ниже среднего & 39 & 38 & 9 & 29 \\
\hline Выше среднего & 36 & 39 & 58 & 45 \\
\hline Высокий & 10 & 9 & 31 & 16 \\
\hline ИТОГО & 100 & 100 & 100 & 100 \\
\hline
\end{tabular}

Студентки отмечают, что заниматься физической культурой и оздоровительной гимнастикой в вузе очень интересно, они всегда могут свободно высказывать свою точку зрения, многие считают, что занятия помогают самореализоваться, в вузе созданы все условия для развития физической культуры, а в трудной ситуации студенты могут обратиться за помощью и к преподавателю. Респонденты подчеркивали, что на комплексно-комбинированные занятия они теперь ходят не только потому, что им нравится общаться с однокурсниками, но и потому, что им нравится организация занятий оздоровительной гимнастикой. Большинство студенток убеждены, что занятия физической культурой помогают формированию здорового образа жизни.

В процессе внедрения комплексно-комбинированных занятий оздоровительной гимнастикой нами были получены следующие результаты анкетирования. Систематически следят за состоянием своего здоровья 73\% участников экспериментальной группы; 78\% считают физическую культуру неотделимым элементом здорового образа жизни; интересуются спортом и занятиями физической культурой 75\% опрошенных; хотели бы заниматься спортом 81\% опрошенных. По данным опроса, из причин, препятствующих занятиям физической культурой и спортом, респонденты наиболее часто указывают нехватку секций по любимым видам спорта в вузе (18\%); недостаток свободного времени (36\%). Результаты в контрольной группе вследствие повторной диагностики существенно не поменялись.

Распределение ценностных направлений студенток вуза по отношению к занятиям физической культурой и оздоровительной гимнастике (контрольная и экспериментальная группы) перед началом опытно-экспериментальной работы указывает на то, что на первом этапе диагностики ведущей ценностью занятий 
является «Возможность общения с сокурсниками», на втором - по важности ценность «Возможность помочь друзьям», на третьем - «Возможность общения с преподавателем» (табл. 3).

\section{Таблица 3. Ценностные ориентации испытуемых}

до и после эксперимента (баллы)

\begin{tabular}{|c|c|c|c|c|}
\hline \multirow{2}{*}{$\begin{array}{l}\text { Ценностные } \\
\text { ориентации } \\
\text { на занятиях }\end{array}$} & \multicolumn{2}{|c|}{$\begin{array}{c}\text { До } \\
\text { эксперимента }\end{array}$} & \multicolumn{2}{|c|}{$\begin{array}{c}\text { После } \\
\text { эксперимента }\end{array}$} \\
\hline & Э.Г. & К.Г. & Э.Г. & К.Г. \\
\hline $\begin{array}{l}1 . \text { Совершенствовать уже имеющиеся знания и } \\
\text { умения для занятий физической культурой }\end{array}$ & 3,7 & 3,5 & 5,9 & 3,3 \\
\hline $\begin{array}{l}\text { 2. Приобрести новые знания, умения и навыки вы- } \\
\text { полнения физических упражнений }\end{array}$ & 3,0 & 3,1 & 5,9 & 3,0 \\
\hline 3. Возможность помочь друзьям & 4,9 & 5,0 & 5,5 & 1,4 \\
\hline 4.Личностная самореализация & 1,2 & 1,0 & 5,4 & 1,2 \\
\hline $\begin{array}{l}\text { 5. Возможность лично участвовать в различных } \\
\text { спортивных мероприятиях }\end{array}$ & 1,0 & 1,2 & 4,9 & 1,2 \\
\hline 6. Возможность общения с сокурсниками & 5,8 & 5,6 & 4,8 & 5,2 \\
\hline 7. Возможность общения с преподавателями & 4,5 & 4,8 & 5,8 & 4,7 \\
\hline
\end{tabular}

Далее по уровню важности следуют ценности «Возможность личностной собственной самореализации в процессе комплексно-комбинированных занятий оздоровительной гимнастикой», однако их ступени находятся на среднем или ниже среднего уровнях, это говорит о том, что испытуемые не верят в доступность самореализации на занятиях. На самом последнем месте расположились ценности «Совершенствовать уже имеющиеся знания и умения», «Приобрести новые знания и умения для занятий физической культурой».

Мы связываем подобное расположение ценностных ориентации с отсутствием интереса к занятиям с целью пополнения знаний, так как они анализируются не с точки зрения их необходимости в жизни, а только как необходимость межличностного общения с преподавателем и однокурсниками.

После окончания опытно-экспериментальной работы наблюдались количественные и качественные изменения ценностных ориентаций студенток экспериментальной группы, в то время как ярко выраженных изменений в контрольной группе не проявилось.

Таким образом, действенность исследованных нами основ продуктивного взаимодействия студентов и преподавателя в комплексно-комбинированном аспекте занятий оздоровительной гимнастикой отразилась в повышении мотивации и увеличении интереса студентов к занятиям физической культурой и спортом, улучшении прочности знаний, а также в вооружении студентов практическими умениями для поддержания и сохранения здоровья, вовлечение студентов к участию в спортивных мероприятиях вуза, активизация студентов для занятий физической культурой и спортом во внеучебное время.

Проведенная нами опытно-экспериментальная работа подтвердила эффективность разработанной модели продуктивной взаимосвязи в процессе комплексно-комбинированных занятий оздоровительной гимнастикой, его положительное воздействие на формирование у студентов потребности в двигательной деятельности, положительного расположения к физической культуре и ценностной ориентации на здоровый образ жизни. Таким образом, по окончании экспе- 
римента $73 \%$ студенток стали бережно следить за состоянием своего здоровья, $78 \%$ - считают физическую культуру неотъемлемым и неотделимым элементом здорового образа жизни, 75\% - проявили интерес к самостоятельным занятиям оздоровительной гимнастикой, $81 \%$ - изъявили желание участвовать в занятиях спортом каких-либо секциях.

Подготовленная нами программа комплексно-комбинированных занятий гимнастикой оздоровительно-развивающей направленности, основанная на научно подтвержденных методических принципах и опытно-экспериментально проверенных структуре и содержании, увеличила эффективность физического воспитания студентов в вузе, доказала свою продуктивность на основе эффективного педагогического взаимодействия, что выразилось в рефлексивном, мотивационном и информационно-познавательном компонентах модели.

Продуктивное взаимодействие открывает большие ракурсы для совершенствования всей системы физкультурного образования в высшем учебном заведении, для развития новой гуманистической концепции взаимодействия «студент + преподаватель», которая может привнести реальный вклад в процесс его гуманизации за счет преодоления ограниченности одностороннего подхода к студенту как объекту педагогического воздействия.

1. Антонюк С. Д., Макарова Л. Н., Мукина Е. Ю., Мистрюкова М. Н. Обоснование пространства двигательной культуры личности на основе принципа интеграции // Вестник Тамбовского государственного технического университета. 2006. Т. 12. №2. С. 577-582.

2. Менхин А. В. Рекреационно-оздоровительная гимнастика: учебное пособие. М: Физическая культура, 2007. 160 с.

3. Менхин Ю. В., Биндусов Е. Е., Попадъина Л. В. Оздоровление людей среднего возраста, занимающихся умственным трудом. Учебное пособие / Гос. ком. РФ по физ. культуре и туризму. Малаховка: МГАФК, 1999. 163 с.

4. Менхин Ю. В., Менхин А. В. Комбинированные и комплексные упражнения. Учебное пособие. Малаховка: МГАФК, 1999. 64 с.

5. Менхин Ю. В., Менхин А. В. Оздоровительная гимнастика: теория и методика: учебник для институтов физической культуры. Ростов на Дону: Феникс, 2002. $382 \mathrm{c}$.

6. Шибкова В. П., Симонов С. Н. Здоровье и здоровый образ жизни современной студенческой молодежи (результаты собственных наблюдений) // Вестник Тамбовского Университета. Серия Гуманитарные науки. Тамбов, 2009. Т. 14. Вып. 1. С 79-83.

7. Шибкова В. П., Симонов С. Н. Педагогическое взаимодействие преподавателя и студента, как ведущий компонент занятий физической культурой. // Физическая культура и спорт - основа здорового образа жизни: материалы V Всероссийской научно-практической конференции (заочной), 21 марта 2008 г. Тамбов: ЗАО «НПО ПК «Спектр», 2008. С. 126-131. 


\title{
Раздел II. \\ ГУМАНИТАРНЫЕ И \\ ОБЩЕСТВЕННЫЕ НАУКИ
}

\section{Атаев Э.Б., Толстяков Р.P. Специфика маркетинговой среды на рынке строительных услуг}

\author{
Atayev E.B., Tolstyakov R.R. \\ Specifics of marketing environment \\ on the market of civil
}

Тамбовский государственный технический университет, Tambov State Technical University

В статье рассматриваются факторы микро- и макромаркетинговой среды применительно к предприятиям строительной сферы. Отражена специфика строительной услуги как объекта маркетинговых усилий. Определены соииально-экономические связи, возникающие между субъектами строительного рынка по поводу оказания строительной услуги.

The factors micro- and macromarketing environment in relation to the enterprises of the construction sector. It reflects the specificity of construction services as an object of marketing efforts. Determine the social and economic relations arising between subjects of the construction market arising on the provision of construction services.

Ключевые слова: маркетинг строительных услуг; субъекты строительного маркетинга; факторы микро- и макросреды строительного рынка.

Key words: marketing of civil; marketing subjects of civil; factors of micro- and macro- civil market.

Любая страна заинтересована в устойчивом развитии строительной отрасли, которая обеспечивает занятость большой части населения и является одной из важнейших сфер предпринимательской деятельности. Кроме того, она позволяет поддержать социальную стабильность общества в целом. Инвестиции в строительство в развитых странах составляют не менее $20 \%$ валового национального продукта [1].

В условиях текущего экономического кризиса наблюдается существенный спад в строительной отрасли Российской Федерации, что приводит к тому, что большинство строительных предприятий решают единственную проблему - 
«как выжить». И лишь немногие организации формируют долгосрочные стратегические планы.

Наверное, ни для кого не секрет, что все же основной целью стратегии строительного бизнеса остается получение долгосрочных конкурентных преимуществ, способных обеспечить помимо выживания еще и устойчивую деятельность организации, а также развитие в обозримом будущем. И вот здесь, отталкиваясь от опыта отечественных и аналогичных зарубежных организаций, можно сказать, что самой эффективной концепцией современных бизнесменов является маркетинговая деятельность в строительстве, которая превыше всего ставит потребности и запросы конечных потребителей [7].

В связи со спецификой развития строительного рынка (муниципальные и государственные заказы, острая нехватка жилья, государственное субсидирование и поддержка, кредитные преференции) применение маркетинга осуществляется фрагментарно, так как в отличие от других отраслей наблюдается доминирование спроса над предложением [3]. Кроме того, присутствует ряд общих тенденций развития российского маркетинга.

Во-первых, более раннее становление экономики западных государств привело к тому, что российский рынок испытывает определенное воздействие своих иностранных партнеров.

Во-вторых, опыт маркетинга тех же западных стран, который пытаются приспособить, не всегда применим на российском специфическом рынке.

В-третьих, в России господствует низкий уровень образования маркетологов: обучение производится по зарубежным изданиям, так как в нашей стране учебная база, применимая к реалиям российского рынка, еще не наработана. Как уже было сказано, зачастую применение зарубежного опыта нецелесообразно или невозможно, в том числе и из-за менталитета русских людей.

В-четвертых, недостоверность маркетинговых исследований - недостаточность информации для проведения исследований - приводит к тому, что результаты однотипных исследований разными маркетологами могут быть противоречивыми. Кроме того, строительные организации могут прибегать к неофициальному ведению бизнеса, что еще больше снижает достоверность исследований.

В-пятых, многие российские предприниматели привыкли доверять деловому чутью и не видят смысла вкладывать средства в проведение маркетинговых исследований [4].

И в последних, одной из значительных причин отсутствия использования маркетинговой деятельности российских предприятий является то, что в результате высокого налогового гнета им выгоднее большую часть своего бизнеса проводить «неофициально», не показывая при этом своих действительных оборотов. Маркетинговые же действия в этих условиях могут только помешать такому методу ведения бизнеса.

Для систематизации маркетинговой деятельности необходимо определить, что будет выступать ее объектом. Фактически - это объекты недвижимости, предлагаемые к реализации строительными фирмами.

Можно выделить:

- дома: многоэтажные, малоэтажные, коттеджи; 
- специальные здания: школы, детские сады, театр, цирк, санаторий, милиция, больницы, пожарная часть;

- промышленные здания: заводы, фабрики, тюрьмы;

- военные объекты и т.д.

Исходя из этой точки зрения, можно сказать, что строительная продукция от других видов продукции имеет ряд отличительных особенностей:

1. Стационарность, неподвижность.

2. Масштабность и разносторонность.

3. Многообразие создаваемой продукции.

4. Разнообразие предметов и средств труда.

5. Строительная продукция в большинстве своем создается вне помещений, на открытом воздухе, в различных геологических, гидрогеологических и климатических условиях.

Эти особенности при создании строительной продукции требуют различных методов исследования маркетинговой деятельности в строительстве [2].

Маркетинговая среда фирмы - это совокупность активных субъектов и сил, действующих за пределами фирмы и влияющих на возможности руководства службой маркетинга устанавливать и поддерживать с целевыми клиентами отношения успешного сотрудничества. Маркетинговая среда любой отрасли, в том числе и строительной, слагается из микросреды и макросреды.

Микросреда строительной фирмы, организации представлена силами, имеющими непосредственное отношение к самой фирме и ее возможностям по обслуживанию (Рис.1):

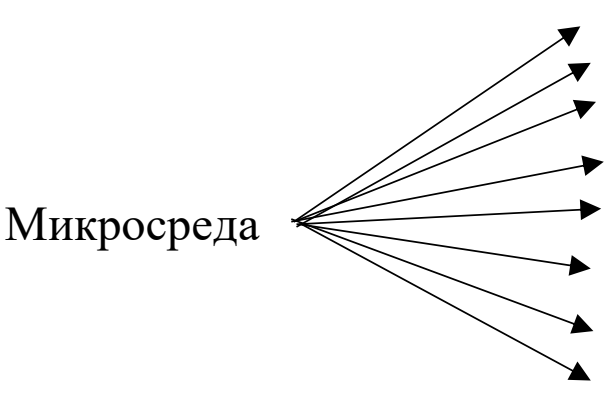

Проектировщики

Заказчики

Поставщики

Строительные организации Маркетинговые посредники

Клиентура

Конкуренты

Контактные аудитории

\section{Рис. 1. Факторы микросреды строительного рынка}

Рассмотрим каждую из сил, действующих в рамках микросреды строительной организации:

1. В качестве проектировщика в России действуют различные юридические и физические лица - независимо от форм собственности, - которые имеют лицензию.

2. Заказчики (инвесторы) - субъекты инвестиционной деятельности, принимающие решение о вложении собственных, заемных и привлеченных имущественных и интеллектуальных ценностей в объекты инвестирования

3. Поставщики - это юридические и физические лица, в качестве которых могут выступать отдельные организации и лица по обеспечению строительных организаций и объектов материальными ресурсами и оборудованием для создания строительной продукции. Поставки осуществляются заказчиком (прямые) и подрядными организациями (по субподряду). 
4. Строительная фирма, организация. В России строительные организации представлены большим перечнем организационных структур, зависящих от вида деятельности, объемов выполняемых работ, видов работ, конструктивов, района деятельности и т. д. Наиболее прогрессивными и распространенными за рубежом являются проектно-строительные фирмы, которые занимаются проектированием и строительством. Такие организации имеют перспективу распространения в России. При разработке маркетинговых планов службы маркетинга строительной фирмы должны учитывать интересы других подразделений фирмы и высшего руководства, которые и составляют микросреду самой фирмы.

5. Маркетинговыми посредниками в продвижении и сбыте строительной продукции являются аукционы, фирмы недвижимости, рекламные и информационные агентства по оказанию маркетинговых услуг и кредитно-финансовые учреждения.

6. Клиентура. В качестве клиентуры строительных организаций выступают различные типы рынков. Строительный рынок товаров и услуг условно можно разделить на следующие пять типов рынков:

- потребительский рынок;

- рынок предприятий;

- рынок посредников;

- рынок государственных организаций;

- международный рынок.

7. Конкуренты - это физические и юридические лица, которые борются между собой за получение максимальной прибыли.

8. Контактные аудитории. В состав маркетинговой микросреды строительной фирмы входят различные контактные аудитории фирмы:

- контактные аудитории государственных учреждений. Руководство фирмы должно учитывать все то, что происходит в государстве и должно откликаться на проблемы безопасности строительной продукции, истины в рекламе и т. д.

- финансовые круги, которые оказывают влияние на способность строительной организации обеспечивать себя капиталом: это банки, инвестиционные компании, брокерские фирмы, фондовые биржи, аукционы;

- различные информационные структуры, распространяющие новости, статьи и т.д. о строительной продукции;

- широкая публика (потребители). Строительной организации необходимо постоянно следить за отзывами и отношением потребителей (публики) к строительной продукции и к своей деятельности. Для создания своего имиджа фирма должна участвовать в благотворительных взносах и т.д.

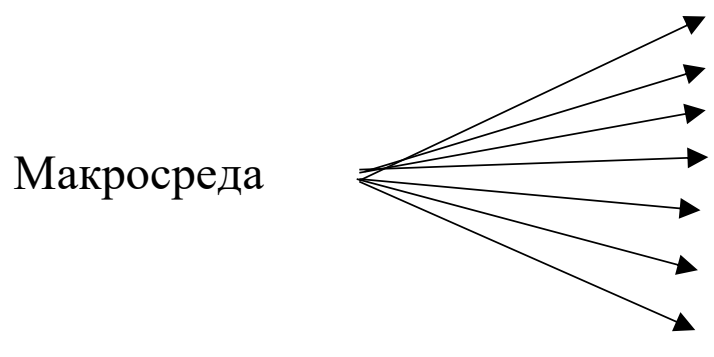

Рис. 2. Факторы макросреды строительного рынка

Правовая среда Политическая среда Экономическая среда Социальная среда Технологическая среда Экологическая среда Демографическая среда 
Макросреда строительной фирмы - это силы более широкого социального плана, которые однонаправленно влияют на развитие как отдельной строительной организации, так и отрасли в целом (рис.2).

Приведем характеристику основных элементов макросреды:

1. Правовая среда включает в себя законы и постановления, регулирующие деятельность отрасли и предприятия. Правовые акты регулируют условия труда и минимальный уровень социальной защищенности сотрудников. От судебной и исполнительной систем власти зависит защищенность и благополучие предприятия, например, в случае неблагонадежности или недобросовестности партнеров.

2. Политическая среда сильно сказывается на маркетинговых отношениях и в первую очередь определяет стабильность экономической, правовой и социальной среды. Она складывается из правовых актов и государственных учреждений, организаций, влиятельных групп общественности и т. д., которые оказывают влияние на различные организации и отдельных лиц, ограничивая их свободу действий в рамках общества.

3. Экономическая среда. Для рынка строительной продукции важно не только наличие самих покупателей и их покупательская способность, возможности, но и уровень их текущих доходов, цен, сбережений, а также доступность кредита. Реакция маркетинга на экономическую среду - это, по сути, реагирование на покупательскую способность потребителей.

4. Социальная среда обусловлена требованиями обеспеченности трудящихся определенным набором услуг, льгот и т. д., кроме того, предприятие имеет определенные социальные обязательства не только перед коллективом, но и перед местным сообществом. Так, местные власти ждут от предприятия проведения политики расширения, а не сокращения рабочих мест.

5. Технологическая (отраслевая) среда связана с уровнем технического процесса и уровнем инновационной деятельности в строительной отрасли. Развитие научно-технического прогресса должно быть направлено на службу человеку. Участникам рынка необходимо разбираться в изменениях, происходящих в научно-технической среде и реагировать на возможные негативные аспекты любой новой идеи, которая может обернуться ущербом для потребителя, вызывать их недоверие и противодействие.

6. Экологическая среда. Промышленная деятельность, без принятия соответствующих мер по защите окружающей среды, отрицательно сказывается на воздушном бассейне, водных ресурсах, растительном и животном мире.

7. Демографическая среда является предметом изучения маркетологов, так как оказывает большое влияние на рынок строительной продукции, структуру и динамику спроса. Так, по-разному деньги тратят пожилые и молодые, мужчины и женщины, женатые и холостые, имеющие детей и не имеющие. Изменение демографических факторов хорошо прогнозируемо. Можно заранее указать на процентный и абсолютный состав населения по полу, возрасту, отношению к браку и количеству детей [6]. 
1. Бочкарев А., Кондратьев В., Матвеева А. 7 нот менеджмента. Настольная книга руководителя. М.: Эксмо., 2008. 964 с.

2. Быковская Е. В. Стратегический менеджмент: Метод. указ. Тамбов: Издво Тамб. гос. техн. ун-та, 2005. 16 с.

3. Злобина Н. В. Экономика качества. Учебное пособие. Тамбов: Издательство ТГТУ, 2009. $111 \mathrm{c}$.

4. Голдрат Э. Цель. Процесс непрерывного улучшения. Киев: ИД «Максимум», 2009. $203 \mathrm{c}$.

5. Деминг Э. Выход из кризиса: Новая парадигма управления людьми, системами и процессами. М.: Альпина Паблишер, 2011. 417 с.

6. Фролова Т. А. Экономика предприятия: Конспект лекций. Таганрог: ТРТУ, 2009. $179 \mathrm{c}$.

7. Чепурин М. Н. Курс экономической теории. Киров: АСА, 2009. 832 с.

\title{
Бородулина Н.Ю., Гуляева Е.А., Макеева Д.Д. Лингвокогнитивные характеристики профессионального языка архитекторов: переводческий аспект
}

\author{
Borodulina N.Yu., Gulyaeva E.A., Makeeva D.D. \\ Linguo-cognitive characteristics of the professional \\ language of architects: translational aspect
}

Тамбовский государственный технический университет Tambov State Technical University

Дается характеристика профессионального языка архитекторов как включающего не только терминологический аппарат и профессиональную лексику, но и выразительные средства языка, такие как метафора, сравнение, эпитет. Подчеркивается значение для переводчика понимания замысла продуцента архитектурного текста, основанного на образных ассоциациях, а также поиск адекватных способов передачи используемых автором (архитектором) выразительных средств на русский язык.

The characteristics of the professional language of architects as including not only the terminological definitions and professional vocabulary but also the expressive means of the language such as metaphors, similes, epithets is given in the article. Emphasis is laid on the importance for a translator to understand the message of an architectural text which is based on figurative associations as well as the search of adequate ways of translation of the expressive means used by the author (architect) into Russian. 
Ключевые слова: язык для специальных ичелей, образность, смысл, языковые соответствия и эквиваленты, перевод.

Keywords: language for specific purposes, imagery, meaning, linguistic correspondences and equivalents, translation.

Отечественные и зарубежные лингвисты уделяют особое внимание характеристике языка для специальных целей (ESP или LSP), который представляет собой систему лексических средств национального языка, структуру знаний о той или иной научной или профессиональной области, выраженную, главным образом, терминами и профессионализмами $[2 ; 3 ; 4 ; 5]$. Французский язык использует понятия «langue de spécialité» / язык специальности и «langues spécialisées» / специальные языки $[1 ; 6 ; 7 ; 8]$. Среди языков для специальных целей, на наш взгляд, менее всего исследован профессиональный язык архитекторов. И это не вполне оправданно, поскольку достижения в области архитектуры и особенно архитектурные проекты последних лет являются предметом обсуждения в профессиональной среде (а это не только архитекторы, но и экономисты, строители, техники, декораторы), а также вызывают интерес у обывателей и тех, для кого данные проекты предназначены (жильцы, офисные работники и т.п.).

Профессиональная коммуникация архитекторов может быть выражена, в частности, в текстах, описывающих достижения и проекты, поражающие смелостью инженерной мысли и новаторством решений. Во французском языке появилось выражение «la folie d'architecture» / «безумие архитектуры», которое передает креативный полет мыслей современных архитекторов. Их творческие идеи вербализуются в архитектурных текстах не только за счет использования слов естественного языка и терминологического аппарата, но и с помощью различных образных языковых средств (метафор, метонимий, эпитетов, сравнений, перифраза и др.), что имеет когнитивно обусловленный характер, связанный с особенностями мышления человека, его индивидуальной и коллективной памятью, лингвокультурными смыслами.

Целью настоящей статьи является демонстрация возможностей переводчика профессиональной коммуникации в передаче смысла текста через обращение к образному замыслу архитектора. Предполагается, что этот замысел повторяется в лингвистическом оформлении текста; на выбор языковых средств оказывают значительное влияние образные ассоциации автора, проявляющиеся в употреблении наряду с профессиональной лексикой таких лексических единиц, как метафора, сравнение и эпитет. Поиск языковых соответствий и эквивалентов, позволяющих сохранить образность, представляет одну из важных задач переводчика. Для этого необходимо не только иметь знания о стилистических особенностях языка переводимого текста (в нашем случае французского), уметь вычленять их среди других языковых средств, но и находить соответствия и эквиваленты в родном языке, добиваясь адекватного перевода.

В качестве иллюстративного материала были выбраны тексты по архитектуре, описывающие современные французские и немецкие детские садики и ясли, созданные по проектам известных архитекторов Томи Унгерера, Поля ле Куэрнека и Мишеля Грассо. Были выявлены и проанализированы использованные в текстах выразительные средства языка (метафоры, эпитеты, сравнения), пред- 
ложены способы их перевода на русский язык. Представляется также важным понимание того, что выбор данных выразительных средств языка имеет лингвокогнитивное обоснование: через язык автор передает образ, порожденный его творческими фантазиями; ассоциации, вызванные в памяти и связанные с особенностями креативного мышления, задают тон повествования и определяют ту смысловую область, которая служит источником создания оригинальных языковых конструкций («клеточная архитектура» яслей, имитирующая форму женской клетки, в небольшом французском городе Саргемин, а также детский садкошка в Германии, навеянный образом любимого животного архитектора).

Проанализированные тексты («Ясли в Саргемин» [9], «Волшебный пузырь» [10] и «Детский сад кошка» [11]) могут быть охарактеризованы с лингвокогнитивной точки зрения как тексты-метафоры. В первых двух текстах через призму женской клетки раскрываются все функциональные особенности конструкции. С помощью сравнений и метафор авторы передают свою клеточную концепцию [9]: «Nous avons imaginé l'ensemble comme un organisme cellulaire, avec son noyau (la crèche), son cytoplasme (ses jardins), et sa membrane (son enceinte)» / Мы представляли себе конструкцию как клеточный организм с ее ядром (яслями), цитоплазмой (группами), мембраной (корпусом). Прямая номинация «concept utérin» / «маточная концепция» и эпитет «entrée «vaginale» / «вагинальный» вход» свидетельствуют о том, что в основе текста-метафоры находится ассоциация с женской клеткой, маткой. Понятным становится метафорический образ яслей, описываемый следующим образом: «Deuxième élément: la crèche. Flottante dans son enceinte, elle accueille le visiteur...». Хотя существительное enceinte имеет значение «ограда, крепостная стена, корпус», оно используется и когда речь идет о беременной женщине. Поэтому переводчик может употребить сравнение с материнским чревом: «Второй элемент - это ясли, которые как бы плавают в чреве матери, встречая своего посетителя ...». Далее такие переводческие трансформации, как конкретизация, лексические и грамматические замены, добавление слов, прием смыслового развития помогают не только передать идею авторов (архитекторов) - маточную концепцию яслей, но и подготовить к развиваемой далее мысли о том, что в этих яслях ребенок находится под защитой, схожей с материнской, как бы продолжает свою жизнь в чреве матери, поскольку здесь создается «effet de renforcer encore l'efficacité de surveillance» / «эффект усиления эффективности контроля»; само здание предстает как «bâtiment d'inspiration organique» / вдохновенное и органичное здание, которое «se fait protecteur et se protège de l'extérieur / «предстает как защищающее и защищенное от внешнего мира».

Для метафоры, стоящей в заголовке второго текста «la bulle enchantée» [10], переводчик подбирает эквивалент «волшебный пузырь», каковым и представляется для детей и взрослых по идее архитекторов маточная конструкция яслей в Саргемин. Ассоциация с волшебством подчеркивается лексическими средствами из данной смысловой области: глаголами (imaginer / воображать, придумывать; percevoir / чувствовать, ощущать себя), существительными (transition / превращение), словосочетаниями (jeu de plafonds / манипуляции с потолками; créer une variété d'espaces et de volumes / играть с пространством и с объемами). Наконец, простая функциональная идея предохранения здания от перегрева с помощью создания бамбукового покрытия передается авторами тек- 
ста через метафору «manteau végétal de bambous» / растительное пальто из бамбука, которая полностью сохраняется при переводе, но заключается переводчиком в кавычки, что подчеркивает ее необычность для русского реципиента: «... habiller le bâtiment d'un manteau végétal de bambous, ne laissant apparaître que de grandes lucarnes venant prendre la lumière»/ одеть здание в «растительное пальто из бамбука», оставляя видимыми только большие слуховые окна, в которые поступает свет.

Образы животных нередко использовались современными архитекторами в их необычных творческих проектах: например, экстравагантный дом-улитка в Софии, необычный отель в виде собаки в США, магазинчик в форме белой утки в США (именно утку там и можно купить), огромный желтый жираф, выполняющий роль опоры в детском центре недалеко от Парижа и т.д.

Нами были исследованы языковые средства, используемые в текстеметафоре, навеянном образом кошки, любимом животным архитектора Томи Унгерера [11]. В тексте подчеркивается «обучающая» идея художника, который «a choisi son animal préféré pour réaliser une école hors norme» / выбрал образ любимого животного, чтобы реализовать идею необычного обучения. Эта идея прослеживается во всем, даже сам архитектор называет посещение садика детьми «la visite anatomique» / «анатомический визит». Необычные сравнения полностью сохраняются при переводе: «A la manière d'une souris qui se fait avaler, les enfants entrent par la bouche du matou / Подобно мышкам, которые будут проглочены, дети входят через рот кошки; «Accroupi tel un sphinx, il guette sa proie...» / На корточках, как сфинкс, кошка высматривает свою добычу.

Через многочисленные метафоры в тексте дается описание здания и помещений: вход в сад - это рот кошки («la bouche»); высунутый язык кошки («la langue dépliée») - это лестница, по которой дети поднимаются в ее голову («la tête du chat»), где находится главный зал. Уши и глаза - это окна, через который проникает свет («une salle principale, baignée de lumière par les yeux et les oreilles» / главный зал, залитый светом через глаза и уши). Живот кошки («le ventre») это раздевалки, классная комната, кухня, столовая и лестницы. Эвакуационный выход - это хвост кошки («la queue»), где дети-мышки по горке съезжают вниз («les souris sont évacuées en cas de secours par le dessous de la queue»). При переводе все образные средства сохраняются, образ полностью калькируется.

Анализируемые тексты являются отражением креативного мышления творческих людей, они требуют особого подхода и не менее нестандартного мышления самого переводчика. Понимание и осмысление придуманных архитектором образов, осознание их повторения в тексте метафорическими средствами из аналогичной смысловой области значительно облегчает работу переводчика, позволяет сохранить образность через такие способы, как калькирование, прием смыслового развития, поиск эквивалентов и соответствий.

Теоретическая значимость проведенного анализа заключается в том, что он вносит вклад в проблему исследования текстов по специальности (LSP) вообще и текстов по архитектуре в частности, в понимание профессиональной коммуникации, как выраженной не только через терминологический аппарат, но и использующей арсенал выразительных средств, который может быть объяснен с точки зрения современной стилистики, когнитивной лингвистики, лингвокультурологии. 
Практическая значимость предполагает возможность использования результатов изыскания в курсах подготовки переводчиков сферы профессиональной коммуникации, в курсах стилистики французского языка и при обучении французскому языку будущих архитекторов.

Проведенное исследование профессионального языка архитекторов подтвердило наше предположение о том, что в нем выразительные средства занимают чрезвычайно важное место. Метафоры, эпитеты и сравнения присутствуют здесь не в качестве стилистического украшения текста, а служат передатчиками архитектурной мысли. Такое понимание языка для профессиональных целей должно быть использовано при переводе французских архитектурных текстов, более богатых экспрессивными выражениями, чем их русские аналоги. Перевод, выполненный с учетом полученных знаний, становится стилистически ярким и сохраняющим лингвокогнитивные интенции автора.

1. Бородулина Н.Ю., Гуляева Е.А., Макеева Д.Д. Particularités linguistiques de la langue professionnelle des architectes // Вестник Тамбовского государственного технического университета. 2014. Т. 20. № 4. С. 838-845.

2. Выгузова Е.Ю., Дорохова Т.Ю. Антропоцентрический аспект к проблеме переводческой эквивалентности // Образование и наука: современное состояние и перспективы развития: сб. науч. тр. по мат-лам Междунар. науч.-практ. конф. 31 августа 2015 г. Ч. 4. Тамбов, 2015. С. 24-26.

3. Евенко Е.В. Гливенкова О.А., Копельник В.И., Шиповская А.А. Процесс смыслообразования при восприятии реципиентом звукового оформления текста // Вестник Тамбовского государственного технического университета.. 2014. Т. 20. №2. C. 381-384.

4. Зяблова О. А. Принципы исследования языка для специальных целей: На примере языка экономики: дисс. ... д-ра филол. наук: 10.02.19: М., 2005. 314 с.

5. Массалина И. П., Новодранова В. Ф. Дискурсивные маркеры в английском языке. Калининград: Издательство ФГОУ ВПО «КГТУ», 2009. 278 с.

6. Dubois J. \& al. Dictionnaire de linguistique. Paris: Larousse. 2001. 514 p.

7. Galisson R., Coste D. Dictionnaire de didactique des langues. Paris: Hachette, 1976. $612 \mathrm{p}$.

8. Lerat P. Les langues spécialisées, PUF, collection Linguistique nouvelle, 1995. $202 \mathrm{p}$.

9. URL: http://archidesignclub.com/magazine/rubriques/architecture/44020creche-a-sarreguemines-par-paul-le-quernec-et-michel-grasso.html

10. URL: http://www.cyberarchi.com/article/la-bulle-enchantee-creche-asarreguemines-14-02-2012-14222

11. URL: http://www.paperblog.fr/6057257/jardin-d-enfants-die-katzewettersteinstr/ 


\title{
Гливенкова О.А., Евенко Е.В., Лябина О.Г. Репрезентация фоносемантического аспекта смысла-тональности в интерпретации художественного текста
}

\author{
Glivenkova O.A., Evenko E.V., Lyabina O.G. \\ Phonosemantic aspect representation of sense-tonality \\ in the text interpretation
}

Тамбовский государственный технический университет Tambov State Technical University

В данной статье рассматривается процесс понимания и интерпретации художественного текста. Основное внимание уделено фоносемантическому аспекту репрезентации смысла-тональности, который формируется за счет восприятия реципиентом звукового оформления текста и анализируется с помощьюю когнитивного алгоритма понимания.

The problem of text comprehension and interpretation is considered in the article. Phonosemantic aspect representation of sense-tonality constructed by the recipient through the perception of the phonosemantic symbols of the text and analyzed through the cognitive algorithm of text comprehension is in the focus of the paper.

Ключевые слова: понимание; интерпретация; фоносемантический аспект; репрезентация; смысл-тональность; рециииент; восприятие; когнитивный алгоритм.

Key words: comprehension; interpretation; phonosemantic aspect; representation; sense-tonality; recipient; perception; cognitive algorithm.

Проблема понимания звуковой организации художественного текста является одной из главных как в герменевтической филологии, так и в преподавательской работе по методике интерпретации текста. В настоящее время существует множество теорий и методов, анализирующих процесс понимания текста, но недостаточно работ, посвященных исследованию понимания звуковой организации художественного текста $[2 ; 3,4]$. Такие современные науки как когнитивная семантика, психолингвистика, герменевтика направлены на изучение процессов понимания и интерпретации художественного текста. Смысловое значение звуковой организации текста всегда признавалось известными поэтами, писателями и учеными.

В настоящей работе рассматривается звуко-музыкальная организация текста в рамках когнитивного понимания, которое непосредственно связано с психологией таких познавательных процессов, как ощущение, восприятие, мышление, категоризация, память и даже подсознание. Человеческий мозг, являясь единой речемыслительной базой, всегда представлял интерес для научных ис- 
следований. Когнитивность (познание) рассматривается психологами как способность к умственному восприятию и переработке внешней информации [6]. Лингвисты и психологи используют парадигмы когнитивности для понимания того, каким образом человеческий мозг осуществляет функции переработки и декодирования информации.

Процессы познания и понимания тесно взаимосвязаны между собой. Наиболее полно проблема понимания раскрывается в текстовой деятельности и тексте как единице общения. Понимание художественного текста как «многомерной художественной стороны...» [5, с. 93] включает в себя три основных этапа: восприятие текста, мыследеятельность с текстом и его интерпретация.

Восприятие реципиентом текста можно рассматривать как переработку программы, заданную автором текста. В процессе понимания происходит координированное исполнение ряда этапов: выделение букв, слов, структурированных в более крупные единицы, такие как словосочетания, темы; декодировка языковых средств; интегрирование текста. Реципиент осмысливает когнитивные структуры к уже усвоенной им информации, и затем, интегрированный им текст, без распадения на отдельные части, синтезируется. Чем больше запас знаний читателя, тем лучше он понимает текст и тем успешнее происходит освоение авторской мысли.

С нашей точки зрения, очень точным является следующее определение понимания: «пониманием называют постижение смысла текста через его элементы с опорой на опыт читателя. Понимание пронизывает все связи человека с миром и является активной деятельностью, использующей лингвистический, культурный и жизненный опыт человека» [1, с. 35].

Понимание - это процесс поиска смыслов текста, осмысление текста в ракурсе исследователя, оно охватывает и синтезирует весь процесс целиком. В нашем исследовании мы опираемся на концепцию Щедровицкого, который рассматривает понимание как активный процесс «мыследействования», «действования с предметными представлениями» [9, с. 35]. Именно при активном понимании возникает необходимость совершать мыслительные усилия, т. е. активно и направленно мыследействовать.

Каждый человек неповторим, своеобразен и уникален, поэтому возникает естественный вопрос о возможности множественности импровизацийинтерпретаций. Интерпретация рассматривается нами как способ словесной фиксации понимания, в результате которого осуществляется построение реципиентом смыслов.

Исследование смысловой стороны текста в процессе интерпретации приводят к анализу тех «смутноуловимых мыслительных образований» [7, с. 8], которые тематизируются под именем «смысл». Так как формирование мыслительного образования происходит в миллисекунды, то индивид оперирует некими единицами в виде сформированных мыслительных образований (представление, ноэма, фрейм, концепт).

Звуки в тексте особым образом аранжированы, что и составляет саму технику создания текста, как со стороны его формы, так и со стороны его содержательных единиц. При восприятии звуковой организации текста реципиентом формируется смысл-тональность с помощью когнитивного алгоритма понимания: 
1. Восприятие текста;

2. Осмысление, воспринимаемых фоносемантических средств текстопостроения; ения;

3. Категоризация осмысленных фоносемантических средств текстопостро-

4. Выявление фоносемантических ассоциаций;

5. Осмысливаемая категоризация;

6. Выявления смысла-тональности.

Например, в приведенном ниже минимальном отрезке текста М. Цветаевой наблюдается сочетание звукоподражательных и паронимических звуковых отношений, которые при осмыслении приводят к построению смыслатональности.

«Не задушена вашими тушами душа» [7, с. 225].

Звуковая организация с доминантой [ш] в этих паронимах является подражанием реального звука удушья. Главное слово «душа» присутствует в двух других значимых словах строки «не задушена» и «тушами» в основных доминантах [д], [у], [ш], [а]. Презрительное употребление слова «туша» для слова «тело» вызывает ассоциации с «холодными, бесчувственными». Данный пример отрезка М. Цветаевой выделяется на фоне употребления паронимии в словосочетании и репрезентирует минорный тип смысла-тональности «тяжелое, мрачное состояние».

Приемом комбинаторного выражения звукосимволической организации можно считать апофонию: повторение частично тождественных звуков или звукокомплексов, в которых варьируется либо только гласный элемент, “zig-zag", либо согласный "hab-bub" - «суматоха», “wakey-talkey" - «сотовый телефон». Этот прием и направлен на то, чтобы создать ассоциации с «бесконечностью», «смешением противоположных сил и направлений».

Описание процесса восприятия дает возможность говорить о том, что в процессе восприятия в результате перцепции, распознавания и передачи звуков происходит формирование сенсорного изображения или представления.

На следующем этапе в процессе осмысления и дальнейшей активной мыследеятельности заканчивается формирование представления. Представление обрастает звукосимволическими или иными ассоциациями, что придает сенсорному изображению целостность. Но так как процесс осмысления неразрывно связан с процессом категоризации, в дальнейшем происходит наиболее сложная операция - осмысливаемая категоризация, которая представляет собой отнесение образа изображения к тому или иному классу объектов, которые являются уже приобретенным знанием реципиента.

В сенсорной системе реципиента происходит сравнение сформированного изображения с множеством других образов, хранящихся в памяти. Возникают звукосимволические ассоциации, являющиеся той звуковой «подсказкой», которая помогает в формировании дальнейшего мыслительного образования и способствует эффективному выделению его основного сложного признака.

В основе ассоциаций лежит физиогномическая природа, когда звук ассоциируется с эмотивными или психофизиологическими свойствами. Примеры подобных ассоциаций многочисленны: маленькие предметы издают обычно более высокие звуки, чем большие объекты; то же можно сказать о твердых пред- 
метах, по сравнению с мягкими; округлая или гладкая форма оказывает на осязание более мягкое впечатление; угловатая или шероховатая более сильное впечатление; грубый телесный контакт - болезнен, легкий - приятен. Например, цвет может быть определен не только по его специфическим хроматическим качествам, но и может представляться веселым или грустным; видимая форма вызывает впечатление силы или слабости; динамичности или статичности; звук кажется нежным или агрессивным. Так, например, звук [i] воспринимается как «светлый» и «угловатый» - это ассоциации, относящиеся к явлению синестезии, а если он ассоциируется с «радостным» и «агрессивным», то речь уже идет о физиогномической природе ассоциаций. В сильных и агрессивных отрезках текста преобладают «жесткие», «твердые» звуки [t], [k], [r], а в идиллических «нежные» и «мягкие» [1], [m], [n].

Следует отметить, что ассоциации возникают благодаря содержащемуся в слове звукосимволическому компоненту и играют ключевую роль в построении смысла-тональности.

Итак, в процессе своей мыслительной деятельности индивид формирует представление о ком-то и о чем-то благодаря особой организации художественного текста. Таким образом, когнитивный механизм звуковой организации текста базируется на понимании, как процессе активной мыследеятельности. Понимание, в свою очередь, представляет собой процесс построения смыслов текста, который выражается вербально в форме интерпретации и непосредственно связан с процессом категоризации.

Среди смыслов художественного текста есть такой, который репрезентирует непосредственно звуковую организацию текста - смысл-тональность. Основу смысла-тональности составляет явление звукосимволизма (которое включает в себя синестезию и кинемику) и организуется с помощью фоносемантических средств: звукосимволической метафоры, ассонанса, аллитерации, паронимии, звукового подхвата, фонетической цепи и других.

Значение фоносемантической организации текста в исследовании текста, его понимании и интерпретации - очень велико. Изучение звуковой ткани текста во всем многообразии звукового символизма на различных уровнях текста: фонемы, словоформы и сегменты текста представляет в настоящее время огромный интерес не только в нашей стране, но и за рубежом. Фоносемантическая теория в тандеме с теорией ассоциаций и герменевтическим, и психолингвистическим подходами дают нам прекрасную возможность многомерного изучения языковых средств текстопостроения в процессе понимания художественного текста.

1. Арнольд И. Механизмы понимания и смыслообразования текстовых произведений // «Понимание и рефлексия»: Материалы I и II герменевтических конференций. Тверь: ТГУ, 1992. Ч. 1. 36 с.

2. Бородулина Н.Ю., Гуляева Е.А. Метафора как средство смыслопостроения в экономическом тексте // Вестник Челябинского государственного университета. Серия: Филология. Искусствоведение / ГОУ ВПО «Челябинский государственный университет». 2009. Вып. 31. № 13 (151). С. 25-30. 
3. Гливенкова О. А., Евенко Е. В., Копельник В. И. Звуковой символизм как средство создания звукосимволической метафоры // Вопросы современной науки и практики. Университет им. В. И. Вернадского. 2014. №2 (51). C. 213-217.

4. Евенко Е. В., Гливенкова О. А., Копельник В. И., Шиповская А. А. Процесс смыслообразования при восприятии реципиентом звукового оформления текста // Вестник ТГТУ. 2014. Том 20. №2. С. 381-384.

5. Карасев О. В. Замечания о статусе герменевтики // Вопросы методологии. М.: Касталь. 1992. №1-2. С. 93.

6. Клещенко Е. Библиотека мозга // Химия и жизнь. 2012. № 12.

7. Попович М. В. Понимание как логико-гносеологическая проблема // Понимание как логико-гносеологическая проблема. Киев: Наукова думка, 1982. C. 5-23.

8. Цветаева М. И. Наследие Марины Цветаевой. М., 1915254 с.

9. Щедровицкий Г. П. Избранные труды. М.: Шк. культ. политолог., 1995. $760 \mathrm{c}$.

\title{
Горбунов И.Н., Толстяков Р.P. Информационные системы геомаркетинга
}

\author{
Gorbunov IN., Tolstyakov R.R. \\ Information systems of geomarketing
}

Тамбовский государственный технический университет Tambov State Technical University

В статье дан обзор наиболее популярных в России геоинформационных систем (ГИС), рассмотрены такие популярные ГИС, как 2GIS, Яндекс.Карты, Навител. Предложена авторская классификация ГИС, включающая критерии «доступ», «стоимость», «страна-разработчик», «мобильность».

In the article the most popular geographic information systems (GIS), considered such a popular GIS as 2GIS, Yandex.Map, Navitel. The author offers classification of the GIS, including criteria of "access", "cost", "co-developer", "mobility".

Ключевые слова: геомаркетинг; геоинформацонная система; маркетинговые исследования.

Keywords: Geomarketing; Geoinformation system; Marketing research. 
Геомаркетинг - одно из направлений маркетингового анализа; технология принятия решений с использованием пространственных данных в процессе планирования и осуществления деятельности в области сбыта продукции, обязательно учитывающая инфраструктуру территории, включающую плотность заселения, характеристики потребителей, расположение конкурентов, транспортные потоки и др.

Как видно из названия, геомаркетинг образовался на стыке дисциплин география и маркетинг. При описании объекта необходима обязательная привязка к местности. В последнее время в быту обычного потребителя многие порталы предоставляют доступ к информационным системам, дающим сведения о тех или иных географических объектах. Такие системы можно считать геоинформационными системами (ГИС). Данные сервисы могут быть положены в базис разработки геомаркетинговой стратегии.

Рассмотрим существующие ГИС и возможность их адаптации к решению геомаркетинговых задач.

2GIS (ДваГИС, до ребрендинга 2011 г. - ДубльГИС) - российская картографическая компания, выпускающая одноименные электронные справочники с картами городов с 1999 г. Проект зародился внутри новосибирской компании «Техноград плюс». Она занималась производством профессиональных ГИС по заказу других организаций. Суть системы заключается в совмещении карты и справочника, то есть геоинформационной системы и городского информационного справочника. На настоящий момент линейка продуктов 2ГИС выглядит так:

API 2ГИС - Набор инструментов для работы с картографическим и справочным контентом. На нем работают как некоторые продукты 2ГИС, так и партнерские сервисы.

Онлайн-версия доступна по адресу: http://2gis.ru. Включает в себя карту, справочник организаций, поиск проезда на общественном и личном транспорте, линейку для измерения расстояний, отображение пробок в некоторых городах. Работает на АРІ 2ГИС.

Мобильная версия поддерживает платформы iOS, Android, Windows Phone, Symbian, Windows Mobile. Версия для Android также портирована на Blackberry OS и MeeGo. Версии для iOS, Android, BB и MeeGo включают в себя тот же набор функций, что и 2ГИС для ПК, плюс отображение «пробок». 2ГИС для Windows Phone отличается от других версий: приложение работает на API 2ГИС, поэтому требует подключения к интернету для работы. Карта состоит из растровых файлов. Анонсировано, что 2ГИС будет предустановлен на мобильных устройствах Fly, поставляемых в Россию.

Версия для ПК работает без необходимости подключения к интернету (офлайн), обновления баз городов выходят 1-го числа каждого месяца и чаще. Имеет те же функции, что и онлайн-версия, теперь с показом «пробок». Интересная особенность - трехмерная векторная карта.

2 GIS Dialer - «звонилка» для Android, работающая с AРI 2ГИС. Определяет входящие звонки из организаций и позволяет находить нужные номера в каталоге организаций. 
2 GIS для браузеров - расширение для популярных браузеров, предоставляющее дополнительную информацию об организации, на сайте которой находится пользователь. Также работает на АРІ 2ГИС.

ЭСТИ МАП (http://www.mapinfo.ru). Компания ЭСТИ МАП была создана в 1992 г. группой сотрудников Российской Академии Наук, ведущими специалистами по обработке пространственных данных. В том же году было подписано партнерское соглашение с MapInfo Corp. (США), разработчиком геоинформационной системы MapInfo Professional. Компания ЭСТИ МАП по соглашению с Pitney Bowes Software Inc. проводит локализацию базового программного обеспечения MapInfo Professional, MapBasic и MapInfo RunTime на русский язык. Каждая новая версия этого программного обеспечения имеет русскоязычный интерфейс и документацию.

Яндекс.Карты - поисково-информационный картографический сервис Яндекса. Открыт в 2004 г. На сервисе представлены подробные карты всего мира. Есть поиск по карте, информация о «пробках», прокладка маршрутов и панорамы улиц крупных и других городов. Для России, Украины, Белоруссии и Казахстана используются только собственные карты компании, которые обновляются ежемесячно; данные для остальных стран мира поставляет компания «НАВТЭК». Маршрут прокладывается даже тогда, когда точка отправления и финальная точка находятся на территориях разных стран.

Карты доступны в четырех вариантах: схемы, спутниковые снимки, совмещенные и Народная карта. Набор возможностей по работе с картами достаточно обширен, но в наиболее полном объеме доступен лишь для ограниченного числа городов. Доступна подсветка района, города или области после поиска организации на сайте. Есть возможность просмотра улиц на картах. Доступен поиск как по географическим объектам (адресам, улицам, городам, регионам и странам), так и по организациям. На картах имеется возможность измерять расстояние, прокладывать маршруты и просматривать панорамы улиц. Имеется возможность в реальном времени просматривать изображения с веб-камер, установленных, как правило, вдоль крупнейших магистралей и возле развязок.

gvSIG - Мощный, удобный ГИС, который используют тысячи пользователей по всему миру. gvSIG использует векторные и растровые файлы карт, возможно удаленное обслуживание благодаря которому возможен анализ и управления географической информацией.

gvSIG Desktop разработана, чтобы быть легко расширяемой программой, позволяя, таким образом, постоянно совершенствовать программное обеспечение, приложения и разрабатывать индивидуальное решение. gvSIG Desktop - это программное обеспечение с открытым кодом для GNU/GPL лицензии, что позволяет его свободно использовать, распространять, изучать и совершенствовать.

Gurtam - белорусский разработчик программного обеспечения Wialon для мониторинга подвижных и стационарных объектов на базе спутниковых навигационных систем ГЛОНАСС и GPS, сотовой связи GSM (GPRS/SMS), спутниковой связи Inmarsat. Решения Gurtam осуществляют спутниковый мониторинг более чем 750000 мобильных объектов по всему миру. Операторы GPS мониторинга используют решения Gurtam в более чем 90 странах мира. Среди интеграторов Gurtam более 100 российских компаний. 
Maps Me. Компания была основана в 2010 г. под названием MapsWithMe c головным офисом в Цюрихе и центром разработки в Минске. В силу отсутствия в Беларуси внутреннего рынка для IT-компаний Юрий Мельничек - основатель компании - начал разработку нишиевого продукта, востребованного по всему миру. Первая версия приложения для операционной системы iOS вышла в апреле 2011 г., а год спустя MapsWithMe занял первое место на конкурсе StartupMonthly в Вильнюсе. А уже в феврале 2012 г. МарsWithМе появился в магазине приложений для Android. В апреле 2012 г. вышла платная «профессиональная» версия, отличавшаяся загрузкой карты в высоком разрешении и дополнительными функциями. Версия для смартфонов Blackberry появилась весной 2014 г.

В июле 2014 . компания сменила название на более короткое - MAPS.ME. MAPS.ME рассматривал предложения о продаже сервиса Яндексу и Google. Однако выбор пал на Mail.ru Group, которая была заинтересована в дальнейшем развитии сервиса и предоставила автономию стартапу внутри своей структуры. На данный момент - это сервис портала Mail.ru, который не несет самостоятельной коммерческой прибыли (отказ от платной версии был осуществлен сразу после продажи Mail.ru group) и служит для увеличения аудитории игровых сервисов.

Навител (http://navitel.ru). Навител - платная проприетарная программа для спутниковой навигации, выпускаемая российской компанией $3 А О$ «Центр навигационных технологий». По итогам 2011 г. на российском рынке навигационных систем доля «Навитела» составляет 80,1\%. Безусловно, «Навител» в первую очередь является навигационной программой, однако настраиваемый фильтр отображения POI (точек интереса - объектов различных типов, например, заправок, кафе, передвижными и стационарными камерами слежения и т. д.), а также поиск по адресам и объектам на карте позволяют отнести ее к геоинформационным системам. Существует в предустановленных вариантах на навигаторах, смартфонах с пробным периодом использования on-line сервиса.

Карты Google (googlemaps.com) - набор приложений, построенных на основе бесплатного картографического сервиса и технологии, предоставляемых компанией Google. Созданы в 2005 г. С сервисом также связано приложение Google Планета Земля - отдельная программа для Windows, а также GNU/Linux, Mac OS. Как и Карты Google, программа Google Планета Земля позволяет просматривать снимки земной поверхности, увеличивать и уменьшать масштаб и строить маршруты передвижения. Ее достоинством являются трехмерное отображение земной поверхности (с учетом рельефа), возможность наблюдения под произвольным углом (а не только отвесно сверху), постепенное уточнение изображения по мере загрузки более детальных фотоснимков.

ГеоСамара (http://geosamara.ru) - отечественный продукт, который развивается с 1996 г. (создан Самарский филиал Межотраслевой ассоциации «Совинформспутник»); коммерческий проект, в рамках которого заказчику предоставляются следующие услуги:

- проектирование, создание и внедрение учетно-аналитических и кадастровых геоинформационных систем муниципального и регионального уровня;

- производство цифровой картографической продукции, создание, ведение и наполнение баз данных геоинформационных систем; 
- коммерческое распространение космических снимков; производство на их основе цифровой продукции, включая формирование, первичную и тематическую обработку растровых изображений;

- научно-исследовательские и опытно-конструкторские работы по созданию математических методов, алгоритмов, информационных технологий и программного обеспечения цифровой обработки сигналов, анализа изображений и распознавания образов.

OpenStreetMap (http://www.openstreetmap.org) - общественный pecypc, coздан сообществом картографов, которые добавляют и поддерживают данные о дорогах, тропах, кафе, вокзалах и многих других объектах по всему миру. OpenStreetMap придает особое значение локальным знаниям. Участники используют аэрофотоснимки, GPS-устройства и низкотехнологичных карты земель для проверки того, что данные OSM являются точными и актуальными.

OpenStreetMap - разнообразное и растущее с каждым днем сообщество: это энтузиасты-картографы, ГИС-профессионалы, инженеры, содержащие серверы OSM, люди, отмечающие районы, пострадавшие от бедствий, и многие др. OpenStreetMap являются открытыми данными: вы можете использовать их для любых целей до тех пор, пока вы указываете авторские права OpenStreetMap и его участников.

Таблица 1. Классификация геоинформационных систем

\begin{tabular}{|l|c|c|c|c|}
\hline $\begin{array}{c}\text { Критерий класси- } \\
\text { фикации } \\
\text { ГИС }\end{array}$ & доступ & стоимость & $\begin{array}{c}\text { страна- } \\
\text { разработчик }\end{array}$ & мобильность \\
\hline 1. 2GIS & On-Line & Бесплатно & Россия & ПК/Мобильно \\
\hline 2. ЭСТИ МАП & Off-Line & Платно & Россия & ПК \\
\hline 3. Яндекс.Карты & On-Line & Бесплатно & Россия & ПК/Мобильно \\
\hline 4. gvSIG & Off-Line & Платно & Россия & Мобильно \\
\hline 5. Gurtam & Off-Line & Платно & Белоруссия & ПК \\
\hline 6. Maps Me & Off-Line & Бесплатно & Белоруссия & Мобильно \\
\hline 7. Навител & Off-Line & Платно & Россия & Мобильно \\
\hline 8. Карты Google & On-Line & Бесплатно & США & ПК/Мобильно \\
\hline 9. ГеоCамара & Off-Line & Платно & Россия & ПК \\
\hline 10.OpenStreetMap & On-Line & Бесплатно & США & ПК \\
\hline
\end{tabular}

Как видно из обзора существуют абсолютно различные по задачам и содержанию геоинформационные системы. В качестве классификационных признаков предлагается использовать (Табл.1):

- способ доступа: on-line, off-line;

- стоимость сервиса: свободно распространяемые, платные;

- страна происхождения: отечественные, зарубежные;

- мобильность: персональный компьютер, мобильные устройства.

Подводя итог, следует отметить, что целью геомаркетинга является повышение эффективности ведения бизнеса. Основные сферы применения - торговля и ритейл. Хотя геомаркетинг является относительно новым направлением маркетингового анализа, но уже достаточно востребован. Интерес к геомаркетинговым исследованиям стимулируется широким спектром имеющихся бесплатных геоинформационных сервисов. 
1. Завражина К. В. Концепция маркетинговой информационной системы в области качества жизни // Вопросы современной науки и практики. Университет им. В.И. Вернадского. 2011. №2. С. 236-240.

2. Ковалева Е. И., Сафонова Н. А., Тинякова В. И. Геомаркетинг в задачах обоснования решений по реализации новой продукции // Вестник Саратовского государственного социально-экономического университета. 2014. №5(54). С. 75-80.

3. Майоров А. А. Геомаркетинговые исследования // Образовательные ресурсы и технологии. 2014. №5 (8). С. 43-48.

4. Толстяков Р. Р., Зюкин С. Г. Маркетинговая информационная система как инструмент менеджмента предприятия // Вестник Тамбовского университета. Серия: Гуманитарные науки. 2012. № 12 (116). С. 84-88.

\title{
Григорьева В.C. К вопросу о «многомерности» концептуальной структуры дискурса
}

\author{
Grigoriewa V.S. \\ To the question of "multidimensionality" \\ of the conceptual structure of discourse
}

Тамбовский государственный технический университет Tambov State Technical University

Статья посвящена анализу проблем одного из важнейших видов человеческой деятельности - речевой, продуктом которой является дискурс. В работе анализируются подходы к изучению этого феномена, дается авторская дефиниция данного понятия. На основе сложности концептуальной структуры дискурса обосновывается интегративный подход кего изучению, позволяющиий решить вопрос о взаимодействии разных типов знаний и когнитивных структур в коммуникативном проиессе, категоризовать и представить дискурсивные модели «процедурной» ситуащии общения.

The article deals with the problems of one of the most important human activities - the speech, which product is the discourse. The paper analyzes the approaches to study of this phenomenon; the author's definition of this concept is given. The integrative approach of the discourse study is based on the complicated components of this notion. This approach makes it possible to solve the problem of interaction of different knowledge types and cognitive structures in the communicative process in order to categorize and present discourse models of a "procedural" situation of communication. 
Ключевые слова: речевая деятельность; антропочентричность; знание; дискурс; когнитивная функция; коммуникативная функция; интерпретирующая функция; конщептуальная структура; категоризащия.

Keywords: speech activity; anthropocentricity; knowledge, a discourse; the cognitive function; the communicative function; the interpreting function; the conceptual structure; the categorization.

Один из важнейших элементов человеческой деятельности и одновременно один из ценнейших ее продуктов - речь - на протяжении всей истории человеческого существования вызывал огромный интерес со стороны философов, психологов, социологов, лингвистов, культурологов. Конец XX - начало XXI столетия в лингвистике отмечены провозглашением в качестве основополагающего положения о том, что изучение языка может считаться адекватным лишь при описании его функционирования в процессе коммуникации. Если прежняя (статическая по своей сущности) лингвистика в познании языка шла от таких языковых объектов, как текст, предложение, слово или его грамматическая форма, то деятельностная лингвистика отправляется от человека, его потребностей, мотивов, целей, намерений и ожиданий, от его практических и коммуникативных действий, от коммуникативных ситуаций, в которых он участвует.

История изучения проблем коммуникации прослеживается на примере создания методов моделирования коммуникативных процессов. Широкое распространение получили модели коммуникации К. Шеннона, У. Уивера, Н. Винера, М. Мак-Люэна, Р. О. Якобсона и др. Для изучения процесса речевого взаимодействия особое значение имело введение Р. О. Якобсоном в модель коммуникации понятий адресант и адресат, а также распространение идей М. М. Бахтина о диалогизме коммуникации, адресованности и хронотопе высказывания. Упоминание фактора адресата в создании речевого сообщения отправителем сообщения стало фактически традицией в лингвистических исследованиях последних лет. Однако ответной реакции адресата на полученное сообщение уделялось не столь пристальное внимание. Подчеркивались лишь отношения иллокутивного вынуждения в диалогическом единстве (А. Н. Баранов, Г. Е. Крейдлин), в качестве примеров диалогических единств выделялись пары вопрос ответ, просьба - реакиия, благодарность - ответ на благодарность (О. Д. Белецкая, Т. В. Абрамова, В. Б. Кашкин). Отмечалась последовательность (серийность) процесса речевого поведения, задающего генерализованные схемы действия, которые и определяют последовательность специфических актов (речевых высказываний) (Р. Титоне). О стереотипичности процесса коммуникации писали И. Н. Горелов и В. Ф. Седов: «Речевая деятельность человека строится, главным образом, на использовании готовых коммуникативных единиц. Формируя высказывания, мы обязательно прибегаем к схемам, шаблонам, клише. А без овладения жанрово-ролевыми стереотипами общения, в которых языковые единицы достаточно прочно увязаны с типическими ситуациями, взаимодействие языковых личностей было бы затруднено» [4, с. 137-138]. Однако процесс речевого взаимодействия в аспекте взаимонаправленности, повторяемости и динамики не был предметом специального исследования. 
Такой комплексный анализ стал возможным с привлечением к исследованию стоящего за коммуникацией и обусловливающего ее ментальнолингвального комплекса, изучение которого началось фактически с развитием идей когнитивной лингвистики, признанием когнитивной сущности языка (см. работы Н. Н. Болдырева, В. З. Демьянкова, В. И. Заботкиной, О. К. Ирисхановой, В. В. Красных, Е. С. Кубряковой, Дж. Лакоффа, Р. Лэнекера, Л. Талми, Ч. Филлмора и др.). В своих исследованиях лингвисты-когнитологи исходят, в первую очередь, из антропоцентрической природы языка, неоднократно привлекавшей внимание ученых, начиная с высказываний В. Гумбольдта, и нашедшей свое отражение в учениях о роли человеческого фактора в языке, в теории номинации, теории о языковой личности, учениях о роли субъекта познания, лингвокреативности.

Суть принципа антропоцентризма, выдвинутого в рамках классической философии, заключается в том, что «человек есть центр Вселенной и цель всех совершающихся в мире событий» [11, с. 26-27]. Особо актуален данный принцип для теории речевого взаимодействия, поскольку его эпицентром является человек как создатель языка: наблюдатель, «концептуализатор» и «категоризатор» объектов, явлений внешнего мира и абстрактных сущностей. В основе всей познавательной деятельности человека лежат функции концептуализации и категоризации, т. е. «осмысление объектов как единиц знания, формирование системы знаний, деление мира на категории и отнесение конкретных предметов и событий к этим категориям с помощью языка» [2, с. 38]. Таким образом, одним из исходных положений и методологическим принципом в данной статье признан антропоцентризм, понятие которого предполагает, что «человек не воспроизводит в готовом виде языковые значения и формы, ... а формирует смыслы и выбирает средства их реализации заново в каждом конкретном акте речевого общения» [3, с. 5].

Антропоцентричность как одна из главных характеристик языка проявляется в его функциях: когнитивной, коммуникативной и специально выделяемой Н. Н. Болдыревым интерпретирующей функции, объединяющей в себе все дополнительные функции, помимо когнитивной и коммуникативной. Как справедливо отмечает Н. Н. Болдырев, «любая языковая деятельность человека связана с интерпретацией, а языковая интерпретация предстает как вид познавательной активности, процесс и результаты понимания и объяснения человеком мира и себя в этом мире» [3, с. 5]. Именно интерпретирующая функция языка позволяет объяснить динамику речевого взаимодействия, изменение индивидуальной картины мира каждого из коммуникантов, его знаний, представлений, мнений, эмотивного состояния на каждом этапе общения.

Модели коммуникативного процесса находят непосредственное отражение в теории дискурса, конверсационном анализе, анализе диалога. В рамках единой антропоцентрической теории языка, создание которой выдвигается Н. Н. Болдыревым как одной из важнейших теоретических задач современной лингвистики в связи с переменой фокуса лингвистических исследований с отдельных языковых объектов как результатов языковой деятельности человека на систему взаимосвязи с природой самого субъекта $[3$, с. 6], возможно по-новому посмотреть на феномен дискурса, историю развития дискурсивного анализа как научной дисциплины. 
Если у истоков дискурсивного анализа находились этнолингвистические исследования, ориентированные на запись и анализ устных текстов разных языков (Ф. Боас) и традиции исследования тематической и коммуникативной организации текста (В. Матезиус), то оформлению дискурсивного анализа как дисциплины предшествовало введение 3. Харрисом термина discourse analysis как метода изучения движения информации в дискурсе и публикация важных работ европейской школы лингвистики текста (Т. В. ван Дейк, В. Дресслер, Я. Петефи, Д. Вундерлих и др.), а также основополагающих американских работ (У. Лабов, Дж. Греймс, Р. Лэнекер, Т. Гивон, У. Чейф). В русистике дискурсивные явления без употребления данной терминологии активно исследовались в 1970-х - 1980х гг. (Е. А. Земская, Б. М. Гаспаров, О. А. Лаптева, О. Б. Сиротинина).

При этом термин дискурс (фр. discours, англ. discourse, нем. diskurs от лат. discursus - беседа, разговор, речь, процесс языковой деятельности) дефинировался неоднозначно с момента его использования в целях языковедческого анализа (см. подробнее: [6, с. 11]). При определении данного понятия делался акцент на дискурс как на вид речевой коммуникации, как единицу общения (Н. Д. Арутюнова, В. В. Богданов, В. Г. Борботько, И. П. Сусов, Н. И. Формановская). Дискурс здесь «многокачественное лингвокогнитивное образование, включающее кроме текста, еще и внеязыковые факторы (знания о познаваемой действительности, мнения, установки, оценки» [1, с. 37]. Со времени своего возникновения понятие «дискурс» претерпело определенные изменения. Если в начале 70-х гг. ХХ века он трактовался как последовательность речевых актов, связанный текст, устная разговорная форма текста, диалог, группа высказываний, связанных между собой по смыслу (см.: [5, с. 349-350]), то в современных определениях акцентируется многоаспектность понятия дискурс, что подводит к необходимости его интегративного исследования. Когнитивная сущность дискурса как особой языковой единицы подчеркивается Е. С. Кубряковой: «...дискурс может быть определен как такая форма использования языка в реальном (текущем времени (on-line), которая отражает определенный тип социальной активности человека, создается в целях конструирования особого мира (или - его образа) с помощью его детального языкового описания и является в целом частью процесса коммуникации между людьми, характеризуемого, как и каждый акт коммуникации, участниками коммуникации, условиями ее осуществления и, конечно же, ее целями» [9, с. 525].

Для анализа общения, коммуникативного взаимодействия индивидуумов недостаточно изучения языка как системы знаков. Равно как и разработанные в теории речевых актов типы прагматических высказываний не дают полной характеристики речевой стратегии говорящего и не дают ответа на то, как достичь наибольшей эффективности речи, какие языковые средства надо использовать для достижения поставленных целей. Вполне вероятно, что ответ на этот вопрос возможно получить, осуществив полный анализ дискурса как языковой единицы, расположенный выше уровня текста, однако значительно сложнее организованной, чем нижестоящие единицы, включая при этом в парадигму исследования дискурсивных единиц социальные, психологические, кинетические, этнографические и другие аспекты. Сравните понимание дискурса как иерархически конструируемой сложной структуры, состоящей из трех уровней, а именно формально-семиотического, когнитивно-интепретируемого 
интерактивного (И. П. Сусов), вербально-семантического (нулевого), тезаурусного (первого) и мотивационно-прагматического (второго) (Ю. Н. Караулов), четырехмерное пространство дискурса П.В. Зернецкого, строящегося по сигматической, семантической, прагматической и временной осям координат. Попытки антропоцентрического подхода к исследованию дискурса прослеживаются и в направлении исследований речевой деятельности в какой-либо социологической cфepe.

В настоящей работе «дискурс» понимается как главная реальность лингвистики, ведь то, что производит говорящий и воспринимает адресат, и есть дискурс, т. е. текст в процессе его использования. Таким образом, умение анализировать дискурс - это и есть умение полноценно отвечать на вопрос о том, как человек пользуется языком. Анализ дискурса не только вбирает в себя достижения классической лингвистики, но и добавляет к ним много нового. Использование интегративного подхода в рамках антропоцентрической теории языка позволяет утверждать, что основной составляющей в производстве дискурса является языковая личность. Дискурс, таким образом, можно дефинировать как продукт языковой личности, продуцируемый вследствие решения ее определенных интенциональных задач путем использовавния когнитивных структур языковой картины мира, интерпретируемых собственным сознанием.

Набор правил употребления языковых единиц как знание о коммуникативной (преимущественно, вербальной) деятельности относится к тому фрагменту концептуальной картины мира человека, который представляет собой суперконцепт «коммуникативная ситуация». Сложность концепта «коммуникативная ситуация» заключается в том, что он вбирает в себя концептуальные структуры всех уровней и реализуется в дискурсивном взаимодействии, где речь идет о репрезентации не просто отдельных речевых актов, а целостных коммуникативных событий, которые представляют собой «совокупность прагматически когерентных речевых действий, направленных на достижение общей коммуникативной цели, все составляющие его речевые акты оказываются связанными этой единой целью и общими условиями реализации» [12, с. 8]. Каждый акт речевого события выступает здесь как тактическое средство, используемое для решения общей стратегической задачи определенного дискурсивного события. И только в общем контексте каждое отдельно взятое речевое действие приобретает смысл как при порождении, так и при интерпретации дискурса. «Речевое общение категоризуется в языке гораздо более изощренно и многообразно, чем любые другие классы естественных объектов» [10, с. 48].

В основе формирования дискурсивных категориальных типов лежат определенные структуры знания. Под знанием в рамках когнитивной лингвистики понимается «то, что уже отложилось в сознании и составляет часть памяти; ... это не собрание случайных фактов, а набор сведений, объединенных в определенную упорядоченную систему» [8, с. 28-29]. Под системой, в данном случае, авторы понимают знания, представленные в языке. Таким образом, категоризуя предметы, явления, события, человек раскрывает те знания, которыми он владеет, когда пользуется языком как средством общения, хранения и получения информации. «Категоризация - это, с одной стороны, знание категорий объектов и явлений и их названий и, с другой стороны, сам процесс отнесения тех или иных 
объектов к конкретной категории, включая присвоение им соответствующих названий» [2, с. 115].

Концептуальная структура дискурса представлена несколькими областями знаний. Одна из них предполагает знание темы диалога, предмета общения. Тема - это интенциональный объект в фокусе интеракций. Она имеет семантическую связанность и принадлежность к определенной сфере. Согласно Н. Н. Болдыреву дифференциация концептов по тематическим областям передаваемого знания представляет содержательную типологию концептов [2, с. 52].

Представление темы в виде семантической сети (сценария (скрипта) или фрейма) отражает структурную типологию концептов. С помощью фрейма создается когнитивный образ предметно-референтной ситуации. «Фрейм оказывает существенное влияние на интерпретацию действительности, поскольку создает определенный фокус восприятия. Фрейм как ментальная схема («рамка в сознании») фокусирует определенные факты, процессы, явления как взаимообусловленные и подразумевающие друг друга» $[13$, с. 60].

Развитие дискурса во времени, своеобразный тип фрейма в динамике, представлен сценарием. Тематические концепты манифестируются в дискурсе с помощью репрезентативных концептов: фонологических, лексических, фразеологических, ономасиологических, словообразовательных, лексикограмматических, грамматических (морфологических и синтаксических), текстовых. Следует отметить, что названные типы концептов гносеологичны по своей сути. Как подчеркивает Н. Н. Болдырев, они являются «теоретическими конструктами человеческого сознания, ... предполагают необходимость полной или частичной реконструкции их содержания» [2, с. 74]. Операционные концепты онтологически орентированы: это единицы обыденного сознания, конкретные в своей референции, т. е. контекстуально и ситуативно обусловленные, в силу чего они могут рассматриваться как отдельные смыслы [Там же].

Таким образом, когнитивный аспект дискурса описывает область содержательной интерпретации знака и его мыслительного эквивалента (значения) и несущего в себе совокупность знаний о мире через установленную в социуме систему понятий, категорий и т.п. о нем. Поскольку каждый из участников коммуникации имеет свой жизненный опыт, обладает своим знанием мира, одна и та же жизненная ситуация может быть воспринята и оценена по-разному, что отражается в речевом взаимодействии неоднозначным использованием концептуальных структур операционного типа.

Роль слушателя, его значение в коммуникативном взаимодействии не является пассивной. Адресат не становится действующим лицом по ходу коммуникативного акта, он является таковым уже на момент начала взаимодействия. Как правило, опытный коммуникант готовится к речевому общению задолго до его инициации, учитывая факторы адресата. Адресант моделирует концепцию прототипического адресата исходя из собственной картины мира посредством соотнесения опытного знания и прогностической оценки. Таким образом, воздействие адресата на речевую ситуацию начинается вообще за его пределами. Категории адресата, адресанта и интенциональности определяют область взаимодействия, в которой происходит пересечение картин мира коммуникантов.

Концептуальная структура дискурса включает также коммуникативнорелевантные знания, составляющие неотъемлемую часть коммуникативной 
компетенции индивида и обеспечивающие адекватность его дискурсивной деятельности. Они разнородны по характеру и состоят из общих и конкретных знаний о ситуации общения, о социальных конвенциях, о принципах речевого общения и иллокутивных силах речевых актов, знаний о различных типах и форматах дискурса и условий их функционирования, знаний об адресате, о ролях коммуникативной деятельности, о том, что Л. Витгенштейн назвал «языковыми играми». Концепты, в основе которых лежит когнитивный образ названных аспектов ситуации взаимодействия, мы предлагаем именовать коммуникативные концепты. Исходя из этих знаний, коммуниканты в ходе коммуникативного взаимодействия вырабатывают свои дискурсивные стратегии и избирают соответствующие тактики для осуществления своих целей и намерений.

Базу для создания когнитивно ориентированной теории коммуникации, как отмечает В. И. Заботкина, заложило введенное Ч. Пирсом понятие «прагматической интерпретанты», отождествляемое им, с одной стороны, с контекстом, с другой стороны, с набором правил употребления, т. е. и в том и в другом случае «прагматическая интерпретанта» трактуется как чисто прагматическая составляющая акта семиозиса [7, с. 48-49]. Заметим, что задействованным при этом оказывается не только прагматическая интерпретанта, но и все виды интерпретирующей функции в целом.

С когнитивной точки зрения взаимодействие коммуникантов в рамках определенной ситуации можно было бы представить как взаимодействие концептуальных систем говорящего и слушающего. Каждому из коммуникантов свойственна своя наивная и языковая картина мира, каждому присуща дискурсивная n-мерная матрица как система взаимосвязанных когнитивных, коммуникативных, социологических, этнических, психологических концептов. В ходе речевого общения происходит постоянное изменение индивидуальных знаний коммуникантов, их трансформация, пополнение, переоценка и пр. Объем и характер знаний коммуницирующих одного отрезка времени не равен таковым другого отрезка времени.

Коммуникативную дискурсивную координату мы предлагаем представить в виде набора элементов, представляющих классы различных речевых действий. Применение типологии речевых действий при анализе дискурса позволяет учитывать межличностные отношения партнеров, их социальный статус, их внутреннее состояние, регулирование предметного поведения.

Представляется рациональным и результативным предложение Н. К. Рябцевой использовать в качестве квалификативного средства репрезентации знаний об использовании языка в типичных ситуациях общения металексику речевого общения [10, с. 49]. Ядро металексики составляют «слова и словосочетания, отражающие устройство языка и его использование. ... МРО (Метаязык речевого общения) включает метаимена (и глаголы) типа приказ, просьба, coвет, намек, приглашение, поздравление, комплимент, предложение, ручательство, жалоба, угроза, оскорбление, ультиматум, шантаж и мн. др. [Там же, с. 45].

Таким образом, краткий обзор существующих классификаций дискурса как продукта речевого взаимодействия показывает неоднородность и неоднозначность его таксономий. Сосуществующие в нем единицы и структуры самой разной природы, выполняющие различные функции, в том числе интерактивные, социально-деятельностные единицы и структуры обусловливают неодно- 
значность, отсутствие логики, заимствование структурных единиц дискурса из абсолютно разных концепций и подходов. Интегративный подход к анализу дискурса позволяет решить вопрос о взаимодействии разных типов знаний и когнитивных структур в коммуникативном процессе, категоризовать и представить дискурсивные модели не только декларативного характера, но и смоделировать изменение когнитивных схем и представлений при конструировании «процедурной» ситуации общения.

1. Алефиренко Н. Ф. Когнитивно-семиологические аспекты лингвокультурологии // Вопросы когнитивной лингвистики. 2006. №1. С. 36-44.

2. Болдырев Н. Н. Когнитивная семантика. Введение в когнитивную лингвистику: Курс лекций. Изд. 4-е, испр. и доп. Тамбов: Издательский дом ТГУ им. Г.Р. Державина, 2014. 236 с.

3. Болдырев Н. Н. Антропоцентрическая сущность языка в его функциях, единицах и категориях // Вопросы когнитивной лингвистики. 2015. № 1 С. 5-12.

4. Горелов И. Н., Седов К. Ф. Основы психолингвистики: Учебное пособие. М.: Лабиринт, 1997. 224 с.

5. Григорьева В. С. Языковая личность, коммуникативная интенция и организация коммуникативного процесса в сказке Э. Т. Хофмана «Песочный человек» (на немецком языке) // Вестник Тамбовского государственного технического университета. 1997. Том 3. №3. С. 346-350.

6. Григорьева В. С. Дискурс как элемент коммуникативного процесса: прагмалингвистический и когнитивный аспекты: монография. Тамбов: Изд-во Тамб. гос. техн. ун-та, 2007. 288 с.

7. Заботкина В. И. Семиотические аспекты представления знаний в семантической структуре слова // Проблемы представления (репрезентации) в языке: Типы и форматы знаний: Сб. науч. тр. М.-Калуга: Эйдос, 2007. С. 180-188.

8. КСКТ - Краткий словарь когнитивных терминов / Е. С. Кубрякова, В. 3. Демьянков, Ю. Г. Панкрац, Г. Л. Лузина; под общ. ред. Е. С. Кубряковой. М.: Изд-во МГУ, 1996. 248 с.

9. Кубрякова Е. С. Язык и знание: На пути получения знаний о языке: Части речи с когнитивной точки зрения. Роль языка в познании мира. М.: Языки славянской культуры, 2004. 560 с.

10. Рябцева Н. К. Знание языка и знания о языке: метаязык речевого общения // Когнитивные исследования языка. Вып. III. Типы знаний и проблема их классификации: Сб. науч. трудов. М.: Изд-во ИЯ РАН, ТГУ им. Г.Р. Державина, 2008. С. 45- 55. $576 \mathrm{c}$.

11. ФЭС - Философский энциклопедический словарь. М: ИНФРА М, 1999.

12. Цурикова Л. В. Межкультурное взаимодействие с позиций когнитивнодискурсивного подхода // Вопросы когнитивной лингвистики. 2006. №1. С 5-15.

13. Чернявская В. Е. Фантомы и синдромы дискурсивной парадигмы // Вопросы когнитивной лингвистики. 2014. №1. С. 54-61. 


\title{
Ильина И.Е., Морозова О.Н., Шмаков С.И. \\ Социокультурный аспект в обучении \\ иностранному языку
}

\author{
Ilina I.E., Morozova O.N., Shmakov S.I. \\ Sociocultural aspect of teaching foreign language
}

В данной статье рассматривается важность сочиокультурной компетенции на уроках иностранного языка в техническом вузе, успешное формирование которой возможно при использовании социокультурного подхода.

This article deals with the importance of sociocultural competence at foreign language lessons in a technical institute. Forming of that competence can be successfully achieved by using sociocultural approach.

Ключевые слова: сочиокультурный подход; компетенция; сочиокультурный аспект; социокультурное образование; коммуникация; жесты; мимика; эмоция; культура; кинесика; интоначия.

Keywords: sociocultural approach; competence; sociocultural aspect; sociocultural education; communication; gestures; mimicry; emotion; culture; kinesics; intonation.

Диалог культур приобретает все большую актуальность в связи с новыми тенденциями в общественном развитии: расширением общественнополитических, социально-экономических и культурных связей между народами, ростом прямых и опосредованных контактов, - являющихся результатом развития современных информационных технологий, во всех сферах человеческой жизнедеятельности. Несмотря на общую положительную тенденцию укрепления связей мирового сообщества, а также и на то, что встреча разных культур делает жизнь людей разнообразнее и интереснее, взаимодействие культур ведет к возникновению новых проблем, связанных с ситуациями межкультурного недопонимания.

Культура любого народа является сложной системой, в которую включено все разнообразие его материальных и духовных ценностей, она есть форма выражения его самобытности мироощущения, нравственных идеалов, традиций и обычаев, в ней отражено «... художественное видение мира, в целом характеризующее все духовные ценности...» и исторической прошлое. [6, с. 16].

В настоящее время мировое сообщество все больше воспринимает идею «диалога культур», которая восходит еще к воззрениям М. М. Бахтина, писавшего, что «чужая культура только в глазах другой культуры раскрывает себя полнее и глубже ...» [1, с. 354], и В. С. Библера, выдвинувшего оригинальную концепцию диалога культур и определявшего его как форму «одновременного бытия - прошлых, настоящих и будущих культур» [3, с. 38].

В. С. Библер рассматривает культуру как универсальный способ общения в масштабе всего человечества. Современные процессы глобализации раскры- 
вают как черты сходства, так и уникальность и самобытность жизни каждого народа. Мировое сообщество все больше воспринимает идеи культурного многообразия и «диалога культур». Одной из форм такого диалога культур выступает реклама. Межкультурный диалог проявляется в ней в опосредованной форме, но продуктивность этого диалога затрагивает многие стороны человеческих взаимосвязей: от экономического успеха рекламируемой продукции до формирования позитивных или негативных гетеростереотипов.

Политические и социально-экономические преобразования в настоящее время повлекли за собой изменения в содержании обучения иностранным языкам. Необходимо не только овладеть умениями, знаниями и навыками, чтобы использовать язык как инструмент общения и познания, но и развивать способности, наличие которых помогает человеку ориентироваться в иноязычной культурно-языковой среде. В связи с этим, появилась необходимость в изучении иностранного языка в неразрывной связи с культурой народа. Использование страноведческой и культурологической возможности благоприятствует коммуникативным навыкам и умениям, дает стимул к самостоятельной работе над языком и способствует решению воспитательных задач.

Основной целью обучения иностранному языку является развитие личности студента в неразрывной связи с преподаванием культуры страны изучаемого языка, что способствует желанию «участвовать в межкультурной коммуникации и самостоятельно совершенствоваться в овладеваемой деятельности» [9, с. 34].

В настоящее время преподавание иностранных языков переживает сложный период переоценки ценностей, пересмотра целей, задач, материалов и т. п. Новые условия потребовали немедленного и коренного изменения как содержания обучения, так и конкретных методов и приемов преподавания иностранного языка.

К социокультурному компоненту обучения относят:

- обычаи, обряды, традиции;

- бытовую культуру;

- повседневное поведение;

- невербальные средства общения;

- национальные особенности мышления представителей той или иной культуры;

- художественную культуру, отражающую культурные традиции того или иного этноса.

Для вузов неязыковых специальностей практическая цель обучения иностранному языку - развитие умений и навыков устного иноязычного профессионального общения. При этом обучающийся должен владеть двумя средствами общения - говорением и аудированием как видами речевой деятельности.

Общение репрезентируется посредством различных вербальных и невербальных средств [7].

Устная речь, как известно, является естественной формой для любой сферы общения. Существуют две формы устной речи: монологическая и диалогическая.

Монологическая устная речь отличается развернутостью и грамматической оформленностью. Часто она требует предварительной подготовки и не все- 
гда сопровождается непосредственной реакцией слушающих (речь по радио или телевидению).

Диалогическая речь обычно бывает не полностью развернутой, т. к. она ситуативна. Многое в ней не высказывается, а подразумевается благодаря контексту, понятному разговаривающим. В диалогической речи большое значение имеют интонация, а также невербальные средства общения. При обучении устной форме общения, речь идет об устных текстах диалогов/монологов, т. к. именно они содержат как вербальные, так и невербальные средства общения, передающие основной объем информации.

Невербальные средства общения играют большую роль в понимании устной речи, т. к. в потоке речи они доминируют над вербальными, способны передавать отдельные понятия и даже суждения, заменять отдельные слова и фразы, передавать информацию об эмоциональном состоянии говорящего, помогают коммуникантам структурировать свой диалог или монолог. Установлено, что в процессе общения с помощью вербальных средств мы передаем и получаем лишь 20-40\% информации, в то время как остальная коммуникация осуществляется за счет невербальных средств.

Знания социокультурной среды изучаемого иностранного языка помогают обучающимся чувствовать себя более уверенно, общаясь на иностранном языке, способствуют повышению их иноязычной коммуникативной компетенции, т. е. позволяют им быть адекватными участниками коммуникации. Это включает понимание имплицитного смысла различных высказываний.

Аспект методики преподавания иностранного языка, в котором исследуются проблемы ознакомления изучающих язык с новой для них культурой, называется лингвострановедением [4], предметом которого являются факты языка, отражающие особенности национальной культуры, изучающейся через язык.

Основоположники лингвострановедения Е. М. Верещагин и В. Г. Костомаров понимают под ним культуроведение, ориентированное на задачи и потребности изучения иностранного языка [5].

Однако лингвострановедение не включает в себя весь комплекс знаний, умений и навыков, связанных с иноязычной культурой, и несколько узок, по сравнению с термином «национальная культура».

Обучающих необходимо познакомить с языковыми единицами, наиболее ярко отражающими национальные особенности культуры народа-носителя языка и среды его существования.

Основным объектом лингвострановедения традиционно считают фоновые знания носителей языка, их вербальное поведение в актах коммуникации.

Социокультурный компонент обучения иностранному языку, на базе которого формируются знания о реалиях, нравах, обычаях, традициях страны изучаемого языка; знания и навыки коммуникативного поведения в актах речевой коммуникации; навыки и умения вербального и невербального поведения, входит в содержание национальной культуры. Социокультурный компонент имеет огромный потенциал в плане включения обучающихся в диалог культур, знакомства с достижениями национальной культуры в развитии общечеловеческой культуры. Как известно, отсутствие непосредственного контакта с носителем иностранного языка в условиях страны изучаемого языка усиливает общеобра- 
зовательную значимость языка и, следовательно, более последовательную опору на социокультурный компонент.

Говоря о национальной культуре, о коммуникативном поведении носителей языка различают вербальное и невербальное поведение.

Совокупность норм и традиций общения, отражающих рекомендуемые правила общения, сложившиеся в обществе в силу исторических традиций, ритуалов, социальных ситуаций, включающих мимику, жесты, позы общающихся, называется невербальным коммуникативным поведением.

Все невербальные средства коммуникации с этнокультурной точки зрения можно разделить на 4 группы:

1. Невербальные средства, совпадающие в исполнении, употреблении и передаче смысла. Например, при приветствии пожимают руки и в России, и в Германии.

2. Невербальные средства, совпадающие в исполнении, но имеющие расхождение в их смыслах и сфере употребления. Немецкий жест «щелкать пальцами» обозначает привлечение внимания. В России этот жест употребляется в значении досады или затруднения в поиске нужного слова.

3. Невербальные средства, совпадающие по смыслу и сфере употребления, но различны в исполнении. Немецкий жест «грозить кому-либо пальцем» имеет расхождение с русским жестом в исполнении: рука согнута в локте, ладонью повернута к слушающему, указательный палец вытянут вперед, остальные пальцы согнуты, кисть выполняет отрывистые движения слева направо, а в русском исполнении ладонь повернута ребром к слушающему, кисть двигается впередназад. Жест счета также имеет некоторые расхождения в исполнении: в России пальцы, начиная с мизинца, сгибаются, а в Германии согнутые пальцы левой руки, начиная с большого пальца, разгибают пальцами правой руки.

4. Невербальные средства специфичные для определенной культуры. Например, в Германии студенты после лекции стучат костяшками пальцев по столу в знак благодарности и приветствия преподавателей университета.

Таким образом, студенты, приобретая знания, вместе с тем должны уметь оперировать отобранным языковым материалом; должны формировать навыки и умения оперирования отобранными страноведческими знаниями (плюсами и нормами повседневного поведения); а также минимумом коммуникативно стереотипизированных телодвижений (мимика, жесты, позы).

Социокультурный компонент способствует более осознанному овладению иностранным языком как средством общения, благодаря чему студенты более глубоко приникают и осознают культуру родной страны, что является на сегодняшний день важным аспектом в воспитании всесторонне развитой личности.

Внутреннее состояние человека, его мысли, желания, отношения к адресату выражаются как в вербальном акте, так и в невербальном. В мимике, жестах, движениях наиболее адекватно выражается эмоциональное состояние человека. Невербальные средства коммуникации необходимо почувствовать и уметь воспроизвести - это основное условие их правильного понимания. Этим-то и отличается «телесный» язык от языка «словесного», в котором слова употребляются не всегда адекватно. Взаимодействие вербальных и невербальных актов в одинаковой степени влияют на понимание речи. Это два составляющих, которые играют главную роль в процессе коммуникации. 
Понимание речи - это активный процесс, результат сложной деятельности адресанта и адресата. По словам Г. В. Колшанского, «категория «взаимного понимания» предполагает, прежде всего, понимание участником коммуникации соответствующих языковых выражений, участвующих в речевых актах". [8, c.156] Понимание в этом смысле становится не только языковой, но и общегносеологической проблемой, поскольку оно включает в себя и знание в области предмета, который является объектом взаимного обсуждения коммуникантов.

Процесс понимания включает в себя несколько этапов. Первый этап заключается в том, что языковые формы воспринимаются как содержательно наполненные, а все высказывание как осмысленное, и тем самым на основе языковой компетенции понимается смысл языкового выражения. Затем происходит реакция адресата на это высказывание, по результатам которой адресант делает вывод, понял или не понял его собеседник. Помимо словесных индикаторов поведения коммуникантов, значительную роль в этом процессе играют и невербальные средства коммуникации, которые служат выявлением адекватного понимания или непонимания.

Изучая иностранный язык, студенты не просто знакомят с зарубежной культурой, но и лучше узнают отечественную культуру, соотнося полученную социокультурную информацию о зарубежных странах с уже имеющимися аналогичными сведениями о России, способствуя адекватной оценке кросс- и субкультурных различий и сходств социокультурного компонента между зарубежными странами и Россией.

1. Бахтин М. М. Эстетика словесного творчества. М.: Искусство, 1986.

2. Библер В. С. Культура. Диалог культу: Опыт определения // Вопросы философии. 1989. №6. С. 31-43.

3. Библер В. С. От наукоучения к логике культуры. Два философских введения в XX век. М.: Политиздат, 1991.

4. Бим И. Л. Теория и практика обучения немецкому языку в средней школе. Проблемы и перспективы. М.: Просвещение, 1988. 125 с.

5. Верещагин Е. М., Костомаров В. Г. Язык и культура: Лингвострановедение в преподавании русского языка как иностранного. Методическое руководство. М.: Русский язык, 1983. 214 с.

6. Иконникова Н. К. Современные западные концепции межкультурной коммуникации: автореф. дисс. ... канд. социол. наук: 22.00.06. М., 1994.

7. Ильина И. Е., Морозова О. Н., Лябина О. Г., Шмаков С. И. Невербальная коммуникация (на немецком языке) // Вестник ТГТУ. 2014. № 2. С. 386-396.

8. Кольшанский Г. В. Коммуникативная функция и структура языка. М.: Наука, 1984. 254 с.

9. Никитенко 3. М., Осиянова О. М. К проблеме выделения культурного компонента в содержании обучения англ. языка в начальной школе. // ИЯШ. 1993. №3. С. 12-16. 


\title{
Исаева О.В. \\ Организация учебной работы \\ в Политехническом лицее-интернате ФГБОУ ВПО «Тамбовский государственный технический университет»
}

\author{
Isaeva O.V. \\ Organization of educational work in the \\ Polytechnic lyceum-boarding school \\ of Tambov state technical university
}

Тамбовский государственный технический университет Tambov State Technical University

Рассматривается применение технологий организачии учебного процесса в современной школе. Представлен авторский опыт организации работы.

The application of study process organization technologies in contemporary school is considered. Author's experience of work organization is presented.

Ключевые слова: образовательный процесс; образование; учебный проu̧ecc.

Keywords: educational process; education; study process.

В сфере образования сложилась тенденция к увеличению объема информации и усложнению изучаемого материала. В таких условиях усвоение знаний во многом определяется уровнем начальной подготовки и личностными особенностями обучаемых, что определяет необходимость введения индивидуального подхода к обучению. Этому препятствует разноуровневая подготовка сельских школьников, несформированность общих навыков в решении задач, принятая в сфере образования система группового обучения и дефицит времени. Политехнический лицей-интернат ФГБОУ ВПО «ТГТУ» был создан с целью развития и совершенствования системы непрерывного образования в Тамбовской области, обеспечения равнодоступности получения образования для детей из сельской местности, подготовки к получению высшего образования, творческому труду в различных сферах научной и практической деятельности, всестороннему образованию и гармоническому развитию личности [2].

Лицей-интернат реализует общеобразовательные программы среднего общего образования (10-11 классы) с углубленным обучением физике, математике, с технической профилизацией по специальностям соответствующих кафедр университета.

Деятельность педагогов ПЛИ ФГБОУ ВПО «ТГТУ», являющихся в большинстве преподавателями технического университета (профессорами и доцентами), направлена на эффективное построение учебного процесса, обеспечение в рамках профильной части учебного плана дифференциации обучения, привлече- 
ние учащихся к научно-исследовательской работе, подготовку к поступлению и учебе в высшем учебном заведении. В связи с тем, что концепция университета связана с понятием универсального и по существу целостного образования, преподаватели стремятся добиться не параллельного существования, а органического синтеза различных учебных дисциплин.

Педагогический коллектив Политехнического лицея-интерната стремится:

- дать учащимся качественное среднее (полное) образование,

- раскрыть способности, интеллектуальный, творческий и нравственный потенциал учащихся,

- привить навыки научно-исследовательской работы с ориентацией на дальнейшее обучение в Тамбовском государственном техническом университете,

- подготовить учащихся к осознанному выбору профессии и поступлению в вуз.

Ситуация осложняется тем, что из-за более высокого уровня требований к знаниям в лицейских классах получаемые учащимися первое время оценки заметно ниже тех, которые были у них в старом месте учебы. Это весьма болезненно воспринимается учащимися, и у некоторых из них появляется сомнение в правильности выбора учебного заведения. Практика работы ПЛИ ФГБОУ ВПО «ТГТУ» (а ранее интерната для одаренных детей при ТГТУ) показала, что указанные проблемы могут быть разрешены такой организацией учебнопознавательной деятельности учащихся, которая строится на принципах индивидуального и дифференциального подхода, подаче учебного теоретического материала с большим «запасом», проблемном обучение при решении задач [6], системе самостоятельной работы учащихся [3], переходе в ряде тем на лекционную систему изложения нового материала, применении эффективных методик обучения [3], максимальном развитии творческих способностей учащихся [5].

Преподавателями используются системы проблемных методик обучения, организуются специальные виды учебной деятельности, где широко применяются современные методы и средства обучения. Для того, чтобы активизировать учебную деятельность лицеиста, используются следующие методы организации и осуществления учебной деятельности: словесные, наглядные, практические, репродуктивные, поисковые, дедуктивные и индуктивные методы, а так же методы самостоятельной работы.

Каждый из методов организации учебно-познавательной деятельности обладает кроме информативно-обучающего мотивационным воздействием. В этом смысле любой метод обучения имеет стимулирующе-мотивационную функцию. Достижения науки и практический опыт работы учителей позволяет использовать методы, специально направленные на формирование положительных мотивов обучения, стимулируя познавательную активность и одновременно содействуя обогащению школьников учебной информацией. Функция стимулирования в данной ситуации выходит на первый план, содействуя осуществлению образовательной функции всех других методов.

Основным источником интереса к самой учебной деятельности является, прежде всего, ее содержание. Для того, чтобы содержание оказывало особенно сильное стимулирующее влияние, оно должно отвечать целому ряду требований, сформулированных в принципах обучения (научность, связь с жизнью, си- 
стематичность, последовательность, наглядности и т. д.) [1]. При этом преподаватель создает ситуацию новизны, актуальности, приближение содержания к самым важным открытиям в науке, технике, к достижениям современной культуры, искусства, литературы. С этой целью учителя используют специальные приемы при презентации научных достижений и открытий, факты, которые в данный момент времени вызывают особый интерес у всей общественности. В этом случае учащиеся значительно ярче и глубже осознают важность, значимость изучаемых вопросов и относятся к ним с большим интересом.

При использовании метода проектов в образовательном процессе лицеяинтерната, обучающиеся включаются в творческую деятельность. При этом взаимоотношения «преподаватель - ученик» меняются. Ученик сам определяет цель деятельности, открывает новые знания, экспериментирует, выбирает, несет ответственность за результаты своей деятельности. Преподаватель помогает ученику выбрать источники знаний, раскрывает возможные формы и методы эксперимента, помогает организовать познавательно-трудовую деятельность, создает условия для проявления активности, помогает оценить полученные результаты и выявить способы совершенствования деятельности. Таким образом, ученик и преподаватель взаимодействуют как партнеры. Ученик учится записывать результаты своей деятельности, а преподаватель дает четкий анализ выполненного проекта.

Все это позволяет развивать личность лицеиста в соответствии с его способностями, интересами и возможностями, а учащимся - достигать успехов в учебе и реализации своих планов по получению высшего образования. Происходит творческое саморазвитие конкурентноспособной и самодостаточной личности: «личности, у которой достаточно высокий уровень автономности, независимости и нравственной культуры, чтобы разобраться в том, что есть добро, а что зло, что служит разрушению и деградации, а что - личностному самосозиданию и саморазвитию» $[9$, с.11].

В результате целенаправленной работы учителя активно внедряют в процесс обучения новые методики, создают современные учебные пособия. Внимание к каждому педагогу, точная реакция на инновационные методики и технологии позволяют делать учебный процесс в лицее-интернате современным, качественным, творческим.

В настоящее время по всем учебным дисциплинам, изучаемым в ПЛИ ФГБОУ ВПО «ТГТУ», разработаны учебно-методические комплексы дисциплин (УМКД). Наличие собственных УМКД и учебников, авторами которых являются преподаватели лицея-интерната, нашло положительную оценку при аккредитации ПЛИ ФГБОУ ВПО «ТГТУ». В Техническом университете (корпус А) оборудована школьная лаборатория по нанотехнологии. Установлены три сканирующих микроскопа с соответствующим компьютерным программным обеспечением. Преподаватели-физики лицея-интерната прошли соответствующую подготовку по работе со сканирующими микроскопами и ведут научноисследовательскую деятельность совместно с лицеистами [8].

Разработка новых программ, направленных на развитие инновационной деятельности, освоение информационного пространства оказывает значительное воздействие на лицеистов, положительно влияет на социальную адаптацию подростков. Одновременно происходит развитие и совершенствование принципов 
демократизации, педагогики сотрудничества, вариативности, добровольного выбора предмета деятельности. Совершенствование содержательного компонента, организационных форм, методов и технологий образования способствует развитию у обучающихся всех групп способностей, развитию креативности, формированию самосознания.

Особенностью обучения в лицее-интернате является приближение организации учебно-воспитательного процесса к вузовской, что подводит ученика к самостоятельному изучению наук. Находят применение технологии, связанные с использованием в учебном процессе вычислительной техники.

Преподавателями и учащимися лицея-интерната освоена мультимедийная учебная информационная система VitaLMS, позволяющая создавать индивидуальные учебные планы. В дополнение к интерактивному обучению (что особенно актуально в период карантина, сильных морозов, болезни учащихся) система управления предоставляет лицеисту и преподавателю обратную связь, дополняемую печатными материалами, обеспечивая мощную среду «смешанного обучения».

Особенностью лицея-интерната является организация в конце каждого полугодия экзаменов по профильным предметам, что позволяет повысить качество знаний по данным учебным дисциплинам. Важнейшая задача, которая ставится перед лицеем-интернатом, - формирование будущей профессиональной элиты.

Мониторинг дальнейшей учебной и научной деятельности выпускников лицея-интерната за 20 лет существования показывает, что более 60\% выпускников оканчивает вуз с красным дипломом. 204 человека, получивших высшее образование, обучалось или обучается в очной или заочной аспирантуре (41 защитили кандидатскую диссертацию). На наш взгляд, приведенные данные на практике подтверждают жизнеспособность и необходимость системы непрерывного образования.

Занятия обучающимся доставляют удовольствие из-за разнообразия форм (лекции, урочная система, семинары, практикумы, лабораторные работы). Высокопрофессиональные педагоги Технического университета стремятся расширить знания учащихся по предметам, используя инновационные образовательные технологии. Проведение школьных занятий в университетских аудиториях и лабораториях оказывает на учащихся большое психологическое влияние. В процессе обучения школьники общаются не только со своими преподавателями, но и со студентами, аспирантами.

Деятельность Политехнического лицея-интерната обеспечивает стабильно высокий уровень абитуриентов, стремящихся получить высшее образование, и полностью соответствует принципам образовательной деятельности, сформулированным на конференции «Современные подходы к формированию законодательных основ образования» [10].

1. Принцип единства образовательного пространства.

2. Принцип паритетности обучения и воспитания.

3. Принцип интеграции образования и науки.

4. Принцип академической свободы.

5. Принцип единства и преемственности уровней образования - «образования через жизнь». 
6. Принцип сбалансированности интересов учащихся, родителей, преподавателей, работодателей и учредителей, как основных участников образовательного процесса.

7. Принцип транспарентности (открытости) образования обществу.

1. Алиева О. Классические гимназии - в каждую губернию // Эксперт. 2015. №35 (954). С. 35-39.

2. Андреев В. И. Конкурентология. Учебный курс для творческого саморазвития конкурентоспособности. Казань: Центр инновационных технологий, 2004. $468 \mathrm{c.}$

3. Андреев В. И. Педагогика высшей школы. Инновационнопрогностический курс: учеб. пособие. Казань: Центр инновационных технологий, 2005. 500 с.

4. Исаева О. В. Инновационные методы работы в «Политехническом лицее-интернате при Тамбовском государственном техническом университете // Успехи современного естествознания. 2006. № 11. С. 92-93.

5. Исаева О. В. Опыт организации учебного процесса в «Политехническом лицее-интернате Тамбовского государственного технического университета // Интеллектуальная и творческая одаренность. Проблемы. Концепции. Перспективы. Тезисы VIII международной научно-методической конференции «Апрельский форум». Париж. 2007. С. 44-45.

6. Исаева О. В. Проблемное обучение при решении физических задач как форма подготовки к олимпиадам // Современные тенденции и направления развития олимпиадного движения по теоретической механике: материалы докладов общероссийской конференции. Тамбов, 2003. Ч. 1. С. 64-66.

7. Мищенко С. В., Исаева О. В., Попов А. И. Развитие творческих способностей учащихся лицея-интерната при Тамбовском государственном техническом университете // Наука. Образование. Культура - третье тысячелетие. Материалы Междунар. симпозиума. Греция, о. Крит. Ретимно, 2005. С. 55-57.

8. Осипова И. А., Иванов В. Е. Элементы нанотехнологий в системе непрерывного образования школа-вуз //Актуальные проблемы обучения математике, физике и информатике в школе и вузе. Материалы межрегиональной научнопрактической конференции учителей. Пенза: ПГПУ. 2009. С.234-236.

9. Сластенин В. А., Исаев И. Ф., Шиянов Е. Н. Педагогика: Учеб. пособие для студ. высш. пед. учеб. заведений / под ред. В. А. Сластенина. М.: Издательский центр "Академия", 2002. 576 с.

10. Садовничий В. А. Концепция и стратегия образовательного законодательства России // Вестник образования России. 2011. №4. С. 68-74. 


\title{
Мамонтова Д.А., Толстяков Р.P. \\ Некоммерческие организации \\ в пространстве российской действительности: \\ сущность и характеристика
}

\author{
Mamontova D.A., Tolstyakov R.R. \\ non-profit organization in space Russian reality: \\ the nature and feature
}

Тамбовский государственный технический университет Tambov State Technical University

В статье анализируется современное состояние некоммерческих организаиий в пространстве российской действительности. Особое внимание уделяется сущьностным характеристикам «третьего сектора экономики». Рассматриваются механизмь финансирования НКО. Также в статье показана особая роль НКО, в силу одновременного выполнения нескольких задач, что обуславливает ее как уникальное звено, связывающее государственный и коммерческий сектор с гражданским обществом.

The article examines the current state of non-profit organizations in the territory of the Russian reality. Pays special attention to Xia essential characteristics of the "third sector". Description focuses the mechanisms of funding NGOs. Also the article shows the special role of NGOs, because of simultaneous execution of multiple tasks, which leads it as a unique link between the public and the commercial sector with civil society.

Ключевые слова: некоммерческие организации.

Keywords: non-profit organization.

В период демократизации всех сторон общественной жизни государства, формирования новых социально-экономических основ народного хозяйства в условиях рынка появление новых отношений между государством и обществом сформировало основы для кристаллизации новых форм общественных отношений, коими стали некоммерческие организации. Однако стоит отметить, что основным вектором государственной политики в сфере общественного развития было, есть и будет формирование социально активного населения с целью совместного решения культурно-нравственных, социально-экономических и воспитательных задач, совершенствование механизма взаимодействия государственного и общественного секторов, а также выработка новых подходов к сотрудничеству. Заметим, что общественное развитие в Российской Федерации испытало значительные последствия политико-экономической нестабильности в периоды формирования рыночных отношений и мирового финансового кризиса [1]. Поставленные задачи государством в сфере развития общественно активного населения реализуются, и значительный вклад в данном направлении играет разви- 
вающийся институт некоммерческих организаций (далее - НКО). Однако с учетом развития НКО в экономике страны формируется запрос на совершенствование механизмов их продвижения, что обуславливает применение соответствующего маркетингового инструментария, адекватно отвечающего запросу общества, государства и экономики в целом.

Но все же, прежде чем непосредственно перейти к анализу маркетинговой компоненты в сфере некоммерческих организаций, считаем необходимым рассмотреть сущность и специфику их деятельности, так как продвижение их деятельности или предлагаемого ими продукта обществу у некоммерческих организаций отличны от коммерческих структур. И это понятно, так как основная задача коммерческой деятельности - получение прибыли, а у некоммерческих организаций данная компонента не является доминантой, следовательно, маркетинг в сфере НКО имеет свои специфические черты, особенно для российской экономики.

Итак, согласно законодательству РФ [3] некоммерческие организации это организации, не имеющие извлечения прибыли в качестве основной цели своей деятельности и не распределяющие ее между участниками. При этом стоит отметить, что НКО в горизонте своей деятельности может осуществлять предпринимательскую деятельность, однако, не в том объеме как коммерческая структура. Также отметим, что НКО создаются для благотворительных, культурных, социальных, образовательных, научных и управленческих целей, целей развития физической культуры и спорта, охраны здоровья граждан, удовлетворения духовных и иных нематериальных потребностей граждан, защиты прав, законных интересов граждан и организаций, разрешения споров и конфликтов, оказания юридической помощи, а также в иных целях, направленных на достижение общественного блага. Подчеркнем, что достижение общественных благ и есть краеугольный камень деятельности НКО, отсюда и формируется значительное количество их видов. Рассмотрим сравнительную таблицу видов некоммерческих организаций.

Широта деятельности НКО обуславливает широкую вовлеченность общества и самое главное увеличивает конкуренцию между ними, что в свою очередь обуславливает применение соответствующего маркетингового инструментария. При этом вышеописанные формы позволяют формировать организации, функционирующие для социальных или экологических целей, с сохранением за ними ограниченного права получения некой прибыли в качестве последующей цели после основной. В данном ключе стоит привести пример Великобритании, где в 2004 г. был принят соответствующий закон, в результате чего количество организаций, функционирующих в общественных интересах, превысило 6 тысяч. Также стоит отметить тот факт, что для выполнения общественно полезной функции данные организации отличаются от бизнес-структур и государства наличием самостоятельности в лице независимости от спонсоров и учредителей (рис.1).

Наличие данной компоненты является залогом сохранения, приобретения и усиления доверия от спонсоров, а также лиц, которым НКО оказывает услуги. В качестве примера можно рассмотреть религиозное НКО. В данном случае НКО занимается благотворительностью и заинтересована в том, чтобы ее деятельность не пересекалась и не сопровождалась пропагандой соответствующих 
религиозных воззрений лицами, являющимися ее учредителями или спонсорами. В обратном случае данная организация рискует лишиться спонсоров, не поддерживающих данные религиозные воззрения, что в свою очередь вызовет соответствующие подозрения у субъектов благотворительности в попытке навязывания им соответствующих религиозных воззрений.

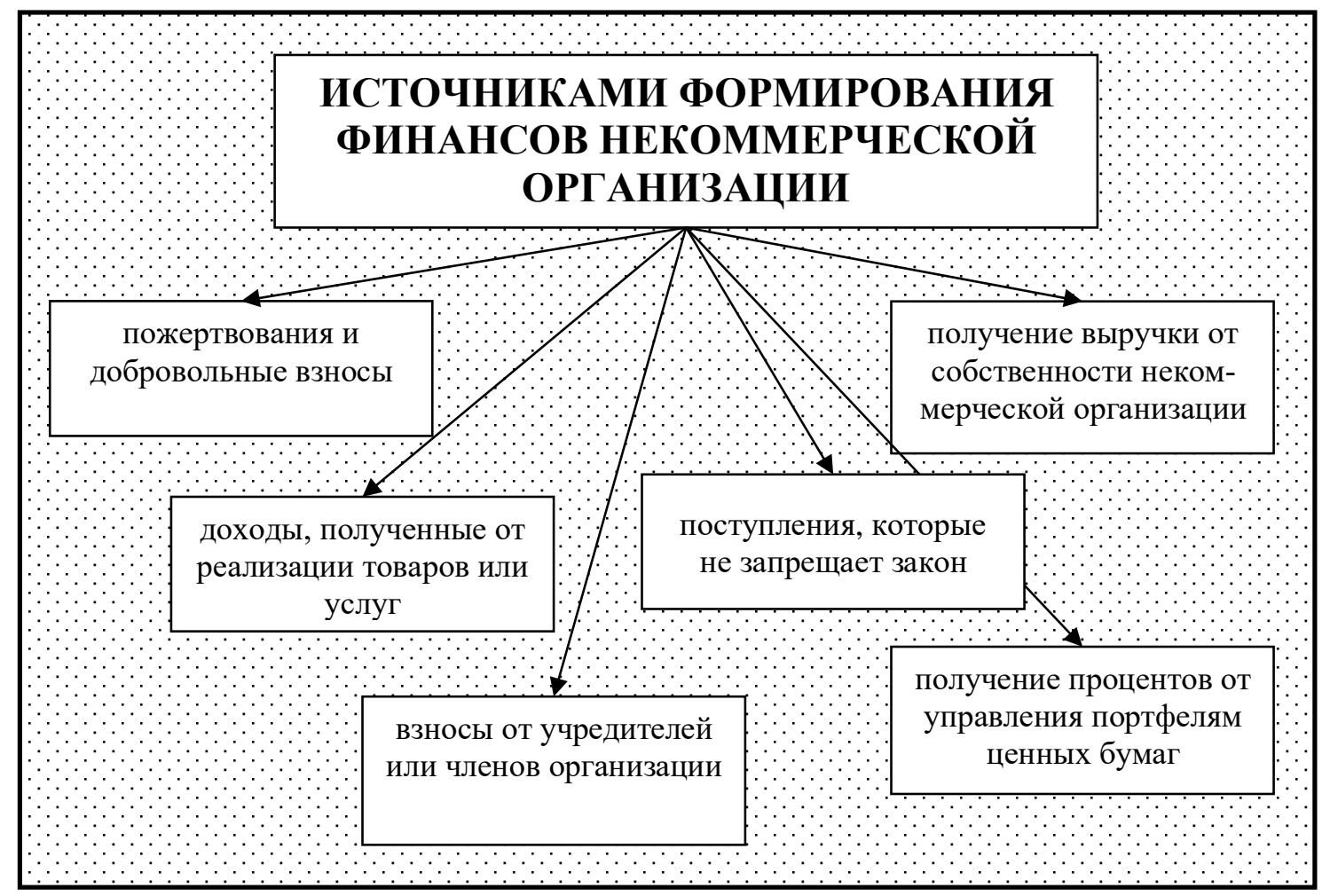

Рис. 1. Источники финансов НКО

Поэтому для нивелирования данных ситуаций в виде нежелательного воздействия со стороны заинтересованных лиц НКО могут применить комплекс мер (нормативные, организационные меры, а также процедуры независимого надзора и контроля).

Стоит сказать, что законодательно список организаций, определенных как «некоммерческие», достаточно широк, а их деятельность включает значительные стороны жизни общества. Учитывая значительный спектр видов НКО, рассмотрим сравнительную таблицу (табл.1).

В своей сущности НКО выполняют одновременно несколько задач, что обуславливает ее как уникальное звено, связывающее государственный и коммерческий сектор с гражданским обществом. Некоммерческие организации могут выступать в качестве:

- самостоятельных хозяйствующих субъектов в экономике государства;

- актором государственной функции в сфере оказания социально значимых услуг лицам относящихся к социально незащищенным слоям общества;

- выступать в качестве институто-образующей структуры в обществе.

Как свидетельствует практика, НКО являются более эффективным актором в решении социальных функции государства, поэтому государство непосредственно заинтересовано в развитии НКО. 
Таблица 1. Сравнительная таблица НКО [3]

\begin{tabular}{|c|c|c|c|c|c|c|}
\hline $\begin{array}{l}\text { Особенности не- } \\
\text { коммерческой } \\
\text { организации } \\
(\text { НКО) }\end{array}$ & $\begin{array}{l}\text { Неком- } \\
\text { мерческое } \\
\text { партнер- } \\
\text { ство } \\
\end{array}$ & $\begin{array}{l}\text { Автономная } \\
\text { некоммер- } \\
\text { ческая орга- } \\
\text { низация }\end{array}$ & $\begin{array}{l}\text { Частное } \\
\text { учрежде- } \\
\text { ние }\end{array}$ & Фонд & $\begin{array}{l}\text { Обще- } \\
\text { ственная } \\
\text { организа- } \\
\text { ция }\end{array}$ & $\begin{array}{l}\text { Ассоциа- } \\
\text { ция (союз) }\end{array}$ \\
\hline Учредители НКО & $\begin{array}{l}\text { граждане } \\
\text { и (или) } \\
\text { юридиче- } \\
\text { ские лица }\end{array}$ & $\begin{array}{l}\text { граждане и } \\
\text { (или) юри- } \\
\text { дические } \\
\text { лица }\end{array}$ & $\begin{array}{l}\text { гражда- } \\
\text { нин или } \\
\text { юридиче- } \\
\text { ское лицо }\end{array}$ & $\begin{array}{l}\text { граждане и } \\
\text { (или) юриди- } \\
\text { ческие лица }\end{array}$ & $\begin{array}{l}\text { не менее } \\
\text { 3-х физи- } \\
\text { ческих лиц }\end{array}$ & $\begin{array}{l}\text { коммерче- } \\
\text { ские или } \\
\text { некоммер- } \\
\text { ческие } \\
\text { юридиче- } \\
\text { ские лица }\end{array}$ \\
\hline Наличие членства & + & - & - & - & + & + \\
\hline $\begin{array}{l}\text { Возможность } \\
\text { НКО заниматься } \\
\text { предпринима- } \\
\text { тельской деятель- } \\
\text { ностью }\end{array}$ & + & + & + & + & + & - \\
\hline $\begin{array}{l}\text { Ответственность } \\
\text { учредителей } \\
\text { (членов) по дол- } \\
\text { гам НКО }\end{array}$ & - & - & + & - & - & + \\
\hline $\begin{array}{l}\text { Обязанность еже- } \\
\text { годно публико- } \\
\text { вать отчеты об } \\
\text { использовании } \\
\text { имущества }\end{array}$ & - & - & - & + & - & - \\
\hline $\begin{array}{l}\text { Существенные } \\
\text { особенности от- } \\
\text { дельных видов } \\
\text { НКО }\end{array}$ & -- & $\begin{array}{l}\text { Работники, } \\
\text { не могут } \\
\text { составлять } \\
\text { более чем } \\
1 / 3 \text { общего } \\
\text { числа чле- } \\
\text { нов колле- } \\
\text { гиального } \\
\text { высшего } \\
\text { органа } \\
\text { управления }\end{array}$ & -- & $\begin{array}{l}\text { 1. Обязатель- } \\
\text { ное наличие } \\
\text { попечитель- } \\
\text { ского совета } \\
\text { 2. Может } \\
\text { быть ликви- } \\
\text { дирован } \\
\text { только по } \\
\text { решению су- } \\
\text { да }\end{array}$ & -- & --- \\
\hline
\end{tabular}

Также считаем необходимым, отметить тот факт, что в отличии от государственных структур при выполнении общественно значимых задач НКО могут привлекать частные ресурсы, а также ресурсы гражданского общества. При этом количество привлекаемых ресурсов зависит от уровня значимости решаемой проблемы, а также за счет собственного имиджа. Подчеркнем, что некоммерческие организации, имеющие несоответствующий имидж, не могут эффективно реализовывать программы фандрайзинга. Именно поэтому НКО максимально заинтересованы в сохранении собственного имиджа. Следовательно, маркетинг в сфере НКО носит особый характер, так как от него во многом зависит эффективность привлечения частных средств и ресурсов для выполнения социально значимых мероприятий.

Учитывая вышесказанное, особенно организационно-правовую форму НКО, в их деятельности мы можем отметить особый риск, риск попадания в зависимость от учредителей и спонсоров. Часто бывает так, что при долговременном взаимодействии НКО с одними и теми же спонсорами НКО становится волеизъявителем не заявленных ценностей, а желаний спонсоров, которые могут иметь корыстный характер. Также спонсоры могут диктовать свои требования и 
правила к деятельности НКО и реализуемым ею проектам. Поэтому для того чтобы снивелировать риск подобных отношений, НКО вынуждены осуществлять политику диверсифицирования собственных источников финансирования. Только так они могут самостоятельно определять направления собственного развития, сохранить свой имидж и привлечь новых партнеров (рис.2).

Отметим, что значительное время некоммерческие организации функционировали в «тепличном режиме», а уровень их финансирования никак не пересекался с уровнем и качеством полученных результатов от их деятельности, при этом превалирующими источниками финансирования для них являлись иностранные капиталы, что является определенным риском для безопасности государства.

Сегодня, можно с уверенностью говорить, что данные организации находятся в высоконкурентной среде, проявляющейся в борьбе за потребителя, а также за источники финансирования. Понятно, что данный положительный поиск становится первоочередной задачей, который не может быть решен без использования современного опыта в области изучения рынков и продвижения соответствующих товаров, по сути, маркетинг [2].

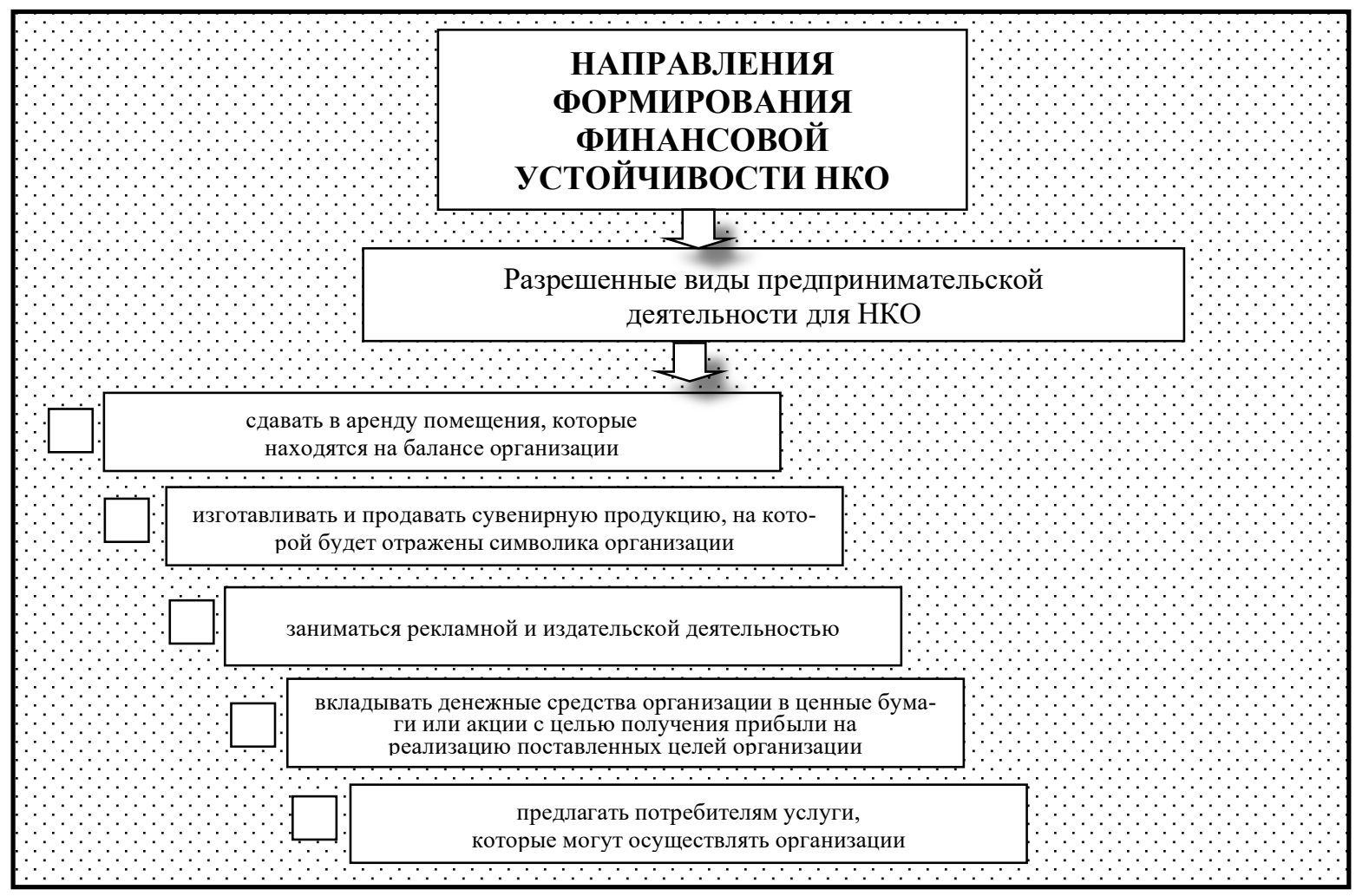

Рис. 2. Разрешенные виды предпринимательской деятельности для НКО

В таких условия НКО необходимо доказать собственную конкурентоспособность по двум направлениям:

- умение привлечь денежные средства;

- умение привлечь потребителя.

Следовательно, как следствие данных обстоятельств, происходит максимальное привлечение финансов в организацию для реализации целей и задач. Поэтому НКО постоянно находятся в поиске новых способов для привлечения капитала, где основным направлением привлечения денежных ресурсов в организацию может выступать маркетинг. 
1. Бунеева Р.И. Концептуальные основы совершенствования социальноэкономического механизма некоммерческой организации (на примере организаций потребительской кооперации) // РИСК: Ресурсы, информация, снабжение, конкуренция. 2010. № 1.

2. Толстяков Р.Р. Информационный маркетинг интернет-ресурсов // Вопросы современной науки и практики. Университет им. В. И. Вернадского. 2007. Т. 1. № 7.

3. Ф3 «О некоммерческих организациях» [Электронный ресурс]. URL: http://www.consultant.ru/popular/nekomerz/71_1.html\#p51

4. URL: http://www.defact.ru/tablica-nko.html

\title{
Нгуен Тхи Ча Ми, Толстяков Р.P. Фандрайзинг в благотворительных организациях
}

\author{
Nguyen Thi Tra My, Tolstyakov R.R. \\ Fundraising for charitable organizations
}

Тамбовский государственный технический университет Tambov State Technical University

В статье рассмотрены теоретические положения о фандрайзинге как о стратегии привлечения спонсорских средств, приведены типь спонсоров и методы их взаимодействия с некоммерческим сектором. Особое внимание уделено источникам фандрайзинга.

The article considers theoretical aspects of fundraising as a strategy to attract sponsorship funds, the types of sponsors and how they interrelate with the non-profit sector. Special attention is paid to sources of fundraising.

Ключевые слова: фандрайзинг; благотворительная организация; источники фандрайзинга.

Keywords: fundraising; Charitable organization; sources of fundraising.

Понятие «фандрайзинг в благотворительных организациях» трактуется в узком смысле как социальная услуга, производящая экономический и социально значимый эффект. В ней задействованы две стороны: благотворительная организация и организация-спонсор. В широком смысле данный термин интерпретируется как экономико-организационный механизм социально ориентированного взаимодействия институтов государства, предпринимательства, некоммерческих 
организаций и частных лиц в целях совместного добровольного решения социально-экономических задач.

В США, Канаде и Великобритании практика благотворительной деятельности используется довольно давно и, можно сказать, стала традиционной как для организаций, так и для рядовых граждан. Этому способствуют, с одной стороны, высокий уровень жизни, а с другой стороны, налоговые вычеты за пожертвования и спонсорскую помощь.

Фандрайзинг - это набор инструментов и способов привлечения спонсорских средств. При всей простоте трактовки практическая реализация фандрайзинговых инструментов значительно затруднена. Это связано как с ментальностью субъектов-доноров, так и зависит от выполнения ряда этических, экономических и правовых принципов.

Практика фандрайзинга в России происходит в большинстве случаев интуитивно и носит фрагментарный характер. Научная база находится в зачаточном состоянии. Некоторые работы описывают фандрайзинг лишь в общем виде, отсутствует классификация методов, методик оценки, и управления эффективностью практически нет. В настоящий момент необходимо углубленное изучение фандрайзинга как социально-экономического явления, способствующего повышению уровня общественного благосостояния и направленного на развитие кооперации в обществе.

Тем не менее, стоит отметить тенденцию возрастания интереса средств массовой информации к данной тематике. Этому способствует государственная политика в области развития некоммерческих организаций посредством создания различных фондов, таким образом, государство делегирует общественным организациям значительную часть социальной работы с населением.

Одним из последних событий в русле данной тенденции стало проведение конференции социально ориентированных некоммерческих организаций, которая проходила в рамках работы общественной площадки «Диалог - Доверие Действие» 28 октября 2015 г. Стоит надеяться, что проблемы и предложения, озвученные по этому поводу на конференции, будут доведены до практических реализаций.

Детализируем содержание субъектов благотворительности, к таковым относятся меценат, спонсор, донор, грант.

Меценат - физическое лицо, которое оказывает материальную, финансовую, организационную и иную благотворительную помощь на бескорыстной добровольной основе.

Спонсор - юридическое или физическое лицо, оказывающее на добровольной и бесприбыльной основе материальную поддержку благотворительной деятельности в целях популяризации исключительно своего имени (названия), торговой марки и т. д.

Донор - юридическое или физическое лицо, оказывающее материальную, финансовую, организационную и иную благотворительную помощь неприбыльным организациям на добровольной бескорыстной основе.

Грант - благотворительный взнос или пожертвование, имеющее целевой характер, предоставленное физическими и юридическими лицами в денежной и натуральной формах. 
Обычно фандрайзинг подразделяют на «внутренний» и «внешний». В первом случае речь идет о внутреннем менеджменте некоммерческой организации, когда разработкой и реализацией стратегии поиска финансирования организация занимается самостоятельно, силами собственных сотрудников.

Второй случай - это одно из направлений консалтинговой деятельности, при котором поиск финансирования осуществляется посредством привлечения профессиональных консультантов по фандрайзингу. В данном случае в этой роли могут выступать как независимые эксперты, так и специализированные фандрайзинговые фирмы.

Основная цель - это разработка стратегии привлечения средств извне, следовательно, задачи фандрайзинга - это подготовка проектов для донорских организаций, социальное партнерство с органами власти, развитие корпоративности, связей с общественностью.

Как уже говорилось, работа с донорами и спонсорами в России затруднена из-за недостаточного количества организаций и лиц, готовых участвовать в данном процессе, а также еще достаточно распространенного стереотипа восприятия некоммерческих организаций как просто просящих материальную помощь, не способных в свою очередь компенсировать ее своими услугами.

Тем не менее, работа благотворителей с НКО может быть обоюдно выгодной, самый простой пример - это повышение престижа и деловой репутации организации-спонсора в глазах общественности. В связи с этим перспективы существования и активной жизнедеятельности российских некоммерческих организаций в настоящее время во многом зависят от степени изучения и овладения их лидерами и членами технологией сбора средств или фандрайзинга, то есть конкретными шагами (путями) или инструментами сбора средств и ресурсов в целом.

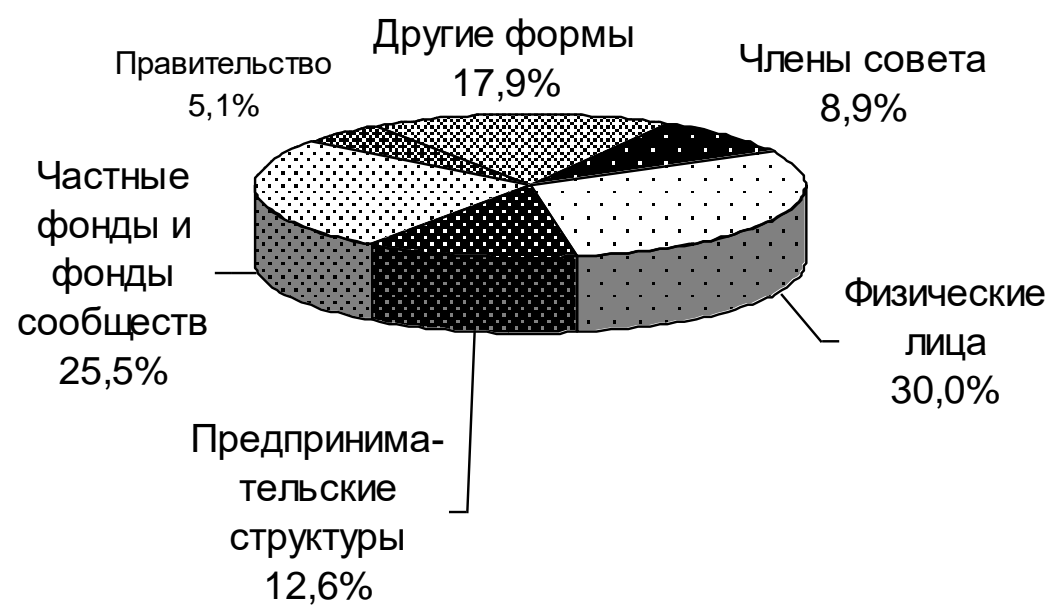

Рис. 1. Источники фандрайзинга

Согласно данным социологического исследования «Правовые инициативы некоммерческих организаций России» можно выделить 7 основных источников фандрайзинга (Рис. 1):

1. Члены совета. Все кампании фандрайзинга проистекают по инициативе совета организации, в связи с чем сами члены совета выступают спонсорами первой волны, своей инициативой стимулируя общую деятельность по фандрайзингу. 
2. Физические лица. Представляет собой основный источник фандрайзинга в США. Большинство программ фандрайзинга получает 70-80\% денег от физических лиц. Они являются наиболее щедрыми и покладистыми благотворителями. В отличие от предприятий, правительственных агентств и организаций, физические лица могут принимать решения мгновенно. В России данный уровень значительно ниже.

3. Предпринимательские структуры.

Есть 3 типа целей, которые предприятия, участвующие в благотворительности, могут ставить перед собой:

- Безвозмездное пожертвование, которое для предприятия не несет какойлибо прямой и даже косвенной выгоды в форме PR. Таким образом, предприятие не рассчитывает на расширение рекламы через пожертвования. В подавляющем большинстве к таким предприятиям относятся крупные корпорации, для которых суммы вкладов на фоне общего бюджета являются незначительными.

- Вклад в благотворительность коррелируется с повышением имиджа предприятия в общественных кругах. Предприятие сосредотачивается на вкладе, направленном на повышение его имиджа, чтобы его образ в глазах общественности стал более ярким и известным. Поэтому чаще спонсируются мероприятия или программы, которые каким-то образом связаны с названием фирмы.

- Получение дохода от спонсорства - это скорее сделка, чем благотворительный дар. Как правило, некоммерческая организация продает, рекламирует и продвигает бизнес-продукты или услуги и получает взносы, вычитающиеся из дохода. Несмотря на реальную прибыль предприятия участника, данный вид фандрайзинга считается ненадежным, т. к. предприятие может выйти из бизнеса в любое время, ведь, несмотря на кажущуюся легкость организовать сбор средств бывает трудным делом для некоммерческих организаций.

4. Частные фонды. Являются важным источником средств, как от отдельных лиц, так и от семей. Они часто работают более свободно, чем фонд сообщества, откликаются более быстро. Некоторые следуют официальным инструкциям, а некоторые спонсируют на основе знакомства.

5. Фонды сообществ. Эти средства часто направлены на повышение качества жизни общества и совершают действия, которые распространяются из одного города в другой штат или страну. Как правило, они дают деньги некоммерческим организациям из прибыли, полученной от пожертвований. Иногда они получают проценты с пожертвований или вложений. Однако такой тип фандрайзинга занимает много времени, поэтому на практике реализуется редко.

6. Правительство. Местное, государственное или федеральное самоуправление тоже жертвует деньги на некоммерческие организации. Федеральные пожертвования реализуются в рамках грантовой деятельности, которая предусматривает четкие цели и индикаторы их выполнения. Как показывает практика, чем ниже уровень, чем больше требуется времени и затрат для рассмотрения и принятия решений на выделение средств.

7. Другие формы:

- Членские взносы.

- Почести - это один из эффективных инструментов фандрайзинга. Доноры, которые дали определенное количество денег, становятся друзьями организации, а самые преданные сторонники - учредителями или благодетелями. 
Не смотря на определенные трудности по внедрению фандрайзинга в практику российского предпринимательства, на лицо - существенные сдвиги, что является подтверждением формирования цивилизованного гражданского общества, одной из характеристик которого является конструктивное, эффективное и действенное сотрудничество трех секторов: государственного, коммерческого и общественного. Именно оно формирует социальное партнерство, основу которого составляют глубокое понимание важности решаемых социальных проблем, возможность взаимодополнения ресурсов и определенные интересы партнеров, их доверие друг к другу.

1. Албегова И. Ф. Технологии фандрайзинга для некоммерческих общественных организаций. Ярославль: ЯРОО «ЦПНО», 2006. 100 с.

2. Коробова Т. С. Социально-экономические условия развития фандрайзинга в благотворительных организациях России (теоретический аспект): автореф. дисс. ... Д-ра экон. наук. М., 2014. 26 с.

3. Мироненко Е. В. Современные формы финансирования некоммерческих организаций: фандрайзинг и эндаумент. URL: http://rae.ru/forum2012/pdf/0626.pdf

4. Форум Доноров, некоммерческое партнерство грантодающих организаций [Электронный ресурc]. URL: www.donorsforum.ru

5. Хрусталев Р. В. Особенности инновационных систем управления взаимоотношениями с клиентами // Вестник ТГТУ. 2013. Т. 19. №3. С. 689-692.

\title{
Толстяков P.P., Гавриков В.А., Анохин С.А. Качество пасажирских перевозок как основной показатель деятельности ПАТП в сфере БДД
}

\author{
Tolstyakov R.R., Gavrikov V.A., Anokhin S.A. \\ Quality of passenger transport as base index of transport \\ organization activities in area of safe traffic
}

Тамбовский государственный технический университет Tambov State Technical University

Анализируются актуальные проблемы качества перевозочного прочесса пассажиров. Особое внимание уделено показателям обеспеченности, доступности и безопасности пассажирского колесного транспорта общего пользования. Выявлена зависимость качества жизни от качества предоставляемых пассажирских перевозочных услуг. 
Analyzes actual problems of quality passenger transport process. Sufficiency, accessibility, safety of passenger transport have especial attention. Investigated dependence quality life and quality transport services.

Ключевые слова: обеспеченность; доступность; безопасность пассажирских перевозок; качество жизни.

Key words: sufficiency; accessibility; safety of passenger transport; quality life.

Общественный транспорт представляет собой огромный комплекс государственных и частных предприятий, цель которого - обеспечить подвижность населения. Изначально причины, побуждающие транспортный комплекс к достижению данной цели, заключались в удовлетворении потребности населения в передвижении, так как альтернатива общественному транспорту (личный транспорт) не была развита. Все усилия транспортной промышленности были направлены на ликвидацию данной проблемы путем массового распространения личного транспорта, в особенности персонального автомобиля. В настоящее время в каждой семье, даже в далеко не самых развитых государствах, имеется по одному - два автомобиля. В результат удалось достичь высокой мобильности населения и низкой потребности в общественном транспорте, а что более важно повысить уровень жизни.

Однако темпы развития автомобилизации резко превысили темпы развития улично-дорожной сети и дорог в целом. Как следствие - неудовлетворительный уровень безопасности дорожного движения и низкая скорость движения в городах, что, соответственно, приводит к высокой аварийности и загрязнению окружающей среды.

Возникла обратная проблема: пересадить население с личных автомобилей на общественный транспорт. Но сделать это является еще более сложной задачей. Почувствовав всю прелесть личного автомобиля, потребитель не спешить пересаживаться в общественный транспорт. И основная причина заключается в низком качестве предоставляемых услуг общественного транспорта.

Доступность личных легковых автомобилей и вялое развитие уличнодорожной сети привели к массовой проблеме «пробок». Экономическая составляющая потерь от «пробок»-заторов, согласно [3], только по г. Москве равна приблизительно 38 млрд. рублей в год. Эта цифра получается путем перемножения удельной задержки автомобиля на 1 км., суммарного годового пробега всего автомобильного парка внутри города и среднечасовой заработной платы. Проблему «пробок» уже не решить путем расширения дорог или перепланировки улиц - слишком дорого, результат не впечатляющий, да и эффект временный. Здесь необходимо задуматься каждому владельцу личного легкового автомобиля об оценке своего времени и возможности пересесть на общественный транспорт с целью сокращения своих затрат. Роль общественного транспорта состоит в том, чтобы этот переход был наименее «болезненным» с сохранением по возможности всех преимуществ личного автотранспорта.

Помимо экономических потерь пробки несут социальные, медицинские и экологические проблемы. Социальные проблемы пробок в своем радикальном положении ведут за собой политические, что приводит к нестабильности в об- 
ществе, а как следствие - к краху эволюции экономической политики. Экологические проблемы пробок тесно взаимосвязаны с медицинскими проблемами. К таким чисто медицинским проблемам, как психические расстройства при неудовлетворительной экологической обстановке добавляются легочные и сердечнососудистые заболевания. Экологическая проблема, связанная с транспортом вообще и пробками в частности, особенно проявляется в весенне-летний период, причем эта проблема интернациональна (смог в Пекине, Москве, Лондоне и других крупных городах по всему миру).

Автомобильный транспорт является одной из самых серьезных проблем для экологии. Из общего вреда, наносимого окружающей среде, более 80 \% приходится на этот вид транспорта.

Инженерные разработки в области автотранспортной экологии, такие как электромобили, двигатели на газообразном топливе, двигатели на этаноле, системы дожигания топлива (катализаторы) и ряд других, в силу своей дороговизны и отсутствия инфраструктуры, способствующей применению, не пользуются популярностью. Изделие в виде автомобиля получается слишком дорогим на выходе и при его обслуживании.

Более простым решением экологической проблемы в городах является развитие общественного транспорта, в особенности колесного. Конечно, стоимость линии для троллейбусов очень высока, но в отличие от среднестатистического физического лица, государство в лице муниципалитета способно осуществить длительные инвестиции, с последующим их возвратом при эксплуатации. Для физического лица приобретение электромобиля заранее несет ему убытки, такие как ежегодное снижение первоначальной стоимости транспортного средства (связанной, как правило, с износом), поиск инфраструктуры, обслуживание и ремонт. На данном этапе транспортного развития, при отсутствии желания создавать объекты инфраструктуры для личного экологического транспорта, рынок потребления данного вида изделий крайне ограничен.

Преимущество общественного автотранспорта перед личным автомобилем в области экологии ярко просматривается в ситуации, когда при одинаковой максимальной скорости движения (в городе не более 60 км./ч.), в одном потоке и прочих равных, автобус или троллейбус перевозит в среднем 50 пассажиров, а, согласно [4], легковой автомобиль - 1,5 человека.

Единственными компаниями, выигрывающими в данной ситуации, являются компании по добыче углеводородов. Потребление топлива и ГСМ неуклонно растет в автотранспортной отрасли независимо от ценовой политики на повышение. В свою очередь качество топлива оставляет желать лучшего.

Bсе перечисленные выше проблемы сильно влияют на качество жизни населения. Развитие общественного автотранспорта - необходимость.

К общественному наземному колесному транспорту в Российской Федерации относятся:

- автобусы большой и малой вместимости;

- троллейбусы;

- маршрутное такси.

Однако в ряде государств (США, Канада, Новая Зеландия) к перечисленному добавляют:

- такси; 
- школьный автобус.

Отсутствие современных методик разработки новых и реконструкции старых маршрутов является существенной проблемой для общественного маршрутного автотранспорта. При разработке маршрутов пользуются, за неимением иных документов, устаревшим Приказом Минтранса РСФСР от 30 декабря 1981 г. № 200 «Об утверждении правил организации пассажирских перевозок на автомобильном транспорте».

Отсутствие доступа к общественному транспорту инвалидов особенно остро ощущается на автобусно-троллейбусном сообщении.

Данную ситуацию можно проследить в условиях города Тамбова. За период 2010-2012 гг. были приобретены муниципальным предприятием новые автобусы ЛиА3-5256 городского типа, но ни один из них не был инвалидного типа. Указанный тип автобуса является высокопольным. Посадка в него затруднительна для пожилых людей, а для инвалидов без посторонней помощи вообще невозможно войти в салон или выйти из него. Решение по закупке именно высокопольных автобусов, при производстве на том же заводе низкопольных автобусов, не ясно. И нужно ли выпускать транспортные средства, предназначенные только для автобусных пассажирских перевозок, высокопольного типа? Ведь троллейбусы перешли на низкопольную конструкцию.

В [5] определена цель государствам, стремящимся развивать гражданское общество и повышать качество жизни на своей территории. Для этого необходимо наделить инвалидов возможностью вести независимый образ жизни и всесторонне участвовать во всех ее аспектах. Государственные органы Российской Федерации должны принимать надлежащие меры по обеспечению людей с ограниченными возможностями доступом наравне с другими к физическому окружению, к информации и связи, а также к транспорту, как в городских, так и в сельских условиях.

Муниципальные предприятия ведут обновление автопарка и стремятся к удовлетворению потребностей всего населения, в частности, инвалидов. Однако это стремление не имеет системности, и, как следствие, возникает много ошибок.

Согласно [5], частные автотранспортные предприятия, предоставляющие услуги пассажирских перевозок, должны учитывать все аспекты доступности для инвалидов. А государство должно следить за этим. Однако частные ПАТП выжимают последнее из собственных автобусов. Их не слишком заботит комфорт здоровых пассажиров, а комфорт инвалидов их интересует еще меньше.

Инвалидность - это эволюционирующее понятие, являющееся результатом взаимодействия между имеющимися нарушениями здоровья человека и барьерами окружающей естественной или искусственной среды, которые мешают его полному и эффективному участию в жизни общества наравне с другими. Одним из таких барьеров является затрудненный доступ к общественному транспорту.

Затрудненность доступа к общественному транспорту заключается не только в посадке-высадке пассажира, но и в отсутствии объявлений остановок, иррациональной системе оплаты проезда (характерной для всех провинциальных регионов), переполненностью транспортного средства (особенно в час пик). В результате, многие инвалиды отказываются от работы вдали от дома, от ча- 
стых поездок по собственным нуждам. Не происходит той интеграции инвалидов в общество, которое способствовало бы повышению качества жизни.

Эта проблема характерна как для автобусов общего пользования, троллейбусов и школьных автобусов, так и для такси. Существуют системы такси для инвалидов, так называемые социальные такси. Суть их в том, что они предназначены исключительно для людей с ограниченными возможностями. Как правило, ими пользуются инвалиды с нарушениями опорно-двигательного аппарата.

Социальное такси вполне комфортно для передвижения на большие расстояния инвалидов. Но данный вид услуг слишком дорог для постоянного использования инвалидами. Применение их обосновано только при разовых поездах, например, к врачу. Кроме того, сама система оплаты предполагает расчет непосредственно с клиентом, в большинстве случаев - наличный. Не всегда инвалиды способны оплачивать подобные услуги самостоятельно.

Для облегчения жизни инвалидов в области доступа к транспорту необходимо ввести в действие систему оплаты, предполагающую включение в медицинский страховой полис инвалида возможность совершать социальные поездки (в больницу, в продуктовый магазин и другие). Данная система аналогична вызову скорой помощи, оплата за вызов которой осуществляется с медицинской страховкой. Серьезного налогового бремени это не вызовет, однако повысит качество жизни населения с ограниченными возможностями.

Ухудшающееся положение экологической обстановки в городах заставляет задуматься о сокращении источников выброса. Согласно [10], изменение климата напрямую связано с последствиями сжигания углеводородов. На транспорте основным источником загрязнения окружающей среды является двигатель внутреннего сгорания. Основная угроза исходит от ДВС, использующих в качестве топлива высокооктановый бензин и дизель. Подобные системы двигателя используются на автомобильном транспорте, основную долю которого занимает легковой автомобиль.

Сокращение использования ДВС на бензине и дизельном топливе, а лучше его замена на иной вид двигателя, является приоритетным направление развития всей транспортной системы. Сокращение использования данного вида двигателей подразумевает сокращение использования легковых автомобилей.

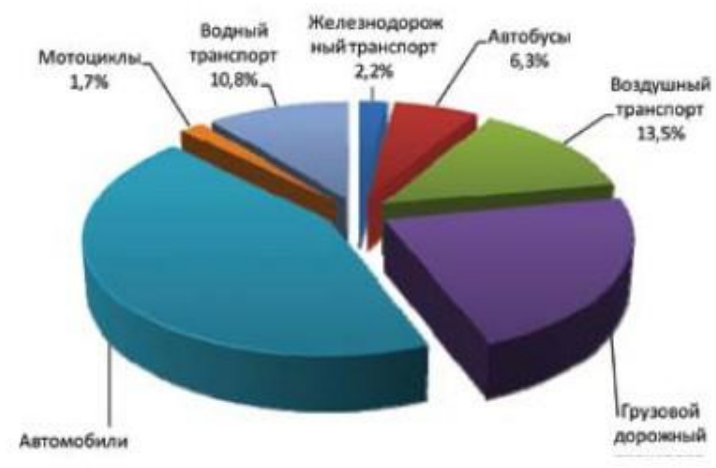

Рис. 1. Состав транспорта

Троллейбусы, использующие альтернативную электродвигательную систему, способны снизить количество вредных выбросов от автотранспорта. Данный вид транспорта не производит в городе таких вредных веществ, как СО 
(угарный газ), CO2 (углекислый газ), NOX (оксиды азота), СН (углеводороды), $\mathrm{SOX}$ (оксиды серы), N2O (закись азота), соединения свинца Рb (при использовании этилированного топлива), твердых частиц $\mathrm{C}$, в отличие от автотранспорта с ДВС. Установлен медицинский факт негативного влияния этих веществ на здоровье человека.

Также троллейбусы обладают конкурентными преимуществами внутри рынка общественного транспорта, в частности перед автобусами:

- меньше выбросов в атмосферу внутри города;

- срок службы подвижного состава выше;

- электродвигатель способен развивать полную мощность во всем диапазоне скоростей;

- обладает системой рекуперации (выработка и передача энергии обратно в сеть), что характеризуется экономичностью;

- более высокое КПД;

- вместимость пассажиров выше (приблизительно на 7-10\%, в зависимости от модели), за счет отсутствия топливных баков и размещения части электрооборудования на крыше.

Конечно троллейбусы - не идеальное транспортное средство. Они имеют ряд недостатков. Так, строительство инфраструктуры очень дорого (в особенности тяговых подстанций). Сметная стоимость 1 км. троллейбусной линии составляет около 4 млн. рублей. Кроме того, не столь эстетичен облик города, опутанного проводами. Хотя продолжаются поиски по уменьшению зависимости троллейбуса от питающих проводов и по увеличению его маневренности, достигая этого путем внедрения увеличенной емкости аккумуляторных батарей. Coвременные троллейбусы способны преодолевать расстояние на аккумуляторных батареях равное 4-5 км., что может снизить потребность в «паутине» проводов.

Экологическая обстановка в крупных городах, особенно в промышленных, крайне не благоприятна. Тамбов - не исключение.

Внедрение в систему общественного транспорта экологически нейтрального транспорта является необходимостью для повышения качества перевозочных услуг и качества жизни в целом.

Совершенствование топливной системы автобусов, переход на сжиженный газ, на этанол или иное альтернативное топливо, уже улучшает экологию окружающей среды. Но дальнейшим шагом в развитии качества жизни является последующее приоритетное использование потребителем общественного транспорта, а не личных автомобилей. Решение первостепенной задачи по стимулированию процесса замены личного автомобиля общественным автотранспортом переведет качество жизни на новый уровень. Этого перехода можно добиться только повышением качества пассажирских перевозок общественным автотранспортом.

Сама по себе система пассажирских перевозок общественным автотранспортом является государственной монополией, т.е. это монополия, созданная в соответствии с действующим законодательством, которое определяет товарные пределы рынка, субъектов монополии, формы контроля и регулирования действий участников монополии.

В соответствии с системой за муниципальным органом (монополист) законом закрепляется обязанность по обеспечению населения в пределах муници- 
палитета транспортом. В связи с тем, что, в большинстве своем, данный муниципальный орган не имеет собственных ресурсов, достаточных для удовлетворения потребностей населения в передвижении, он организует конкурс среди пассажирских автотранспортных предприятий. Лоты на конкурсе представляют собой набор из прибыльных и социальных (фактически убыточных) маршрутов. Выигравшее лот ПАТП осуществляет по заданным маршрутам пассажирские перевозки. Стараясь минимизировать свои издержки и повысить прибыль, ПАТП под любыми предлогами нарушает график движения своих автобусов на маршруте. Нарушение графика выражается в снятии автобусов с маршрута задолго до времени окончания пассажирских перевозок и в недобросовестной конкуренции за пассажиров на остановке.

Конкуренция за пассажиров происходит, как правило, в межпиковые часы, когда поток пассажиров ослабевает и заполнение автобусов не полное, на участках улично-дорожной сети пересечения конкурирующих маршрутов (альтернативных маршрутов). Это выражается в максимальной задержке интервала движения перед автобусом-конкурентом и сопровождается обгонами, частыми перестроениями на дороге, «подрезанием», скоплением автобусов на остановках (более четырех, при длине остановке в 30 м. суммарная длина автобусов превышает 48 м.), безостановочный проезд остановок общественного транспорта. Как следствие - высокий риск ДТП, угроза жизни и здоровью пассажиров и иных участников дорожного движения, несоблюдение графика движения, отсутствие комфортности пассажиров, высокая аварийность. В результате - низкий уровень качества и безопасности пассажирских перевозок.

На примере городских пассажирских перевозок видна неэффективность искусственной конкуренции в рамках государственной монополии, более того, данная конкуренция оказывается вредной для качества жизни населения.

Система пассажирских перевозок в городе должна измениться кардинально. Конкурс на маршруты нужно прекратить. Гораздо эффективнее будет создать муниципальному органу унитарное предприятие и на его базе осуществлять перевозки, объявить конкурс на заключение контракта об аренде транспортных средств с владельцами автобусов и нанять на работу водителей и сопутствующий персонал.

Можно воспользоваться аутсорсингом при поиске инфраструктуры, тем более пустующие приватизированные и муниципальные площади имеются в большом количестве. Это поможет решить проблемы с техническим обслуживанием и ремонтом транспортных средств, их стоянкой и охраной, которые в настоящее время осуществляются только на бумаге.

Победителем конкурса на заключение контракта будет являться владелец транспортных средств, запросивший минимальную стоимость аренды. Выбор арендодателя (участника конкурса) не ограничивается территорией муниципалитета, в конкурсе могут участвовать все желающие из других регионов.

Данное решение поможет избавиться от проблем неэффективной искусственной конкуренции и создать систему менеджмента качества городского общественного автотранспорта.

Создание единого графика движения городского общественного автотранспорта является первостепенной задачей. 
Некоторое время назад в городе Тамбове появились «умные» остановки с электронным табло, которое показывало проходящие маршруты через данную остановку и время ожидания необходимого автобуса. Но указанное табло погасло достаточно быстро. Информация, высвечивающаяся на нем, не соответствовала действительности. Автобусы, которые в соответствии с электронным табло должны были прибыть к остановке через 4-5 минут, подъезжали через 15-30 минут и более, а иногда и вовсе не появлялись по причине схода с маршрута. Система мониторинга автобусов на маршруте, находящаяся в работе муниципального органа (Управление транспорта), не выдает никакой иной информации, кроме наличия или отсутствия подвижного состава на линии, способной помочь в принятии необходимых мер по регулированию движения автобусов на маршруте. Отсутствует в системе возможность расчетов показателей движения, необходимых для принятия решений по контролю общественного транспорта.

Согласно [9], сложилась аналогичная ситуация во всех городах России, где пытались внедрить данную систему мониторинга, не исключение - и город Москва. Перечисленные выше проблемы распределения маршрутов, а также проблема пробок, являются основными причинами неэффективности системы мониторинга, более того ее ненужности в данных условиях. А условия таковы, что каждое ПАТП, работающее на том или ином маршруте, формирует свое расписание движения своих автобусов без согласования с другими участниками системы городского общественного транспорта, что создает нездоровую внешнюю, а зачастую и внутреннюю среди автобусов одного маршрута конкуренцию.

Формирование единого графика движения общественного автотранспорта внесет ясность в планирование движения пассажиров, повысит качество перевозок и лояльность потребителей, а также улучшит эффективность внедрения информационных технологий на транспорте. Без системы единого графика движения городского общественного автотранспорта внедрение информационных технологий - пустая трата времени, а сам единый график движения будет эффективен, если в его систему будет внедрена опция контроля скоростей.

Подсистема оплаты проезда входит в систему городского общественного автотранспорта. Она характеризует степень выполнения обязательств, как со стороны потребителя, так и со стороны перевозчика.

Объем безбилетных проездов от общего количества при действующих на территории Российской Федерации подсистемах оплаты достигает 12-20\%. Такие потери существенно влияют на рентабельность городского общественного автотранспорта и делают невозможным его дальнейшее развитие, что в условиях прогрессирующей урбанизации недопустимо.

Необходимость изменить подсистему оплаты продиктовано низкой степенью удовлетворенности потребителей от ее работы. Так или иначе, она представляет собой взимание платы за проезд через кондукторов или водителей, что в последнем случае небезопасно.

Обход кондуктора пассажиров по салону автобуса с целью взимания оплаты за проезд в час пик создает массу неудобств потребителям, находящимся в данный момент в автобусе. Не более удобны «сидячие» кондукторы у передней двери, используемой для выхода пассажиров, или водители. Необходимость протискиваться при выходе на своей остановке делает положение среднестати- 
стических пассажиров отчаянным, заставляя некоторых из них выходить в другую дверь, чаще всего не заплатив. Для пожилых пассажиров такая подсистема создает еще большие неудобства. Кондукторы у каждой двери являются экономически затратными: увеличивается фонд заработной платы при сокращении количества пассажирских мест в салоне, как следствие, и доходов с одного автобуса.

Решением проблемы взимания платы за проезд является внедрение электронной системы оплаты. В качестве платежного средства вводится электронная карта или ее аналог. С развитием сотовой телефонии таким аналогом может быть мобильный телефон с установленным на нем необходимым программным обеспечением. Данное программное обеспечение в виде приложения для мобильного аппарата должно располагаться в открытом доступе. Однако для внедрения подобной мобильной системы необходим доступ к балансу потребителя, что вызовет серьезное сопротивление мобильных операторов, считающих зачисленные (но не использованные!) денежные средства уже своими.

Сама стоимость проезда рассчитывается по довольно странным тарифам. Разработка тарифа происходит самостоятельно друг от друга каждым муниципальным органом, исходя из статистических данных предшествующего периода и возможных затрат в расчетном периоде [1], как правило, уже с заранее установленной рентабельность не менее $12 \%$, что существенно превышает европейский опыт рентабельности в 3-6\%.

Рассчитанная стоимость проезда одного пассажира является фиксированной, что в корне неправильно, так как один пассажир может проехать одну остановку, а другой может сесть в автобус в начале маршрута и выйти из него в конце. Первый в этом случае по сложившейся подсистеме оплаты проезда заплатит столько же, сколько второй, хотя место им было занято на более короткий срок. Работающая подсистема тарифов несправедлива не только к первому потребителю, но и к ПАТП, так как тариф усредненный и не окупает проезд из начала в конец маршрута.

Необходимо создать более справедливую подсистему оплаты. Такой может стать дифференцированная оплата проезда. Тариф будет распространяться не на разовый проезд пассажира, а на 0.1 км. с учетом простоя автотранспортного средства в минутах. Пассажир, входя в салон автобуса, будет прикладывать электронную карту к вмонтированному (например, в турникет) считывающему устройству. Считывающее устройство будет фиксировать время и место входа пассажира, снимая всю сумму за проезд от места посадки до конца маршрута. Это делается во избежание ситуации, когда пассажир может войти с заранее недостаточным количеством средств на карте. Затем, проехав необходимое расстояние, пассажир прикладывает вторично электронную карту к считывающему устройству, которое, рассчитав пройденное расстояние от момента посадки и количество простоев в пути, возвращает на электронную карту пассажира неиспользованные средства. Под простоем понимается время движения автотранспортного средства со скоростью менее заданной (ее принимают самостоятельно, но не более 20 км./ч.). Нужно также не забывать о том факте, что стоимость за проезд в общественном автотранспорте формирует стоимость жизни населения. В среднем за один месяц для одного работающего человека в городе Тамбове проезд отнимает от месячного дохода 800 рублей. 
В целом, для того, чтобы население поняло саму идею отказа от личного автомобиля в пользу общественного автотранспорта не как навязанное мнение, а как прогрессивную современную идею, необходимо претворять в жизнь маркетинговые методы. Ведь основным конкурентом общественного автотранспорта является личный автомобиль, за которым стоит мировой автопром. Американская мечта, цель Г. Форда по распространению своей продукции, заключающаяся в обеспечении личным автомобилем каждую семью, на данный момент близка к осуществлению. Межвидовая конкуренция не менее агрессивна, чем внутренняя. Государству необходимо задуматься над очередной сдачей своих позиций в пользу международных корпораций, или все-таки проводить умную политику общественного транспорта.

Проводятся попытки популяризации общественного транспорта. Внедряется условно-бесплатный беспроводной Интернет, были попытки организации передвижных музеев и т. д. Но для реальных результатов необходимо систематизировать подход к менеджменту качества пассажирских перевозок общественным транспортом. Система менеджмента качества - основа пассажирских перевозок общественным автомобильным транспортом.

1. Анохин С.А. Статистические методы оценки качества перевозочного процесса городского общественного автотранспорта // Вопросы современной науки и практики. Университет им. В.И. Вернадского. 2012. № 4 (42).

2. Астахов К.О., Анохин С.А. Показатели комфортности пассажирских перевозок городским общественным автомобильным транспортом и их оценка потребителем (на примере г. Тамбова) // Вопросы современной науки и практики. Университет им. В.И. Вернадского. 2013. № 1 (45).

3. Блинкин М. Цена жизни и времени / Журнал Forbes, 2010 год [Электронный ресурс]. URL: http://www.forbes.ru/column/42704-tsena-zhizni-i-vremeni

4. Джекобс Д. Смерть и жизнь больших американских городов / пер. с англ. Леонид Мотылев. М.: Новое издательство, 2011. 460 с.

5. Конвенция о правах инвалидов. Принята резолюцией 61/106 Генеральной Ассамблеи Организации объединенных наций от 13.12.2006 года. URL: http://www.un.org/ru/documents/decl_conv/conventions/disability.shtml

6. Кутенев В. Ф., Козлов А. В., Теренченко А. С., Шюте Ю. В. Проблемные вопросы ограничения выбросов СО2 от автотранспортных средств // Журнал «Автомобильных инженеров». 2010. № 3 (62).

7. Методика инвентаризации выбросов загрязняющих веществ в атмосферу для автотранспортных предприятий (расчетным методом). М.: Министерство транспорта Российской Федерации, 1998.

8. Спиридонов М. Как придумать идею для бизнеса в Интернете? Личный опыт основателя GetTaxi / Журнал Forbes, 2013 год [Электронный ресурс]. URL: http://www.forbes.ru/tehno-opinion/internet-i-telekommunikatsii/162124-kakpridumat-ideyu-dlya-biznesa-v-internete-lichny?page $=0,0$ 